\title{
ÁCAROS (ARTHROPODA: ACARI) EDÁFICOS DA MATA ATLÂNTICA E CERRADO DO ESTADO DE SÃO PAULO, COM ÊNFASE NA SUPERFAMÍLIA RHODACAROIDEA
}

\author{
EDMILSON SANTOS SILVA
}

Dissertação apresentada à Escola Superior de Agricultura "Luiz de Queiroz", Universidade de São Paulo, para obtenção do título de Mestre em Ciências, Área de Concentração: Entomologia.

\section{PIRACICABA}

Estado de São Paulo - Brasil

Dezembro - 2002 


\title{
ÁCAROS (ARTHROPODA: ACARI) EDÁFICOS DA MATA ATLÂNTICA E CERRADO DO ESTADO DE SÃO PAULO, COM ÊNFASE NA SUPERFAMÍLIA RHODACAROIDEA
}

\author{
EDMILSON SANTOS SILVA \\ Engenheiro Agrônomo
}

Orientador: Prof. Dr. GILBERTO JOSÉ DE MORAES

\author{
Dissertação apresentada à Escola Superior de \\ Agricultura "Luiz de Queiroz", Universidade de São \\ Paulo, para obtenção do título de Mestre em \\ Ciências, Área de Concentração: Entomologia.
}

\section{PIRACICABA}

Estado de São Paulo - Brasil

Dezembro - 2002 


\title{
Dados Internacionais de Catalogação na Publicação (CIP)
} DIVISÃO DE BIBLIOTECA E DOCUMENTAÇÃO - ESALQ/USP

\author{
Silva, Edmilson Santos \\ Ácaros (Arthropoda : Acari) edáficos da Mata Atlântica e Cerrado do \\ Estado de São Paulo, com ênfa se na superfamília Rhodacaroidea / \\ Edmilson Sa ntos Silva. - - Pira cica ba, 2002. \\ $86 \mathrm{p}$. \\ Dissertação (mestrado) - - Escola Superior de Agricultura Luiz de \\ Queiroz, 2002. \\ Bibliografia.
}

1. Acari 2. Arthropoda 3. Biodiversidade 4. Cerrado 5. Fauna edáfica 6. Mata Atlântica 7. Pa rasitologia I. Título

CDD 595.7

"Permitida a cópia total ou parcial deste documento, desde que citada a fonte - $\mathrm{O}$ autor" 
A Deus, por me permitir a vida e a realização de meu sonho profissional. A toda minha família, especialmente aos meus pais e à minha noiva Jurema Rosa de Queiroz, pela confiança, apoio, amor e dedicação. 


\section{AGRADECIMENTOS}

Em especial ao Prof. Dr. Gilberto José de Moraes, pela excelente orientação, amizade, confiança, incentivo e credibilidade demonstrado durante nosso convívio.

Em especial ao Prof. Dr. G. W. Krantz, do Departamento de Entomologia da Universidade Estadual do Oregon, Corvallis - USA, pela confirmação das identificações dos ácaros Rhodacaroidea.

Em especial ao Prof. Dr. Mário M. Inomoto, pela colaboração na identificação dos nematóides coletados; ao Prof. Dr. Sinval Silveira de Oliveira Neto, pelo auxílio nas análises estatísticas; ao Dr. Carlos H. Flechatmann pelo material didático despedido e ao Prof. Dr. Luiz Carlos B. Ferraz pelas várias dúvidas tiradas e, a odos pelo incentivo e amizade.

Aos Professores e funcionários do Departamento de Entomologia, Fitopatologia e Zoologia Agrícola (ESALQ/USP), pela colaboração no desenvolvimento deste trabalho e nas disciplinas no decorrer do Curso de Pós-Graduação. As secretárias Ana e Regina pela competência e disposição em sempre ajudar nas tarefas burocráticas.

A todos os professores que contribuíram na minha formação, em especial a Prof. Reinalice de Melo Lordêlo.

Aos meus ex-orientadores de iniciação científica, Alfredo Carvalho, Anacleto dos Santos, Antônio Nascimento, e Rômulo Carvalho pelo incentivo e amizade. 
A ESALQ-USP (Escola Superior de Agricultura 'Luis de Queiroz' da Universidade de São Paulo), ao Programa de Pós-Graduação em Entomologia Agrícola e ao Departamento de Entomologia, Fitopatologia e Zoologia Agrícola desta Instituição pelo acolhimento, suporte técnico e logístico para o desenvolvimento do meu trabalho de pesquisa e enriquecimento profissional.

Ao CNPq (Conselho Nacional de Desenvolvimento Científico e Tecnológico) e PRONEX (Programa de Apoio a Núcleos de Excelência, Ministério da Cultura e Tecnologia) pelo suporte financeiro.

A toda a minha família, em especial aos meus pais (José O. Silva e Maria V. Silva), a todos os irmãos (Edvandro, Hélio, Evanildes, Marenilda, José, Zeinho, Neide e Jorginho) e aos cunhados Gildete e Luís que sempre me incentivaram no meu trabalho e deram-me forças para continuar esta lida.

A minha noiva Jurema pela dedicação, incentivo, amor e por ter segurado a barra nas horas difíceis e toda a sua família em especial (Valmira, Antônio e Conce) que sempre me incentivaram no meu trabalho e deram-me forças para continuar esta lida.

A Dr ${ }^{\mathrm{a}}$ Aloyséia Noronha, Dr. Luís Geraldo Soria e Dr. Nilton F. Sanches, pelos contatos proporcionados, apoio, amizade e incentivo.

Ao meu grande amigo Laércio Alves de Carvalho, por ter me ajudado a vencer esta batalha, pelo companheirismo, incentivo e palavras de estímulos.

Aos amigos Aníbal R. Oliveira e Denise Návia pelo companheirismo, pelas idéias, incentivo e toda colaboração na redação desta dissertação. 
Ao Sr. Lázaro Vanderlei F. Silva, a Srt ${ }^{\mathrm{a}}$ Sônia Antedomenico pela colaboração na coleta e extração de todo o material de estudo e a bibliotecária Silvia Zinsley pelas correções realizadas deste trabalho.

A todos os meus amigos de república, em especial (Marcelo Miranda e Genelício Rocha) e aos amigos e colegas da graduação em especial a Joselice L. Lima, Maxuel, Sandra Selma, Naílton Almeida, Ivani Santos Caio Maguisa, Caio Mário, Maurício, José (Zé Galinha), Luciano, Leandro, Cecinio Neto e Girlene Santos pelo incentivo e companheirismo.

A todos meus amigos da Embrapa de Cruz das Almas-BA em especial (Sr. José Luís Conceição, Raimundo P. Silva, José C. Neri e Fabio Galvão) que me ajudaram nesta vitória e aos amigos de Cruz das Almas e município de São Felix que sempre apostaram em mim, em especial Manuel Menezes, Jonas Lobo, Luciano Cardoso, Marcelo Cardoso, Anelito Cardoso e Genilson Santos.

A todos os colegas do curso de pós-graduação, em especial Antônio Carlos Lofego, Jeferson Mineiro, Geni Sodré, Geraldo Arruda, Tatiane Oliveira, Raf De Vis, José F. Garcia, Simone Prado, Luciano Pacelli, Uemerson e Marisonia e à equipe do Setor de Zoologia (Andréia, Cláudia, Cristiane, José Luís, Juarez, Luís, Michele, Rafael, Renata e Vera), pela amizade e companheirismo.

A todos os amigos do Consulado Baiano que me recebeu com muito carinho aqui em Piracicaba, dando apoio para prosseguir, em especial ao Sr. Pedro Louça (Cônsul Baiano) e sua maravilhosa família.

Este trabalho foi parcialmente financiado pela Fundação de Amparo à Pesquisa do Estado de São Paulo (FAPESP) no âmbito do Programa BIOTA/FAPESP - O Instituto Virtual da Biodiversidade (www.biotasp.org.br). 


\section{SUMÁRIO}

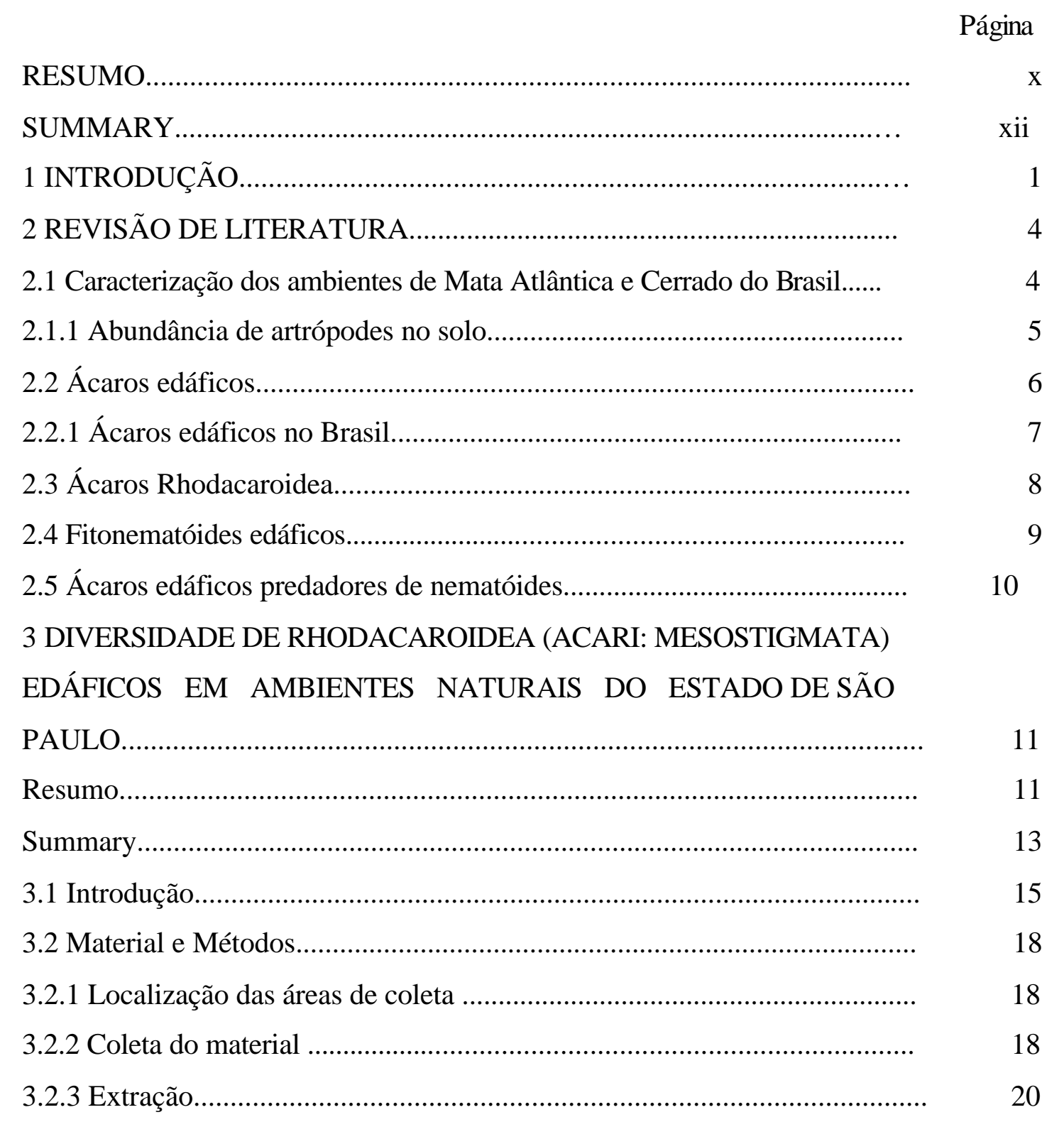


3.2.4 Triagem e identificação..........................................................................

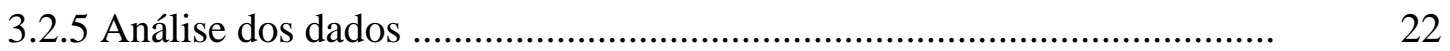

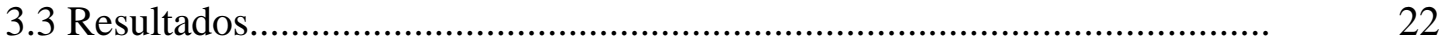

3.3.1 Predominância de Rhodacaroidea em diferentes localidades e

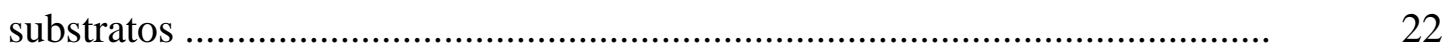

3.3.2 Predominância de famílias e gêneros de Rhodacaroidea............................. 23

3.3.3 Diversidade e predominância de gêneros de Rhodacaroidea sob as espécies vegetais consideradas....................................................................... $\quad 30$

3.3.4 Similaridade entre espécies de arecáceas de acordo com as morfoespécies de Rhodacaroidea encontrados ................................................. 30

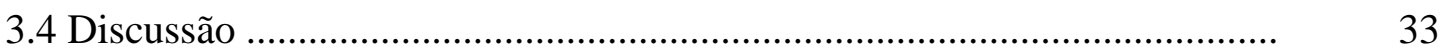

3.4.1 Predominância de Rhodacaroidea em diferentes localidades e substratos 33

3.4.2 Predominância de famílias, gêneros e morfoespécies de Rhodacaroidea. 34

3.4.3 Diversidade e predominância de gêneros de Rhodacaroidea sob as

espécies vegetais consideradas...................................................................... 36

3.4.4 Similaridade entre espécies de arecáceas de acordo com as morfoespécies de Rhodacaroidea encontrados.................................................. 37

3.5 Conclusões......................................................................................

4 DIVERSIDADE DE ÁCAROS (ARACHNIDA: ACARI) E FITONEMATÓIDES (NEMATA) EDÁFICOS DA MATA ATLÂNTICA DO ESTADO DE SÃO PAULO......................................................................

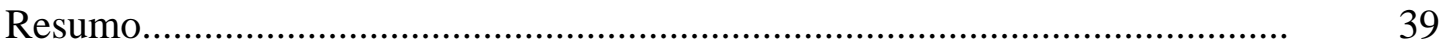

Summary

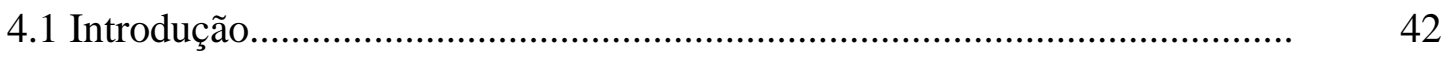

4.2 Material e Métodos......................................................................................

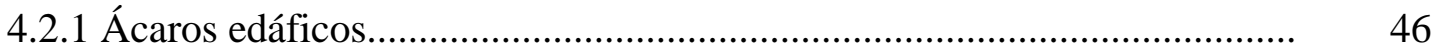

4.2.1.1 Coleta do material em campo.................................................................

4.2.1.2 Extração e triagem..................................................................................

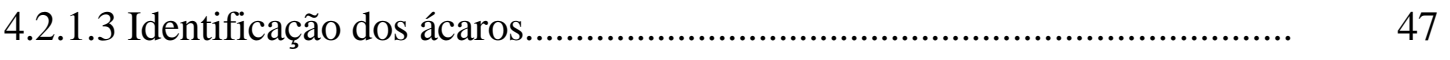




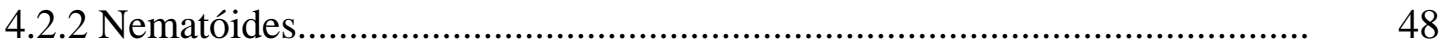

4.2.2.1 Coleta de material em campo...............................................................

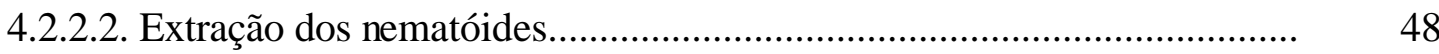

4.2.2.3 Identificação e quantificação dos nematóides............................................

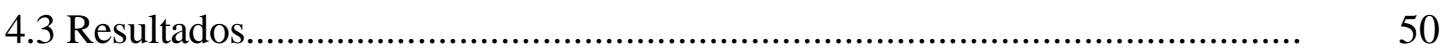

4.3.1 Proporções de ácaros coletados em diferentes camadas do substrato e diferentes estações........................................................................................... 50

4.3.2 Totais de ácaros em diferentes estações do ano.......................................... 51

4.3.3 Freqüência de ocorrência das ordens de ácaros........................................... 53

4.3.4 Diversidade de famílias de Mesostigmata, Prostigmata e Astigmata......... $\quad 54$

4.3.5 Diversidade de gêneros e morfoespécies de Mesostigmata, Prostigmata e Astigmata................................................................................. 57

4.3.6 Fitonematóides coletados a diferentes profundidades no solo..................... $\quad 59$

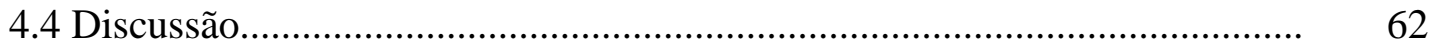

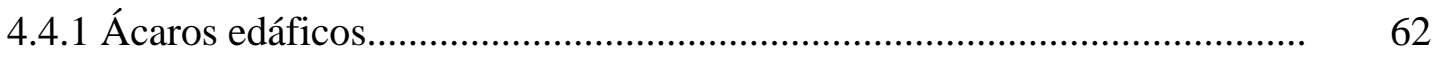

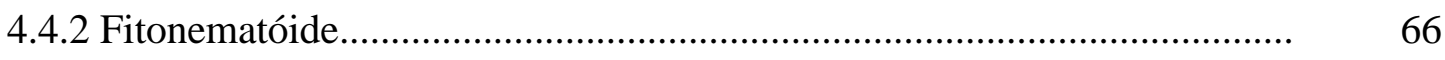

4.4.3 Associação de ácaros e fitonematóide........................................................... 68

4.5 Conclusões.............................................................................................

5 CONCLUSÕES GERAIS.........................................................................

REFERÊNCIAS BIBLIOGRÁFICAS............................................................. 


\title{
ÁCAROS (ARTHROPODA: ACARI) EDÁFICOS DA MATA Atlântica e Cerrado do ESTAdo de SÃo PaUlo, Com ÊNFASE NA SUPERFAMÍLIA RHODACAROIDEA
}

\author{
Autor: EDMILSON SANTOS SILVA \\ Orientador: PROF. DR. GILBERTO JOSÉ DE MORAES
}

\section{RESUMO}

A fauna edáfica de ácaros, apesar de abundante e muito diversa em ambientes naturais, ainda é pouco conhecida no Estado de São Paulo. O presente estudo foi realizado em duas partes. A primeira parte teve como objetivo avaliar a abundância e diversidade dos ácaros da superfamília Rhodacaroidea na Mata Atlântica (Pariquera-Açu, Cananéia, Piracicaba e São Pedro) e no Cerrado (Luiz Antonio, Pirassununga e São Carlos), em amostras de solo $(0-5 \mathrm{~cm})$ e folhedo tomadas à base de plantas das famílias Arecaceae e Myrtaceae, respectivamente. Para extração dos ácaros, as amostras foram processadas através de um equipamento do tipo Berlese-Tullgren modificado. Obteve-se um total de 969 Rhodacaroidea adultos, sendo 913 na Mata Atlântica e 56 no Cerrado. Foram encontrados 776 e 193 Rhodacaroidea no folhedo e no solo, respectivamente. Os ácaros encontrados pertencem a 15 gêneros diferentes. Os gêneros mais comuns na Mata Atlântica foram Neogamasellevans Loots \& Ryke e Ologamasus Berlese, no folhedo, e Rhodacarus Oudemans, no solo. No Cerrado, Rhodacarus foi o gênero mais comum em ambos os substratos. Trinta e uma morfoespécies de Rhodacaroidea foram encontradas na Mata 
Atlântica, e cinco, no Cerrado. A uniformidade das frequiências de ocorrência de morfoespécies foi maior na Mata Atlântica que no Cerrado. A uniformidade também foi maior no folhedo que no solo da Mata Atlântica. Na segunda parte deste estudo, avaliaram-se a diversidade, a abundância e a distribuição dos ácaros edáficos no folhedo e em diferentes profundidades (0-5, 10-15, 20-25 e 30-35 cm) do solo. Avaliaram-se também os mesmos parâmetros para os fitonematóides presentes no solo às diferentes profundidades mencionadas. As coletas foram realizadas em Pariquera-Açu e Cananéia, na base da palmeira Euterpe edulis Mart. A extração dos ácaros foi realizada como indicado anteriormente. A extração dos fitonematóides foi realizada pelo método de Jenkins. Nesta parte, coletaram-se 2717 ácaros, 80\% dos quais, do folhedo. No solo, a maior quantidade de ácaros foi encontrada na camada de 0-5 cm, exceto no outono. A maior abundância de ácaros no solo e no folhedo foi verificada no inverno. As ordens encontradas foram: Oribatida (80\%), Mesostigmata (18\%), Prostigmata e Astigmata, (juntos 2\%). Os Oribatidas não foram identificados em níveis taxonômicos mais baixos no presente estudo. No folhedo, foram identificados 14 famílias, 19 gêneros e 32 morfoespécies de ácaros. No solo, foram encontradas 17 famílias, 19 gêneros e 27 morfoespécies. Neogamasellevans e Ologamasus foram os gêneros mais abundantes e diversos dentre os ácaros identificados. Dezesseis gêneros de fitonematóides foram encontrados. O número total de fitonematóides encontrados em cada profundidade, para todas as plantas amostradas, variou de 10 a 7340 indivíduos. Helicotylenchus Steiner foi o gênero mais abundante, seguido de Discocriconemella Grisse \& Loof e Aorolaimus Sher. Os fitonematóides foram abundantes em todas as profundidades consideradas. Considerando-se a predominância dos ácaros na camada mais superior do solo, é de se esperar que os ácaros que por ventura estejam predando aqueles nematóides possam apresentar alguma eficiência apenas na camada mais superficial do solo. $\mathrm{O}$ aprofundamento nas pesquisas sobre a fauna de Rhodacaroidea em ambientes natu gera informações que poderão ser utilizadas em futuros estudos, para o controle biológico de ácaros-praga no solo. 


\title{
EDAPHIC MITES (ARTHROPODA: ACARI) OF THE MATA ATLÂNTICA AND CERRADO ECOSYSTEMS IN THE STATE OF SÃO PAULO, WITH EMPHASIS ON THE SUPERFAMILY RHODACAROIDEA
}

\author{
Author: EDMILSON SANTOS SILVA \\ Adviser: PROF. DR. GILBERTO JOSÉ DE MORAES
}

\section{SUMMARY}

Although abundant and very diverse in the natural environments, the fauna of edaphic mites is still poorly known in the State of São Paulo. The present study was conducted in two parts. The objective of the first part was to evaluate the abundance and diversity of mites of the superfamily Rhodacaroidea in the Mata Atlântica (Pariquera-Açu, Cananéia, Piracicaba and São Pedro) and in the Cerrado (Luiz Antonio, Pirassununga and São Carlos) ecosystems, in soil $(0-5 \mathrm{~cm})$ and litter samples taken at the base of plants of the families Arecaceae and Myrtaceae, respectively. For extraction of the mites, the samples were processed through a modified Berlese-Tullgren equipment. A total of 969 adult Rhodacaroidea were obtained, 913 from Mata Atlântica and 56 from Cerrado. In relation to the substrate, 776 Rhodacaroidea were found in the litter and 193 in the soil. Those mites belong to fifteen different genera. The most common genera in Mata Atlântica were Neogamasellevans Loots \& Ryke and Ologamasus Berlese, in the litter, and Rhodacarus Oudemans, in the soil. In Cerrado, Rhodacarus was the most common genus in both substrates. Thirty one morphospecies of Rhodacaroidea were found in 
Mata Atlântica, and five, in Cerrado. The equitability of the frequencies of occurrence of the morphospecies was higher in Mata Atlântica than in Cerrado. It was also higher in the litter than in the soil of Mata Atlântica. In the second part of this study, the diversity, abundance and distribution of edaphic mites in litter and soil samples of different depths $(0-5,10-15,20-25$ and $30-35 \mathrm{~cm})$ were studied. The same parameters were also evaluated for plant nematodes present in soil samples at those different depths. Samples were taken in Pariquera-Açu and Cananéia, at the base of Euterpe edulis Mart (Arecaceae). Mites were extracted as indicated previously. Nematodes were extracted by Jenkins method. A total of 2717 mites was collected, $80 \%$ of which in the litter samples. In the soil, the largest number of mites was collected between 0 and $5 \mathrm{~cm}$ from the surface, except in the fall. Highest abundance of mites in the litter and soil was observed in the winter. The mite orders found were: Oribatida (80\%), Mesostigmata (18\%), Prostigamata and Astigamata (combined, 2\%). Oribatida were not identified at lower taxonomic levels in this study. In the litter, 14 families, 19 genera and 32 morphospecies of mites were identified. In the soil, 17 families, 19 genera and 27 morphospecies were identified. Neogamasellevans and Ologamasus were the most abundant and diverse genera. Sixteen genera of plant nematodes were identified. The total number of plant nematodes found at each depth, for the combined samples, varied between 10 and 7340. Helicotylenchus Steiner was the most abundant genus, followed by Discocriconella Grisse \& Loof and Aorolaimus Sher. Nematodes were abundant at all considered depths. Considering the predominance of the mites between 0 and $5 \mathrm{~cm}$ from the soil surface, it is conceived that predation on the former by the predatory mites may have some significance only at that depth. Further research on the fauna of Rhodacaroidea in natural environments generate information that could be used in future studies for the biological control of edaphic pest mites and nematodes. 


\section{INTRODUÇÃO}

Um dos maiores desafios enfrentados pela humanidade hoje é evitar o colapso dos recursos e serviços que comprometam as futuras gerações. Dentro deste contexto, a conservação da diversidade biológica e o manejo racional e sustentável dos recursos naturais são hoje os problemas mais sérios em nosso planeta, com interfaces abrangentes nos campos social e econômico. Para enfrentá-los há necessidade de se gerar conhecimentos sobre os recursos vivos do planeta e suas interações com as atividades humanas.

No passado, as áreas de Mata Atlântica e de Cerrado eram extensas, ocupando grande parte do território nacional. Hoje, resta muito pouco destas áreas preservadas, especialmente no Estado de São Paulo. Mesmo assim, estas áreas de Mata Atlântica e de Cerrado têm sofrido constantes ameaças de extinção pelo homem. Devido à redução significativa das áreas de Mata Atlântica e de Cerrado, é de fundamental importância para a ciência que se conheça a fauna presente no solo desses ambientes, estudando suas interações com a flora local, buscando explicações para o equilíbrio ecológico que há nesses sistemas.

Pouco se conhece sobre a fauna edáfica de ambientes naturais no Brasil. Esta escassez de conhecimento está relacionada ao pequeno número de trabalhos realizados sobre este assunto. A maioria destes trabalhos refere-se à taxonomia e registros de ocorrências de alguns dos organismos presentes nestes ambientes.

As plantas da família Arecaceae conhecidas popularmente como palmeiras são essencialmente tropicais, embora cosmopolitas (Joly, 1991). Muitas palmeiras são de grande importância econômica. A arecácea conhecida como palmito juçara (Euterpe edulis Mart.), é uma das plantas mais importantes da Mata Atlântica do ponto de vista 
econômico e está, hoje, ameaçada de extinção (Reis \& Reis, 2001). As Myrtaceae são plantas comuns da flora brasileira, freqüentes em ecossistemas naturais e de ampla distribuição no mundo. Muitos gêneros de Myrtaceae são cultivados comercialmente.Tanto as palmeiras como as mirtáceas são constituintes importantes da flora da Mata Atlântica e do Cerrado.

Os ácaros são organismos do filo Artropoda, agrupados em 2 superordens, 7 ordens (Evans, 1992) e cerca de 400 famílias (Krantz, 1978). Estes organismos vivem nos mais diversos ambientes e habitats, desde os desertos às geleiras polares, às águas do mar e a grandes profundidades do solo (Krantz, 1978). Os ácaros edáficos são muito diversos e pouco conhecidos, principalmente no Brasil. Geralmente os ácaros edáficos mais abundantes em ambientes naturais pertencem à ordem Oribatida (Wallowork, 1983). Os ácaros da ordem Mesostigmata comumente são também bastante numerosos e diversos em solos de ambientes naturais (Krantz \& Ainscough, 1990). Dentro da ordem Mesostigmata, encontra-se a superfamília Rhodacaroidea. Lee (1970), Krantz (1978) e Evans (1992) consideram que esta superfamília é composta pelas famílias Ologamasidae, Rhodacaridae e Digamasellidae. Estes ácaros são primariamente de vida livre no solo e no folhedo e possuem ampla distribuição mundial (Krantz \& Ainscough, 1990). A maioria dos representantes desta superfamília é predadora de outros artrópodes e nematóides (Lee, 1973; Krantz, 1978; Walter, 1986, Evans, 1992).

Os nematóides são organismos do filo Nemata, bastante abundantes no solo e de comportamento muito variável (Weischer \& Brown, 2001). Muitos destes organismos atacam plantas, podendo lhes causar danos significativos na produção agrícola (Sasser et al., 1978).

Este trabalho teve por objetivo determinar a diversidade de ácaros da superfamília Rhodacaroidea em amostras de solo e folhedo coletados sob plantas das famílias Arecaceae e Myrtaceae, em ambientes de Mata Atlântica e de Cerrado do Estado de São Paulo, bem como avaliar a distribuição da fauna edáfica de ácaros e fitonematóides no perfil do solo e o grau de associação existente entre os táxons estudados sob plantas de palmito juçara em uma área de Mata Atlântica deste mesmo Estado. 


\section{REVISÃO DE LITERATURA}

\subsection{Aspectos do ambiente de Mata Atlântica e de Cerrado do Brasil}

O pouco que resta das áreas de Mata Atlântica e de Cerrado do Estado de São Paulo tem sofrido constantes ameaças de extinção pelo homem. Essas ameaças se devem a práticas agrícolas feitas de maneira inadequada, em extensas áreas, buscando produções cada vez maiores, a qualquer custo (Altieri,1994). Com isso, é de fundamental importância o estudo da fauna edáfica (que vive no solo e no folhedo) destes ambientes, para o conhecimento das interações destes organismos com o meio e para a obtenção de conhecimentos que permitam a manutenção do equilíbrio ecológico em ambientes agrícolas, através de táticas de controle biológico.

Na Mata Atlântica uma das principais famílias de plantas é Arecaceae, popularmente conhecidas como palmeiras. São essencialmente tropicais, embora cosmopolitas (Joly, 1991). São representadas por cerca de 3500 espécies reunidas em mais de 240 gêneros (Lorenzi, 1996). Muitas palmeiras são de grande importância econômica pelos diferentes produtos que delas são extraídos e utilizados pelo homem, principalmente em sua alimentação, a exemplo do coco e seus derivados, azeite de dendê, palmito, entre outros.

No Cerrado, uma das principais famílias de plantas é Myrtaceae. Também são plantas comuns da flora brasileira. Várias espécies são cultivadas comercialmente. Essa família possui uma ampla distribuição no mundo, embora os grandes centros de diversidade estejam nas Américas e na Austrália. Nesta família, são conhecidos aproximadamente 100 gêneros e 3000 espécies (Joly, 1993). Muitas espécies de Myrtaceae são cultivadas comercialmente, produzindo frutos comestíveis, como por 
exemplo, a pitanga, a goiaba e a jaboticaba. O eucalipto, mirtácea introduzida da Austrália, é extensivamente cultivado no Brasil para a produção de celulose.

Tanto as palmeiras como as mirtáceas são constituintes importantes da flora da Mata Atlântica e do Cerrado.

O palmito juçara (Euterpe edulis Mart.), da família Arecaceae, é uma das plantas mais importantes da Mata Atlântica do ponto de vista econômico. Esta planta, hoje ameaçada de extinção, tem sido ao longo dos anos fonte de alimento de povos e animais da floresta desde tempos remotos (Reis \& Reis, 2001). Na atualidade, plantios comerciais de juçara estão sendo implantados e estudos vinculados a plantas dessa família, em ambientes naturais, são de grande valia para que se possa conhecer os organismos que convivem naturalmente com essas plantas. Como tem sido observado para muitas plantas, alguns organismos que com elas convivem em harmonia em condições naturais, podem, em condições de cultivo comercial, tornar-se pragas. Estes mesmos organismos podem ainda causar danos severos a outras plantas, também em cultivos comerciais.

\subsection{1 - Abundância de artrópodes no solo}

A fauna edáfica de artrópodes é bastante grande por quase todo o perfil do solo. Especialmente em áreas de mata, esta fauna se torna muito mais abundante e diversa principalmente nas primeiras camadas do solo (Adis, 1988). Autores como Rodrigues, (1986); Adis et al., (1987 a, b); Adis, (1988); Harada \& Bandeira (1994), confirmaram que aproximadamente 61 a $64 \%$ da fauna vivem nos primeiros $3,5 \mathrm{~cm}$ de profundidade, 20 a $21 \%$ entre 3,5 a $7 \mathrm{~cm}, 10$ a $12 \%$ entre 7 a $10,5 \mathrm{~cm}$ e 5 a $8 \%$ entre 10,5 a $14 \mathrm{~cm}$ de profundidade no solo. À medida que aumenta o perfil do solo, a densidade populacional dos artrópodes diminui (Price \& Benham, (1977); Harada \& Bandeira, (1994)), embora alguns grupos sejam mais abundantes nas camadas mais profundas. Alguns trabalhos relatam que a distribuição e abundância e diversidade dos artrópodes no solo estão diretamente relacionados com a umidade, temperatura e, tipo de solo, e com a presença, o tipo e a diversidade de folhedo em dado ambiente (Belfield, (1956); Gill, (1969)). 
Alguns estudos mostram que os atrópodes mais abundantes no solo são ácaros, e que estes correspondem a mais de 50\% dos artrópodes edáficos (Plowman, (1979); Adis, (1988)).

\section{2 - Ácaros edáficos}

Ácaros são organismos do filo Arthropoda, subfilo Chelicerata, classe Arachnida e subclasse Acari. As espécies de ácaros são agrupadas em duas superordens, sete ordens e cerca de 400 famílias (Krantz, 1978; Evans, 1992). As ordens mais comuns são Oribatida, Mesostigmata, Prostigmata, Astigmata e Ixodida, outras duas ordens (Notostigmata e Holothyrida) são raras. Estes organismos apresentam uma considerável diversidade em relação ao comportamento alimentar e habitats que ocupam. O hábito alimentar dos ácaros varia consideravelmente mesmo dentro de cada família. Podemos encontrar, dentre estes, espécies predadoras, fitófagas, algívoras, fungívoras, detritívoras, parasitas de vertebrados e invertebrados e ainda algumas que se alimentam de matéria orgânica em decomposição. Os ácaros podem ser encontrados desde as regiões polares até as desérticas, em quase todo tipo de substrato, como poeira, grãos armazenados, água, solo, folhedo, parasitando plantas e animais vertebrados e invertebrados (Krantz, 1978). Em alguns desses substratos os ácaros são bem conhecidos, a exemplo dos ácaros fitófagos, alguns dos quais são pragas importantes.

Em outros substratos, os ácaros são geralmente pouco conhecidos, como é o caso dos ácaros edáficos, principalmente no Brasil. Esse fato se deve a grande diversidade de espécies, ao restrito número de especialistas e de publicações nessa área e à inexistência de chaves taxonômicas apropriadas para a acarofauna nacional (Moraes \& Oliveira, (1996); Flechtmann \& Moraes, (2000)). Deve-se considerar também a falta de catálogos de ácaros edáficos. Dentre os catálogos existentes, estão o de Moraes et al., (1986) para os ácaros da família Phytoseiidae e o de Wisniewski \& Hirschmann (1993), para os ácaros da família Uropodidae.

Geralmente os ácaros edáficos mais abundantes em ambientes naturais pertencem à ordem Oribatida (Wallowork, 1983). No Brasil, a maioria dos trabalhos com esta 
ordem de ácaros foi realizado na Região Norte e tratam de levantamentos da fauna de Oribatida e a descrição de espécies (Adis, 1987; 1988; Adis et al., 1989; Ribeiro \& Schubart, 1989; Oliveira \& Frankli, 1993; Franklin et al., 1997; 1998).

Os ácaros da ordem Mesostigmata comumente são também bastante numerosos e diversos em solos de ambientes naturais (Krantz \& Ainscough, 1990).

\subsection{1 Ácaros edáficos no Brasil}

No Brasil, a maioria dos trabalhos envolvendo Mesostigmata edáficos refere-se à taxonomia e registros de ocorrências. O maior número de trabalhos encontrados são referentes à superfamília Uropodina, especialmente no Estado de São Paulo. A maioria destes trabalhos é sobre a descrição de espécies.

A Região Norte apresenta o maior número de trabalhos com descrição de espécies de Uropodina encontrados no solo e folhedo. Para o Estado do Acre, no município de Rio Branco, apenas uma espécie de ácaro edáfico está registrada Trichocylliba aguaboae descrita por Hirschmann (1992). Em Belém, Estado do Pará, foram descritas poucas espécies de ácaros. Dentre estas estão Uropoda tendiculata e $U$. laqueata (Hirschmann, 1972d); Tetrasejaspis eustructa (Hirschmann, 1973b); Baloghibrasiluropoda foveolatasimilis (Hirschmann, 1973c) e Baloghjakaszabia baloghi (Hirschmann, 1973d). O Estado do Amazonas, em particular o município de Manaus, possui a maior quantidade de espécies de ácaros descritas da região Norte (Hirschmann, 1972b, c, d; 1973a, b, c, d, g, h, i, j; 1975d; 1977 b; Hirschmann \& Zirngiebl-Nicol, 1972a, b, c; Zirngiebl-Nicol \& Hirschmann, 1973a; 1975).

Na Região Nordeste, nos Estados de Maranhão e Pernambuco também foram descritas muitas espécies de ácaros pertencentes à família Uropodidae (Hirschmann, 1969c; 1972a, b, c, d; 1973a, b, e, j; 1976d; 1977b; Zirngiebl-Nicol \& Hirschmann, 1973a; 1975). No município de Goiana, em Pernambuco, Moraes et al., (1997), registraram a ocorrência do fitoseídeo Neoseiulus gracilis (Muma, 1962) em solo, sendo a primeira vez encontrada esta espécie neste tipo de substrato no Brasil. 
Na Região Centro-Oeste, em Brasília - DF, Hirschmann (1973c) descreveu um gênero e espécie novos, Baloghibrasiluropoda e B. foveatoides. No Estado do Mato Grosso, no município de Rosário d'Oeste, Trajano \& Gnaspini-Neto (1991) relataram a ocorrência de ácaros Diarthrophollus sp. (Diarthrophollidae) e Macrocheles coprophila (Macrochelidae) na gruta do Currupira.

Na Região Sul, nos Estados do Paraná e Santa Catarina, há vários trabalhos de descrição de espécies pertencentes ao grupo Uropodina (Sellnick, 1954; Hirschmann, 1969c, 1972d, 1973a, 1975a, b, c; 1976c; 1981a, c).

Na Região Sudeste, nos Estados de Minas Gerais, Rio de Janeiro e São Paulo, há vários trabalhos de descrição e de ocorrência de espécies de ácaros da subordem Mesostigmata (Trajano \& Gnaspini-Neto, 1990; Hirschmann, 1972). O Estado de São Paulo possui o maior número de trabalhos de descrição e citação de ocorrência de espécies. As espécies de Uropodina descritas foram encontradas em vários municípios do Estado, como Santos, São Vicente, Campinas, Iporanga e Americana (Hirschmann, 1969c, 1972d, 1973a, 1976a, c; 1977a, 1978, 1991, 1992b; Hirschmann \& ZirngieblNicol, 1972a, c; Zirngiebl-Nicol \& Hirschmann, 1972c, 1975). A acarofauna edáfica também é conhecida nos municípios de Pariquera-Açú, Cananéia e Piracicaba (Denmark \& Muma, 1973; Mineiro \& Moraes, 2001; Zacarias \& Moraes, 2001). Com relação à família Phytoseiidae, Karg (1983) descreveu Amblyseius hexadens encontrado em folhedo, no município de Barueri, São Paulo. Quanto à ocorrência de espécies de Mesostigmata, há relato de uma expedição realizada por várias grutas no Estado, onde Trajano \& Gnaspini-Neto (1990) registraram uma interessante acarofauna pertencente à subordem Mesostigmata.

\section{3 Ácaros Rhodacaroidea}

Os Rhodacaroidea pertencem a ordem Mesostigmata e os indivíduos que compõem esta superfamília são em grande parte predadores de vários organismos que vivem no solo (Lee, 1970). Estes ácaros são primariamente de vida livre no solo e no folhedo e possuem ampla distribuição mundial (Krantz \& Ainscough, 1990). Lee (1970), 
Krantz (1978) e Evans (1992) consideram que esta superfamília é composta pelas famílias Ologamasidae, Rhodacaridae e Digamasellidae. Recentemente, Karg (1998) acrescentou uma outra família (Gamasiphidae) a este grupo, considerado por Lee (1970) uma subfamília de Rhodacaridae. Alguns Digamasellidae habitam túneis feitos em madeira por coleópteros (Lindquists, 1975). A maioria dos representantes desta superfamília é predadora de outros artrópodes e nematóides (Lee, 1973; Krantz, 1978; Walter, 1986; Evans, 1992; El-Banhawy, 1999).

São poucas as informações sobre ácaros edáficos da superfamília Rhodacaroidea no Brasil. Alguns trabalhos existentes são relatos de levantamentos sobre acarofauna edáfica no Estado de São Paulo Trajano \& Ginaspini-Neto, (1990) e Mineiro \& Moraes, (2001).

\subsection{Fitonematóides edáficos}

Os nematóides são organismos do filo Nemata, de comportamento muito variável. Muitos são parasitos de animais, inclusive do próprio homem (Weischer \& Brown, 2001). Outros são de vida livre, no solo, alimentando-se de fungos, bactérias, algas e até mesmo predando outros nematóides ou parasitando artrópodes. Outros ainda atacam plantas, podendo lhes causar danos significativos. Sasser et al. (1978) relataram que alguns fitonematóides podem causar perdas estimadas em $12 \%$ na produção agrícola, representando prejuízo anual de cerca de 100 bilhões de dólares em todo o mundo.

Os fitonematóides são um dos constituintes da fauna natural, estando presentes onde quer que vegetem plantas. Sob condições de vegetação natural, diversificada, uma apreciável variedade de espécies de fitonematóides costumam ocorrer, cada um deles em nível populacional relativamente baixo. Portanto nesse tipo de situação, nenhum dano aparente parece decorrer do parasitismo pelos fitonematóides sobre as suas plantas hospedeiras (Weischer \& Brown, 2001). Contudo, sob a influência humana, uma dada espécie de fitonematóide pode rapidamente tornar-se uma espécie praga. 
Rossi (1995) encontrou o fitonematóide (Pratylenchus coffeae Zimmermann) parasitando raízes de juçara em plantios comerciais no município de Miracatu em São Paulo, sem causar danos aparentes à cultura. Esse fitonematóide ataca outras culturas como batata (Curi et al., 1974), banana (Almeida et al., 1978), mas são mais danosos a plantas de café (Monteiro \& Lordello, 1974) e de citros (Prates \& Lordello, 1980).

\section{5 - Ácaros edáficos predadores de nematóides}

Os ácaros edáficos são os artrópodes mais abundantes na mesofauna do solo e folhedo, tanto em número de espécies como em indivíduos (Oliveira, 1999). Estudos realizados com ácaros Mesostigmata (Epsky et al., 1988; Walter \& Ikonen, 1989; Crossley Jr. et al., 1992) mostraram que estes organismos podem ser utilizados no controle biológico de outros ácaros, artrópodes e nematóides. Segundo Crossley Jr. et al., (1992) o hábito alimentar destes ácaros é bem diversificado. Walter (1988), trabalhando com a fauna edáfica, constatou a existência de 33 espécies de artrópodes que se alimentam de nematóides. Dentre estes artrópodes, estão espécies de ácaros Parasitiformes das famílias Zerconidae, Ologamasidae, Parasitidae, Laelapidae, Ascidae, Rhodacaridae, Macrochelidae, Eviphididae, Phytoseiidae e Veigaiidae; e espécies de ácaros Acariformes das famílias Alycidae, Alicorhargiidae, Tydeidae, Eupodidae, Paratydeidae, Acaridae, Galumnidae, Haplozetidae e Cerotozetidae.

São conhecidos Mesostigmata edáficos pertencentes às famílias Ascidae, Laelapidae, Macrochelidae, Parasitidae, Eviphididae, Veigaiidae, Ologamasidae e Rhodacaridae, que predam fitonematóides. Existem vários trabalhos em outros países, que relatam ácaros de algumas daquelas famílias predando fitonematóides (Ito, 1971; Imbriani \& Mankau, 1983; Inserra \& Davis, 1983; Walter, 1986, 1988; Epsky et al., 1988). Walter \& Ikonen (1989) apresentaram estudos detalhados sobre os aspectos biológicos que influenciam ácaros Mesostigmata a regularem as populações de fitonematóides.

Walter \& Ikonen (1989) estudaram ácaros da família Tydeidae em condições de campo e laboratório. Embora estes autores tenham considerado estes ácaros como 
importantes predadores de nematóides de vida livre em campo, em condições de laboratório estas informações não foram confirmadas. Neste mesmo trabalho, foi verificado que o menor ácaro testado, Protogamasellus mica, consumiu cerca de $1.09 \mu \mathrm{g}$ de fitonematóide/ $\mu \mathrm{g}$ de peso corporal do ácaro/dia, que é uma quantidade muito maior que a consumida por ácaros maiores, como por exemplo, Lasioseius sp., o qual consumiu 0.218. $\mu \mathrm{g}$ de fitonematóide/ $\mu \mathrm{g}$ de peso corporal do ácaro/dia.

Ito (1971) realizou testes com as espécies de ácaros Macrocheles muscaedomesticae (Scopoli), Parasitus sp., Fuscuropoda sp. e Glyptholaspis confusa (Foa) alimentando-as com nematóides das espécies Rhabditis elongata (Schneider), $R$. teres (Schneider), Panagrellus redivivus (Linaeu), Aphelenchus avenae Bastian e Aphelenchoides compositicola Franklin. Como resultado, constatou que estes nematóides foram presas adequadas para o desenvolvimento dos ácaros, com exceção da espécie G. confusa, que não se alimentou dos nematóides. Imbriani \& Mankau (1983), estudaram o ciclo de vida e os hábitos alimentares de um ácaro predador, Lasioseius scapulatus, da família Ascidae, alimentando-o com o fitonematóide A. avenae e constataram que tal ácaro possui potencial para ser utilizado no controle biológico de fitonematóides. 


\section{DIVERSIDADE DE RHODACAROIDEA (ACARI: MESOSTIGMATA) EDÁFICOS EM AMBIENTES NATURAIS DO ESTADO DE SÃO PAULO}

\section{Resumo}

Apesar dos ácaros Rhodacaroidea em ambientes naturais tropicais serem muito abundantes, existem poucas informações sobre estes ácaros no mundo. O presente estudo foi conduzido para se avaliar a diversidade de ácaros daquela superfamília no folhedo e no solo (0-5 cm de profundidade), na base plantas das famílias Arecaceae e Myrtaceae em ecosistemas de Mata Atlântica e Cerrado do Estado de São Paulo, respectivamente. Os locais de coletas foram: Pariquera-Açu, Cananéia, Piracicaba e São Pedro, na Mata Atlântica, e Luiz Antonio, Pirassununga e São Carlos, no Cerrado. Para extração dos ácaros as amostras de solo e folhedo foram processadas através de um equipamento do tipo Berlese-Tullgren modificado. Coletaram-se 969 Rhodacaroidea adultos, sendo 913 na Mata Atlântica e 56 no Cerrado. O número de ácaros coletados no folhedo (776) foi muito maior que o número coletado no solo (193). Foram encontradas representantes de três famílias de Rhodacaroidea: Ologamasidae (841 ácaros), Rhodacaridae (98 ácaros) e Digamasellidae (apenas um ácaro). Ologamasidae foi à família mais numerosa na Mata Atlântica (830 ácaros), enquanto

Rhodacaridae foi à família mais abundante do Cerrado (45 ácaros). Doze gêneros de Ologamasidae, dois de Rhodacaridae e um de Digamasellidae foram identificados neste estudo. No folhedo e no solo da Mata Atlântica foram encontrados 13 e 7 gêneros de Rhodacaroidea, respectivamente. Os gêneros mais comuns na Mata Atlântica foram: Neogamasellevans Loots \& Ryke (cerca de 52\% no folhedo e 55\% no solo), Ologamasus 
Berlese no folhedo (cerca de $21 \%$ ) e Rhodacarus Oudemans no solo (cerca de 35\%). No folhedo e no solo do Cerrado foram encontrados 3 gêneros de Rhodacaroidea em cada substrato. Os gêneros mais abundantes neste ambiente foram Rhodacarus (cerca de 25\% no folhedo e $64 \%$ no solo) e Rhodacarellus Willmann (cerca de $32 \%$ no solo). Trinta e uma morfoespécies de Rhodacaroidea foram encontradas na Mata Atlântica, das quais 18 foram encontradas só no folhedo, duas só no solo e 11 em ambos substratos. As mais abundantes foram Rhodacarus sp. Neogamasellevans sp. 1 e Neogamasellevans sp. 6, com cerca de 10\% cada. No Cerrado, cinco morfoespécies foram encontradas, três no folhedo e duas, diferentes daqueles, no solo. A mais abundante foi Rhodacarus sp., com $60 \%$ dos espécimes coletados. Foi observada uma uniformidade maior das freqüências de ocorrência de morfoespécies na Mata Atlântica que no Cerrado. Observou-se também uma maior uniformidade das frequiências de ocorrência de morfoespécies no folhedo do que no solo da Mata Atlântica. As arecáceas com maior abundância e diversidade de Rhodacaroidea foram Euterpe edulis Mart. e Bactris setosa Mart. Sob cada uma dessas espécies, foram determinados, respectivamente, 12 e 10 dos 15 gêneros de Rhodacaroidea encontrados neste estudo. Os Rhodacaroidea sob as espécies de mirtáceas foram relativamente poucas. Apenas cinco gêneros foram encontrados na base destas plantas. Utilizando-se o índice de Mountford para realizar a análise de similaridade, foi possível distinguir dois grupos de Arecaceae em relação às espécies de Rhodacaroidea associados. O primeiro, composto por Astrocarium aculeatissimum (Schott), Bactris setosa Mart. e Attalea dubia (Mart.); o segundo, composto por Syagrus romanzoffiana (Cham.) e E. edulis. O aprofundamento nas pesquisas sobre a fauna de Rhodacaroidea em ambientes naturais gera informações que poderão ser utilizadas em futuros estudos, para o controle biológico de ácaros-praga no solo. 


\section{DIVERSITY OF EDAPHIC RHODACAROIDEA (ACARI: MESOSTIGMATA) IN NATURAL ENVIRONMENTS OF THE STATE OF SÃO PAULO}

\section{Summary}

Although very abundant in natural tropical environments, the Rhodacaroidea mites have been relatively little studied around the world. The present study was conducted to evaluate the diversity of mites of that superfamily in the litter and soil $(0-5 \mathrm{~cm}$ depth), at the base of plants of the families Arecaceae and Myrtaceae in the Mata Atlântica and Cerrado ecosystems of the State of São Paulo, respectively. Samples were collected at Pariquera-Açu, Cananéia, Piracicaba and São Pedro, in the Mata Atlântica, and Luiz Antonio, Pirassununga and São Carlos, in the Cerrado ecosystems. For extraction of the mites, the samples were processed through a modified Berlese-Tullgren equipment. A total of 969 adult Rhodacaroidea were obtained, 913 from Mata Atlântica and 56 from Cerrado. In relation to the substrate, 776 Rhodacaroidea were found in the litter and 193, in the soil. Representatives of three families of that superfamily were found: Ologamasidae (841 mites), Rhodacaridae (98 mites) and Digamasellidae (only on mite). Ologamasidae was the most numerous family in Mata Altântica (830 mites), while Rhodacaridae was most abundant family in Cerrado (45 mites). Twelve genera of Ologamasidae, two of Rhodacaridae and one of Digamasellidae were identified in this study. In the litter and soil of Mata Atlântica, thirteen and seven genera of Rhodacaroidea were found, respectively. The most common genera in Mata Atlântica were Neogamasellevans Loots \& Ryke (ca. 52\% in the litter and 55\% in the soil) and Ologamasus Berlese in the litter (ca. 21\%) and Rhodacarus Oudemans in the soil (ca. 35\%). In the litter and soil of Cerrado three genera of Rhodacaroidea were found in each substrate. The most abundant genera in this ecosystem were Rhodacarus (ca. 25\% in the litter and $64 \%$ in the soil) and Rhodacarellus Willmann (ca. 32\% in the soil). Thirty one morphospecies of Rhodacaroidea were found in Mata Atlântica, of which eighteen were found only in the litter, 
two only in the soil and eleven in both substrates. The most abundant were Rhodacarus sp., Neogamasellevans sp. 1 and Neogamasellevans sp. 6, with ca. $10 \%$ each. Five morphospecies were found in Cerrado, 3 in the litter and two, different ones, in the soil. The most abundant was Rhodacarus sp., with $60 \%$ of the specimens collected. The equitability of the frequencies of occurrence of the morphospecies was higher in Mata Atlântica than in Cerrado. It was also higher in the litter than in the soil of Mata Atlântica. Arecaceae with higher abundance and diversity of Rhodacaroidea were Euterpe edulis Mart. And Bactris setosa Mart. Under each of those species, twelve and ten of all fifteen genera collected in this study were identified. Rhodacaroidea were relatively few under the Myrtaceae. Only five genera were found at the base of those plants. Using the Mountford index for the analysis of similarity, two groups of Arecaceae could be distinguished in relation to the associated Rhodacaroidea. The first was composed by Astrocarium aculeatissimum (Schott), Bactris setosa Mart. and Attalea dubia (Mart.); the second was composed by Syagrus romanzoffiana (Cham.) and E. edulis. Further research on the fauna of Rhodacaroidea in natural environments generate information that could be used in future studies for the biological control of edaphic pest mites. 


\subsection{Introdução}

O pouco que resta das áreas de Mata Atlântica e de Cerrado do Estado de São Paulo tem sofrido constantes ameaças de extinção pelo homem. Essas ameaças se devem a práticas agrícolas feitas de maneira inadequadas, em extensas áreas, buscando produções cada vez maiores a qualquer custo (Altiere,1994). Com isso, é de fundamental importância o estudo da fauna edáfica (que vive no solo e no folhedo) daqueles ambientes, para o conhecimento de suas interações com o meio e para a obtenção de conhecimentos que permitam a manutenção do equilíbrio ecológico em ambientes agrícola, através de táticas de controle biológico.

As plantas da família Arecaceae são monocotiledôneas conhecidas popularmente como palmeiras. São essencialmente tropicais, embora cosmopolitas (Joly, 1991). São representadas por cerca de 3500 espécies reunidas em mais de 240 gêneros (Lorenzi, 1996). Muitas palmeiras são de grande importância econômica pelos diferentes produtos que delas são extraídos e utilizados pelo homem, principalmente em sua alimentação, a exemplo do coco e seus derivados, azeite de dendê, palmito, entre outros.

As Myrtaceae são plantas comuns da flora brasileira, freqüentes em ecossistemas naturais. Várias espécies são cultivadas comercialmente. Essa família possui uma ampla distribuição no mundo, embora os grandes centros de dispersão sejam nas Américas e na Austrália. Nesta família, são conhecidos aproximadamente 100 gêneros e 3000 espécies (Joly, 1993) muitos espécies de Myrtaceae são cultivadas comercialmente, produzindo frutos comestíveis, como por exemplo, a pitanga, a goiaba e a jaboticaba. O eucalipto, mirtácea introduzida da Austrália, é extensivamente cultivada no Brasil para a produção de celulose.

Tanto as palmeiras como as mirtáceas são constituintes importantes da flora da Mata Atlântica e do Cerrado.

Ácaros são organismos do filo Arthropoda, subfilo Chelicerata, classe Arachnida e subclasse Acari. As espécies de ácaros são agrupadas em duas superordens, sete ordens (Evans, 1992) e cerca de 400 famílias (Krantz, 1978). Estes organismos vivem nos mais 
diversos ambientes e habitats, desde os desertos às geleiras polares, águas do mar e grandes profundidades do solo (Krantz, 1978).

Os ácaros edáficos são muito diversos e pouco conhecidos, principalmente no Brasil. Esse fato se deve ao restrito número de especialista e de publicações nessa área, e à inexistência de chaves taxonômicas apropriadas à acarofauna nacional (Flechtmann \& Moraes, 2000). Geralmente os ácaros edáficos mais abundantes em ambientes naturais pertencem à ordem Oribatida (Wallowork, 1983). Os ácaros da ordem Mesostigmata comumente são também bastante numerosos e diversos em solos de ambientes naturais (Krantz \& Ainscough, 1990).

Muitos dos Mesostigmata são predadores de artrópodes e podem ser encontrados em solo, folhedo ou plantas (Krantz, 1978). No Brasil, a maioria dos trabalhos sobre ácaros edáficos desta ordem refere-se à taxonomia e registros de ocorrências. A Região Norte apresenta o maior número de trabalhos com descrição de espécies de Mesostigmata do grupo Uropodina, encontrados no solo e folhedo. Para o Estado do Acre, no município de Rio Branco, apenas uma espécie de ácaro edáfico está registrada, Trichocylliba aguaboae, descrita por Hirschmann (1992a). Em Belém, Estado do Pará, foram descritas Uropoda tendiculata e U. laqueata (Hirschmann, 1972d); Tetrasejaspis eustructa (Hirschmann, 1973b); Baloghibrasiluropoda foveolatasimilis (Hirschmann, 1973c) e Baloghjakaszabia baloghi (Hirschmann, 1973d). O Estado do Amazonas possui a maior quantidade de espécies de ácaros descritas da Região Norte (Hirschmann, 1972b, c, d; 1973a, b, c, d, g, h, i, j; 1975d; 1977b; Hirschmann \& Zirngiebl-Nicol, 1972a, b; Zirngiebl-Nicol \& Hirschmann, 1973a; 1975).

Na Região Nordeste, nos Estados de Maranhão e Pernambuco, também foram descritas muitas espécies de ácaros pertencentes à famí lia Uropodidae (Hirschmann, 1969c; 1972a, b, c, d; 1973a, b, e, j; 1976d; 1977b; Zirngiebl-Nicol \& Hirschmann, 1973 a; 1975). No município de Goiana, em Pernambuco, Moraes et al. (1997) registraram a ocorrência do fitoseídeo Neoseiulus gracilis (Muma, 1962) em solo. 
Da Região Centro-Oeste, em Brasília - DF, Hirschmann (1973 c) descreveu um gênero novo, Baloghibrasiluropoda e uma espécie nova, B. foveatoides. No Estado do Mato Grosso, no município de Rosário d'Oeste, Trajano \& Gnaspini-Neto (1991) relataram a ocorrência de ácaros Diarthrophollus sp. (Diarthrophollidae) e Macrocheles coprophila (Macrochelidae) na gruta do Currupira.

Na Região Sul, nos Estados do Paraná e Santa Catarina, há vários trabalhos de descrição de espécies pertencentes ao grupo Uropodina (Sellnick, 1954; Hirschmann, 1969c, 1972d, 1973a, 1975a, b, c; 1976c; 1981a, c).

Na Região Sudeste, nos Estados de Minas Gerais, Rio de Janeiro e São Paulo, há vários trabalhos de descrição e ocorrência de espécies de ácaros da subordem Mesostigmata (Trajano \& Gnaspini-Neto, 1991; Hirschmann, 1972).

O Estado de São Paulo possui o maior número de trabalhos de descrição e citação de ocorrência de espécies. As espécies de Uropodina descritas foram encontradas em vários municípios do Estado, como Santos, São Vicente, Campinas, Iporanga e Americana (Hirschmann, 1969c, 1972d, 1973a, 1976a, c; 1977a, 1978, 1991, 1992b; Hirschmann \& Zirngiebl-Nicol, 1972a, c; Zirngiebl-Nicol \& Hirschmann, 1972c, 1975). A acarofauna também é um pouco conhecida nos municípios de Pariquera-Açú, Cananéia e Piracicaba (Denmark \& Muma, 1973; Mineiro \& Moraes 2001; Zacarias \& Moraes 2001). Um estudo recente sobre a abundância e diversidade de ácaros edáficos da ordem Mesostigmata no município de Piracicaba-SP foi conduzido por Mineiro \& Moraes (2001).

Dentro da ordem Mesostigmata, encontra-se a superfamília Rhodacaroidea. Lee (1970), Krantz (1978) e Evans (1992) consideram que esta superfamília é composta pelas famílias Ologamasidae, Rhodacaridae e Digamasellidae. Recentemente, Karg (1998) acrescentou uma outra família (Gamasiphidae) a este grupo, considerado por Lee (1970) uma subfamília de Rhodacaridae. Estes ácaros são primariamente de vida livre no solo e folhedo e possuem ampla distribuição mundial (Krantz \& Ainscough, 1990). Alguns Digamasellidae habitam túneis feitos em madeira por coleópteros (Lindquists, 1975). A maioria dos 
representantes desta superfamília é predadora de outros artrópodes e nematóides (Lee, 1973; Krantz, 1978; Walter, 1986; Evans, 1992; El-Banhawy, 1999).

São poucas as informações sobre ácaros edáficos da superfamília Rhodacaroidea no Brasil. Assim este trabalho teve como objetivo determinar a diversidade destes ácaros em amostras de solo e folhedo coletados sob plantas das famílias Arecaceae e Myrtaceae, em ambientes de Mata Atlântica e Cerrado do Estado de São Paulo.

\subsection{Material e Métodos}

\subsubsection{Localização das áreas de coleta}

Foram realizadas coletas trimestrais, durante o ano de 2000, uma em cada estação do ano, em dois ecossistemas do Estado de São Paulo. As coletas foram realizadas em oito localidades, como discriminado na Tabela 1.

\subsubsection{Coleta do material}

Na Mata Atlântica, as coletas foram feitas sob as seguintes espécies de Arecaceae: Euterpe edulis Mart., Syagrus romanzoffiana (Cham.), S. oleracea (Mart.) Becc., Bactris setosa Mart., Astrocarium aculeatissimum (Schott), Attalea dubia (Mart.) Burret, Geonoma schottiana Mart., G. brevispatha Barb. Rodr., Acrocomia aculeata (Jacq.). No Cerrado, os ácaros foram coletados sob as seguintes espécies de Myrtaceae: Psidium guajava L., $P$. australe Cambess, P. guianeense (Aubl.) DC., P. cinereum Mart. Ex DC., Campomanesia pubescens (DC.) Berg, Myrcia guianensis (Aubl.) DC., M. venulosa DC. e M. bella Cambess. Uma amostra de solo e outra de folhedo foram tomadas sob a copa de três plantas de cada espécie vegetal selecionada em cada campo. As amostras de folhedo e solo foram coletadas de dois pontos diferentes, dentro de um raio de $50 \mathrm{~cm}$ da base das planta. As 
amostras de folhedo foram tomadas com auxílio de uma moldura metálica de 15 x $15 \mathrm{~cm}$. Essa moldura era lançada na área pré-estabelecida, tomando-se todo o folhedo da área delimitada pela moldura e acomodando-o em sacos plásticos. O material coletado foi acondicionado em caixa de isopor, resfriada por bolsas térmicas (à base de celulose vegetal) (Gelo- $\mathrm{x} 囚)$, para transporte ao laboratório, mantendo-se a temperatura no interior da caixa entre 12 e $21^{\circ} \mathrm{C}$.

Tabela 1. Caracterização dos ambientes de Mata Atlântica e de Cerrado do Estado de São Paulo, nos quais foram coletadas amostras de solo e folhedo no ano 2000.

\begin{tabular}{|c|c|c|c|}
\hline Localidade & Município & Coordenadas & Tipo de vegetação \\
\hline \multicolumn{4}{|c|}{ Mata Atlântica } \\
\hline $\begin{array}{l}\text { Área particular - } \\
\text { SP226, Rod. J.H. de } \\
\text { Oliveira Rosa, km } 16\end{array}$ & Cananéia & $\begin{array}{l}24^{\circ} 53^{\prime} 45^{\prime \prime S} \text { e } \\
47^{\circ} 50^{\prime} 17^{\prime \prime O}\end{array}$ & Restinga arbórea \\
\hline $\begin{array}{l}\text { Estação Ecológica de } \\
\text { Ibicatu }\end{array}$ & Piracicaba & $\begin{array}{l}22^{\circ} 46^{\prime} 43^{\prime \prime} \mathrm{S} \mathrm{e} \\
47^{\circ} 49^{\prime} 32^{\prime \prime} \mathrm{O}\end{array}$ & $\begin{array}{l}\text { Floresta estacional } \\
\text { semidecídua }\end{array}$ \\
\hline $\begin{array}{l}\text { Área particular - } \\
\text { SP304, Rod. Geraldo } \\
\text { de Barros, km } 183\end{array}$ & São Pedro & $\begin{array}{l}22^{\circ} 38^{\prime} 58^{\prime} \mathrm{S} \mathrm{e} \\
47^{\circ} 48^{\prime} 31^{\prime \prime} \mathrm{O}\end{array}$ & $\begin{array}{l}\text { Floresta estacional } \\
\text { semidecídua }\end{array}$ \\
\hline $\begin{array}{l}\text { Área particular - } \\
\text { SP304, Rod. Geraldo } \\
\text { de Barros, km } 204\end{array}$ & SãoPedro & $\begin{array}{l}22^{\circ} 33^{\prime} 57^{\prime \prime} \mathrm{S} \text { e } \\
47^{\circ} 57^{\prime} 28^{\prime \prime O}\end{array}$ & $\begin{array}{l}\text { Floresta estacional } \\
\text { semidecídua }\end{array}$ \\
\hline $\begin{array}{l}\text { Núcleo de Agronomia } \\
\text { do Vale do Ribeira - } \\
\text { IAC }\end{array}$ & Pariquera-Açu & $\begin{array}{l}24^{\circ} 36^{\prime} 41^{\prime \prime S} \text { e } \\
47^{\circ} 53 ' 23^{\prime \prime O}\end{array}$ & $\begin{array}{l}\text { Floresta Ombrófila } \\
\text { densa }\end{array}$ \\
\hline \multicolumn{4}{|c|}{ Cerrado } \\
\hline $\begin{array}{l}\text { Estação Ecológica } \\
\text { Jataí }\end{array}$ & Luiz Antonio & $\begin{array}{l}21^{\circ} 36^{\prime} 13^{\prime \prime S ~ e} \\
47^{\circ} 47^{\prime} 17^{\prime \prime} \mathrm{O}\end{array}$ & $\begin{array}{l}\text { Cerrado "stricto } \\
\text { sensu" }\end{array}$ \\
\hline Campus da USP & Pirassununga & $\begin{array}{l}21^{\circ} 56^{\prime} 20^{\prime \prime} \mathrm{S} \mathrm{e} \\
47^{\circ} 28^{\prime} 26^{\prime \prime O}\end{array}$ & $\begin{array}{l}\text { Cerrado "stricto } \\
\text { sensu" }\end{array}$ \\
\hline $\begin{array}{l}\text { Fazenda Canchim- } \\
\text { Embrapa }\end{array}$ & São Carlos & $\begin{array}{l}21^{\circ} 54^{\prime} 50^{\prime \prime} \mathrm{S} \mathrm{e} \\
47^{\circ} 49^{\prime} 21^{\prime \prime O}\end{array}$ & $\begin{array}{l}\text { Cerrado "stricto } \\
\text { sensu" / Campo } \\
\text { cerrado }\end{array}$ \\
\hline
\end{tabular}


As amostras de solo foram coletadas entre a superfície e $5 \mathrm{~cm}$ de profundidade, com o auxílio de um cilindro metálico de 6,0 x 5,7 x 5,0 cm de diâmetro externo, interno e altura, respectivamente, com uma das extremidades cortantes. Em cada ponto de coleta de amostra de solo, o folhedo foi retirado e o cilindro foi posicionado com a extremidade cortante para baixo. Em seguida, este foi introduzido no solo por golpes sucessivos de martelo em uma pequena tábua sobreposta ao cilindro (Edwards, 1991). Cada conjunto cilindro-amostra foi retirado do solo circundante com o auxílio de uma espátula e acondicionado em um saco plástico, devidamente etiquetado, com os dados referentes às localidades, planta amostrada e data de coleta. $\mathrm{O}$ acondicionamento e transporte ao laboratório foram semelhantes ao procedimento adotado para as amostras de folhedo.

\subsubsection{Extração}

A extração dos ácaros do folhedo e do solo foi realizada através de um equipamento do tipo Berlese-Tullgren modificado (Oliveira, 1999). Este equipamento era composto por uma caixa de madeira $(101 \times 70$ x $51 \mathrm{~cm})$ dividida em dois compartimentos por uma placa de poliestireno. O compartimento superior continha as amostras e as fontes de luz e calor, enquanto o compartimento inferior continha os funis de polietileno e os frascos de vidro com uma solução de $1 \%$ de formol para o recebimento dos ácaros. $\mathrm{O}$ equipamento permitia a extração de 21 amostras concomitantemente.

No caso do solo, toda a amostra coletada foi utilizada para a extração dos ácaros $\left(127,6 \mathrm{~cm}^{3}\right)$. Já no caso do folhedo, uma subamostra da amostra trazida do campo foi utilizada na extração; a subamostra correspondeu ao volume do cilindro de PVC do

equipamento de extração (aproximadamente 471,2 $\mathrm{cm}^{3}$ ). Em alguns casos, a amostra de folhedo coletada no Cerrado não foi suficiente para preencher o cilindro utilizado no equipamento de extração.

No presente trabalho, a extração dos ácaros se deu durante três dias, com a voltagem das lâmpadas sendo aumentada gradualmente do primeiro ao terceiro dia, da seguinte forma: 
primeiro dia, $10 \mathrm{~V}\left(35^{\circ} \mathrm{C}\right)$; segundo dia, $30 \mathrm{~V}\left(45^{\circ} \mathrm{C}\right)$ e terceiro dia, $50 \mathrm{~V}\left(55^{\circ} \mathrm{C}\right)$.

Com as lâmpadas atuando como fonte de luz e calor, as amostras foram desidratadas gradualmente de cima para baixo durante o processo de extração. A luz, calor e baixa umidade relativa no compartimento superior levaram os ácaros a migrar para o compartimento inferior da caixa, mantida no escuro, a temperaturas menores e a níveis de umidade mais elevada. Os ácaros e demais artrópodes caíram nos funis, que os direcionaram aos frascos com solução de formol. Após a extração, os ácaros foram tomados da solução de formol e transferidos para uma solução de álcool (70\%), com 5\% de glicerina.

\subsubsection{Triagem e identificação}

O material coletado em cada frasco foi transferido para uma placa de Petri para observação sob estereomicroscópio. Os ácaros e os demais organismos foram separados em frascos com álcool 70\%, de acordo com a ordem a que pertenciam. Os Oribatida e outros artrópodes que não ácaros foram mantidos em álcool 70\%, enquanto os ácaros de outras ordens foram montados em lâminas, utilizando-se meio de Hoyer (Flechtmann, 1983). Após a montagem, as lâminas foram colocadas em estufa para secar, por um período de 10 dias, posteriormente, os Rhodacarioidea foram separados dos demais grupos de ácaros para estudos mais detalhados. As fêmeas adultas desta superfamília foram identificadas até gênero, sendo então separadas em morfoespécies. Os machos e os imaturos não foram identificados pela inexistência de informações adequadas na literatura que permitissem que isso fosse feito. Para a identificação, utilizou-se, de início, a chave dicotômica elaborada por Mineiro \& Moraes (2001). Também foram utilizados os trabalhos de Krantz (1978) e Krantz \& Ainscough (1990), para ordens e famílias, bem como as publicações de Evans \& Till (1979) e Lee (1970) para gêneros de Rhodacaroidea. 


\subsubsection{Análise dos dados}

A uniformidade das freqüências com que as morfoespécies foram encontradas foi determinada através dos índices de Pielou (Odum, 1988). Para este índice, utilizou-se nas fórmulas o logarítimo de base $10\left(\log _{10}\right)$. $\mathrm{Na}$ análise de similaridade entre as espécies vegetais em relação às morfoespécies de Rhodacaroidea que abrigavam, foram consideradas apenas as espécies de Arecaceae dos sítios da Mata Atlântica, pois foi muito reduzido o número de ácaros sob as Myrtaceae no Cerrado. As morfoespécies mais raras não foram consideradas nesta análise; foram consideradas apenas aquelas representadas por um total de pelo menos 14 exemplares, nas amostras de folhedo e solo analisadas.

\subsection{Resultados}

Um total de 969 Rhodacaroidea adultos foi encontrado neste estudo, na Mata Atlântica e no Cerrado.

\subsubsection{Predominância de Rhodacaroidea em diferentes localidades e substratos}

A maior quantidade de Rhodacaroidea foi encontrada na Mata Atlântica (Tabela 2). No folhedo deste ecossistema, estes ácaros foram muito abundantes (761 ácaros), especialmente em Cananéia (371 indivíduos). Os números de Rhodacaroidea no folhedo em Pariquera-Açu (206 indivíduos) e na região de Piracicaba (184 indivíduos) foram muito próximos. Estes ácaros foram muito raros no folhedo do Cerrado, onde apenas 15 indivíduos foram encontrados, dificultando a comparação entre os números encontrados nos diferentes sítios deste ecossistema.

No solo, o número de Rhodacaroidea foi quase sempre muito baixo (entre 8 e 18 ácaros por localidade), exceto na região de Piracicaba, onde 131 indivíduos foram encontrados. 
Tabela 2. Adultos (fêmeas e machos) de Rhodacaroidea encontrados em folhedo e solo de diferentes localidades do Estado de São Paulo 2000.Os números indicam os totais encontrados em amostras de folhedo $\left(471,2 \mathrm{~cm}^{3}\right)$ e igual número de amostras de solo (127,6 cm $\mathrm{cm}^{3}, 0-5 \mathrm{~cm}$ de profundidade), seguidos (entre parênteses) pela correspondente porcentagens, em cada substrato.

\begin{tabular}{lcc}
\hline Ambiente/município & Folhedo & Solo \\
\hline & \multicolumn{2}{c}{ Mata Atlântica } \\
\cline { 2 - 3 } Cananéia & $371(47,8)$ & $13(6,7)$ \\
Piracicaba + São Pedro & $184(23,7)$ & $131(67,9)$ \\
Pariquera-Açu & $206(26,5)$ & $8(4,1)$ \\
Subtotal & $\mathbf{7 6 1}(\mathbf{9 8 , 1 )}$ & $\mathbf{1 5 2}(\mathbf{7 8 , 8})$ \\
& & \\
Luiz Antônio & $6(0,8)$ & $15(7,8)$ \\
Pirassununga & $0(0,0)$ & $18(9,3)$ \\
São Carlos & $9(1,2)$ & $8(4,1)$ \\
Subtotal & $\mathbf{1 5}(\mathbf{1 , 9})$ & $\mathbf{4 1}(\mathbf{2 1 , 2})$ \\
\hline & & $\mathbf{1 9 3}(\mathbf{1 0 0 , 0})$ \\
\hline
\end{tabular}

\subsubsection{Predominância de famílias e gêneros de Rhodacaroidea}

Representantes de Ologamasidae e Rhodacaridae foram encontrados nos dois substratos e nos dois ecossistemas estudados. Um único exemplar de Digamasellidae foi encontrado neste estudo, na Mata Atlântica (Tabela 3). 
Tabela 3. Adultos (fêmeas e machos) de Rhodacaroidea por família e respectivos gêneros encontrados em folhedo e solo de diferentes localidades do Estado de São Paulo, 2000. Os números indicam os totais encontrados em amostras de folhedo (471,2 $\mathrm{cm}^{3}$ ) e igual número de amostras de solo $\left(127,6 \mathrm{~cm}^{3}, 0-5 \mathrm{~cm}\right.$ de profundidade), seguidos (entre parênteses) pela correspondente porcentagem, em cada substrato.

\begin{tabular}{|c|c|c|c|c|}
\hline \multirow[t]{2}{*}{ Famílias e gêneros } & \multicolumn{2}{|c|}{ Mata Atlântica } & \multicolumn{2}{|c|}{ Cerrado } \\
\hline & Folhedo & Solo & Folhedo & Solo \\
\hline OLOGAMASIDAE & $739(99,2)$ & $91(65,2)$ & $9(75,0)$ & $2(4,5)$ \\
\hline Neogamasellevans & $389(52,2)$ & $77(55,4)$ & $8(66,7)$ & $0(0,0)$ \\
\hline Ologamasus & $159(21,3)$ & $5(3,6)$ & $1(8,3)$ & $0(0,0)$ \\
\hline Notogamasellus & $21(2,8)$ & $0(0,0)$ & $0(0,0)$ & $0(0,0)$ \\
\hline Hydrogamasellus & $3(0,4)$ & $0(0,0)$ & $0(0,0)$ & $0(0,0)$ \\
\hline Afrogamasellus & $0(0,0)$ & $0(0,0)$ & $0(0,0)$ & $2(4,5)$ \\
\hline Gamasiphoides & $34(4,6)$ & $5(3,6)$ & $0(0,0)$ & $0(0,0)$ \\
\hline Gamasiphis & $3(0,4)$ & $1(0,7)$ & $0(0,0)$ & $0(0,0)$ \\
\hline Gênero novo 1 & $95(12,8)$ & $2(1,4)$ & $0(0,0)$ & $0(0,0)$ \\
\hline Gênero novo 2 & $7(0,9)$ & $0(0,0)$ & $0(0,0)$ & $0(0,0)$ \\
\hline Gênero novo 3 & $5(0,7)$ & $0(0,0)$ & $0(0,0)$ & $0(0,0)$ \\
\hline Gênero novo 4 & $20(2,7)$ & $0(0,0)$ & $0(0,0)$ & $0(0,0)$ \\
\hline Gênero novo 5 & $3(0,4)$ & $1(0,7)$ & $0(0,0)$ & $0(0,0)$ \\
\hline RHODACARIDAE & $5(0,7)$ & $48(34,5)$ & $3(25,0)$ & $42(95,5)$ \\
\hline Rhodacarus & $5(0,7)$ & $48(34,5)$ & $3(25,0)$ & $28(63,6)$ \\
\hline Rhodacarellus & $0(0,0)$ & $0(0,0)$ & $0(0,0)$ & $14(31,8)$ \\
\hline DIGAMASELLIDAE & $1(0,1)$ & $0(0,0)$ & $0(0,0)$ & $0(0,0)$ \\
\hline Digamasellus & $1(0,1)$ & $0(0,0)$ & $0(0,0)$ & $0(0,0)$ \\
\hline TOTAL & $745(100,0)$ & $139(100,0)$ & $12(100,0)$ & $44(100,0)$ \\
\hline
\end{tabular}


No folhedo, representantes de Ologamasidae foram consideravelmente mais abundantes que Rhodacaridae, especialmente na Mata Atlântica, onde os Rhodacaridae foram muito raros. No solo, entretanto, os Rhodacaridae corresponderam a aproximadamente um terço dos Rhodacaroidea coletados na Mata Atlântica, e a quase 96\% dos Rhodacaroidea coletados no Cerrado.Foram encontrados neste estudo espécies pertencentes a 12 gêneros de Ologamasidae, 2 de Rhodacaridae e 1 de Digamasellidae.

Treze gêneros de Rhodacaroidea foram encontrados na Mata Atlântica, seis dos quais, só no folhedo. Cinco gêneros desta superfamília foram encontrados no Cerrado, um dos quais só no folhedo e dois, só no solo.

Na Mata Atlântica, Neogamasellevans foi o gênero mais numeroso, tanto no folhedo quanto no solo, correspondendo a mais de $50 \%$ dos Rhodacaroidea encontrados em cada um daqueles substratos deste ecossistema. O segundo gênero mais abundante neste ecossistema foi Ologamasus no folhedo (cerca de $21 \%$ do total) e Rhodacarus no solo (cerca de $35 \%$ do total). Também bastante abundantes no folhedo foram os ácaros de um gênero não descrito, designado como "Gênero novo 1" (cerca de $13 \%$ do total).

No Cerrado, o número de Rhodacaroidea no folhedo foi bastante reduzido em comparação com a Mata Atlântica. Isto inviabiliza qualquer avaliação consistente em relação à predominância dos diferentes grupos neste substrato. No solo, o número de Rhodacaroidea também foi relativamente baixo, mas permitiu verificar que a maioria dos ácaros encontrados pertencia ao gênero Rhodacarus (cerca de 64 \% do total), seguido pelo gênero Rhodacarellus (cerca de $32 \%$ do total).

Trinta e uma morfoespécies de Rhodacaroidea foram encontradas na Mata Atlântica, das quais 18 foram encontradas só no folhedo e duas só no solo (Figura 1). As morfoespécies mais abundantes foram Rhodacarus sp., Neogamasellevans sp. 1 e Neogamasellevans sp. 6, cada uma correspondendo a cerca de $10 \%$ do total de Rhodacaroidea identificados na Mata Atlântica. No folhedo, as morfoespécies mais abundantes foram Neogamasellevans sp. 1 e Neogamasellevans sp. 6, enquanto no solo, a morfoespécie mais abundante foi Rhodacarus sp., seguida, de longe, por Neogamasellevans sp. 8. 


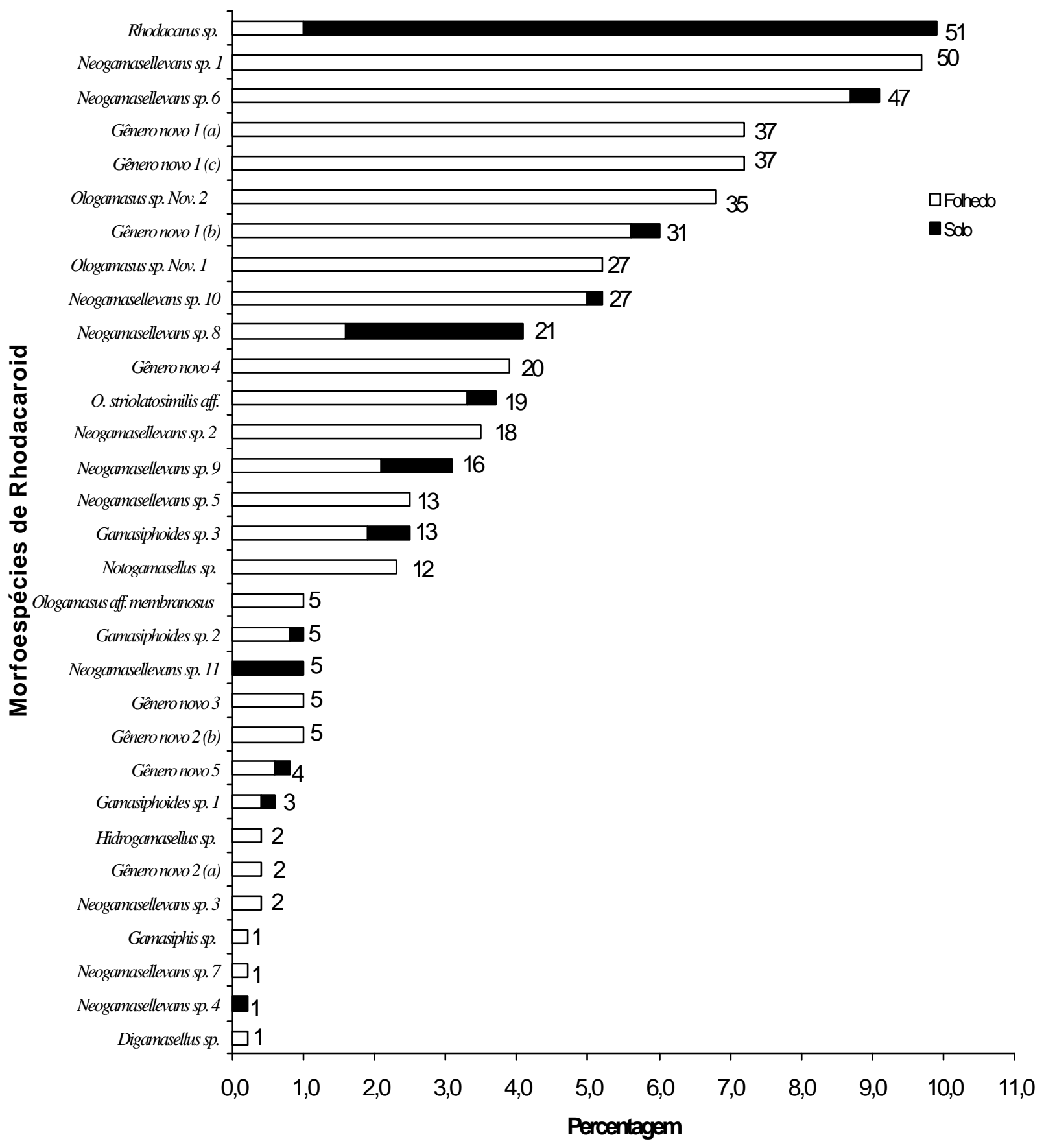

Figura 1- Proporções e número de indivíduos (à direita de cada coluna) das morfoespécies de Rhodacaroidea coletadas em amostras de folhedo e solo tomadas sob arecáceas da Mata Atlântica do Estado de São Paulo, em 2000. 
A diversidade de morfoespécies foi consideravelmente menor no Cerrado que na Mata Atlântica, como seria de se esperar, pela abundância muito menor de ácaros naquele ecossistema. Cinco morfoespécies foram encontradas, três no folhedo e duas, diferentes daquelas, no solo (Figura 3). A morfoespécie mais abundantes no Cerrado foi Rhodacarus sp., correspondendo a mais de $60 \%$ dos espécimes de Rhodacaridae coletados. Todos os indivíduos daquela morfoespécie foram coletados no solo do Cerrado.

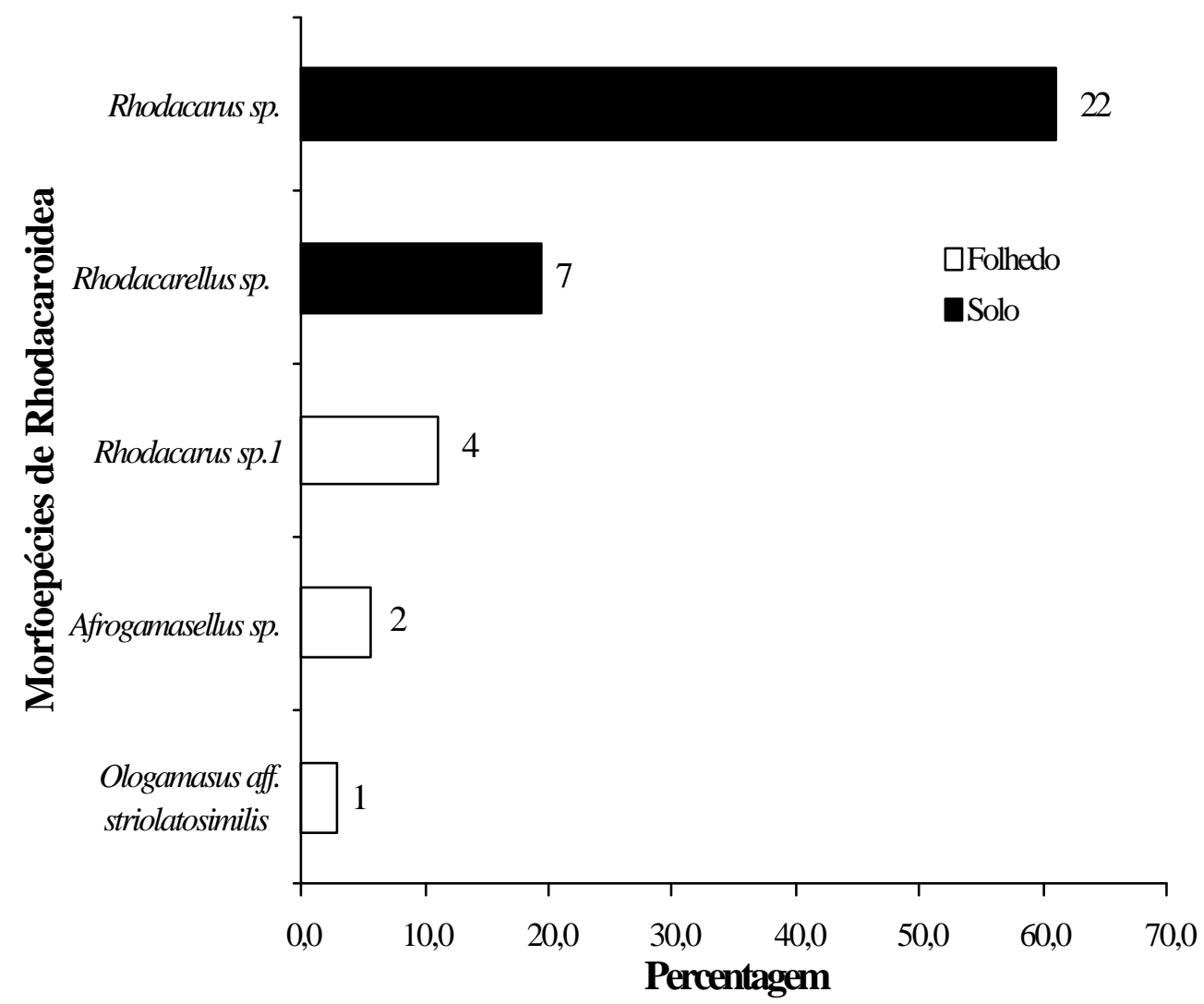

Figura 2 - Proporções e número de indivíduos (à direita de cada coluna) das morfoespécies de Rhodacaroidea coletados em amostras de folhedo e solo tomadas sob mirtáceas do Cerrado do Estado de São Paulo, em 2000. 
Na Mata Atlântica, o grau de uniformidade das frequiências das morfoespécies encontradas foi maior que no Cerrado, como se observa pela inclinação muito menor da curva de dominância (Figura 3) corresponde àquele ecossistema. Os índices de Pielou correspondentes foram 0,042 e 0,098 respectivamente.

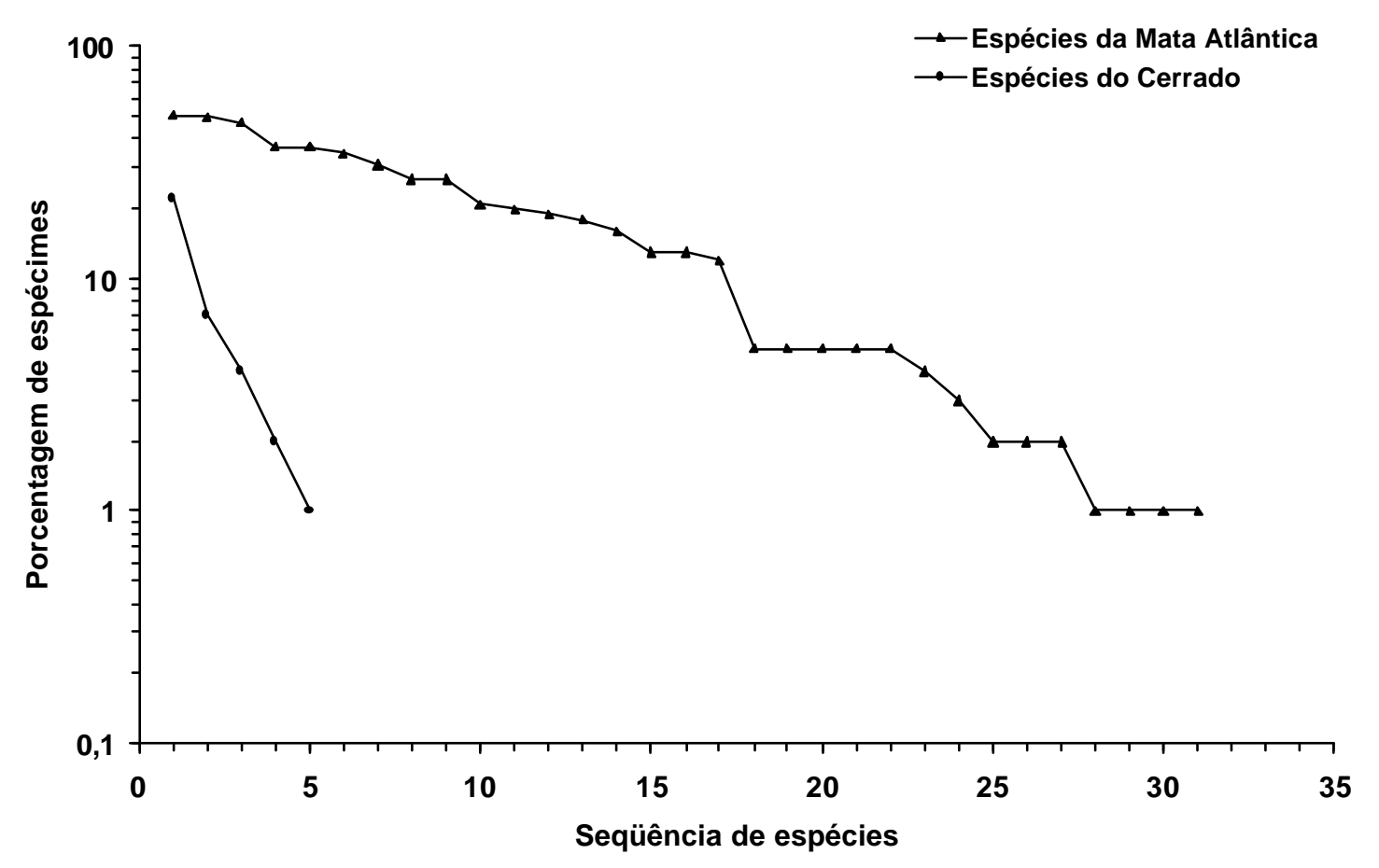

Figura 3 - Curvas do componente de dominância da diversidade de espécies de ácaros para 516 e 36 espécimes de Rhodacaroidea coletados em amostras de folhedo e solo tomadas sob arecáceas da Mata Atlântica e mirtáceas do Cerrado do Estado de São Paulo, respectivamente, em 2000. 
Considerando-se o ecossistema da Mata Atlântica, onde os Rhodacaroidea foram mais numerosos, observa-se que o gau de uniformidade de freqüência de morfoespécies é maior no folhedo do que no solo (figura 4). Os índices de Pielou (Odum, 1988) correspondentes foram 0,060 e 0,054 respectivamente.

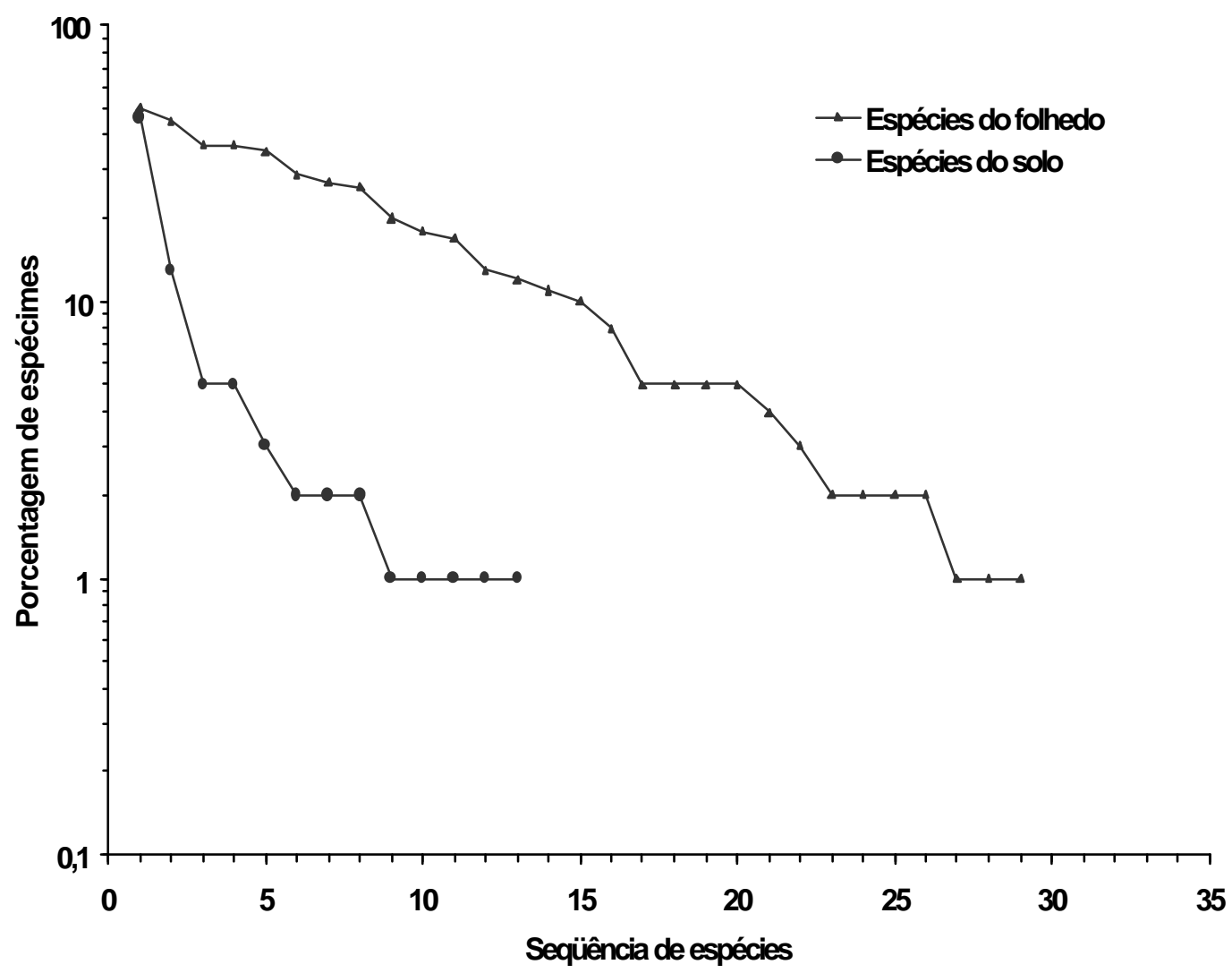

Figura 4 - Curvas do componente de dominância da diversidade de espécies de ácaros para 433 e 83 espécimes de Rhodacaroidea coletados em amostras de folhedo e solo, respectivamente, tomadas sob arecáceas da Mata Atlântica do Estado de São Paulo, em 2000 . 


\subsubsection{Diversidade e predominância de gêneros de Rhodacaroidea sob as espécies vegetais consideradas}

As maiores quantidades de Rhodacaroidea foram encontradas sob as arecáceas $E$. edulis (254 ácaros), S. romanzoffiana (179 ácaros) e A. aculeatissimum (169 ácaros), na Mata Atlântica (Tabela 4). A maior diversidade de gêneros destes ácaros foi observada sob E. edulis (12 gêneros) e B. setosa (10 gêneros), seguidas de $S$. romanzoffiana e $A$ aculeatissimum, com sete gêneros cada uma. As demais arecáceas apresentaram cada uma entre um e cinco gêneros de Rhodacaroidea. Alguns gêneros de Rhodacaroidea (Neogamasellevans e Ologamasus) se destacaram por estarem presentes praticamente em todas as arecáceas consideradas neste estudo.

Houve diferença grande entre as plantas em relação ao número de ácaros por planta. As mirtáceas apresentaram menores índices de ácaros por planta em relação a maioria das espécies vegetais de arecáceas. Sob nenhuma destas espécies de planta foram encontrados mais que três gêneros destes ácaros. Rhodacarus se destacou por estar presente em todas as espécies de mirtáceas consideradas neste estudo.

A correlação entre o número de gêneros por planta e o número de ácaros por planta

foi menor $\left(R^{2}=0,4558\right)$ do que quando se correlacionou o número de gêneros por planta com o total de ácaros coletados por planta $\left(R^{2}=0,7399\right)$. O que já era de se esperar, pois, quando se tem um maior número de amostras, conseqüentemente, terá uma maior diversidade de gêneros.

\subsubsection{Similaridade entre espécies de arecáceas de acordo com as morfoespécies de Rhodacaroidea encontradas}

Dois grupos distintos de arecáceas puderam ser observados de acordo com as morfoespécies de Rhodacaroidea encontradas sob cada espécie de planta (Figura 5).

O primeiro grupo é composto pelas espécies vegetais A. aculeatissimum, B. setosa e A. dubia. Estas espécies vegetais foram amostradas em Pariquera-Açu e/ou Cananéia, mas não na região de Piracicaba. Neste grupo pode-se evidenciar um subgrupo composto 
Tabela 4. Totais de espécies de cada gênero de Rhodacaroidea coletados em amostras de folhedo e solo tomadas sob arecáceas da Mata Atlântica e mirtáceas do Cerrado do Estado de São Paulo, em 2000.

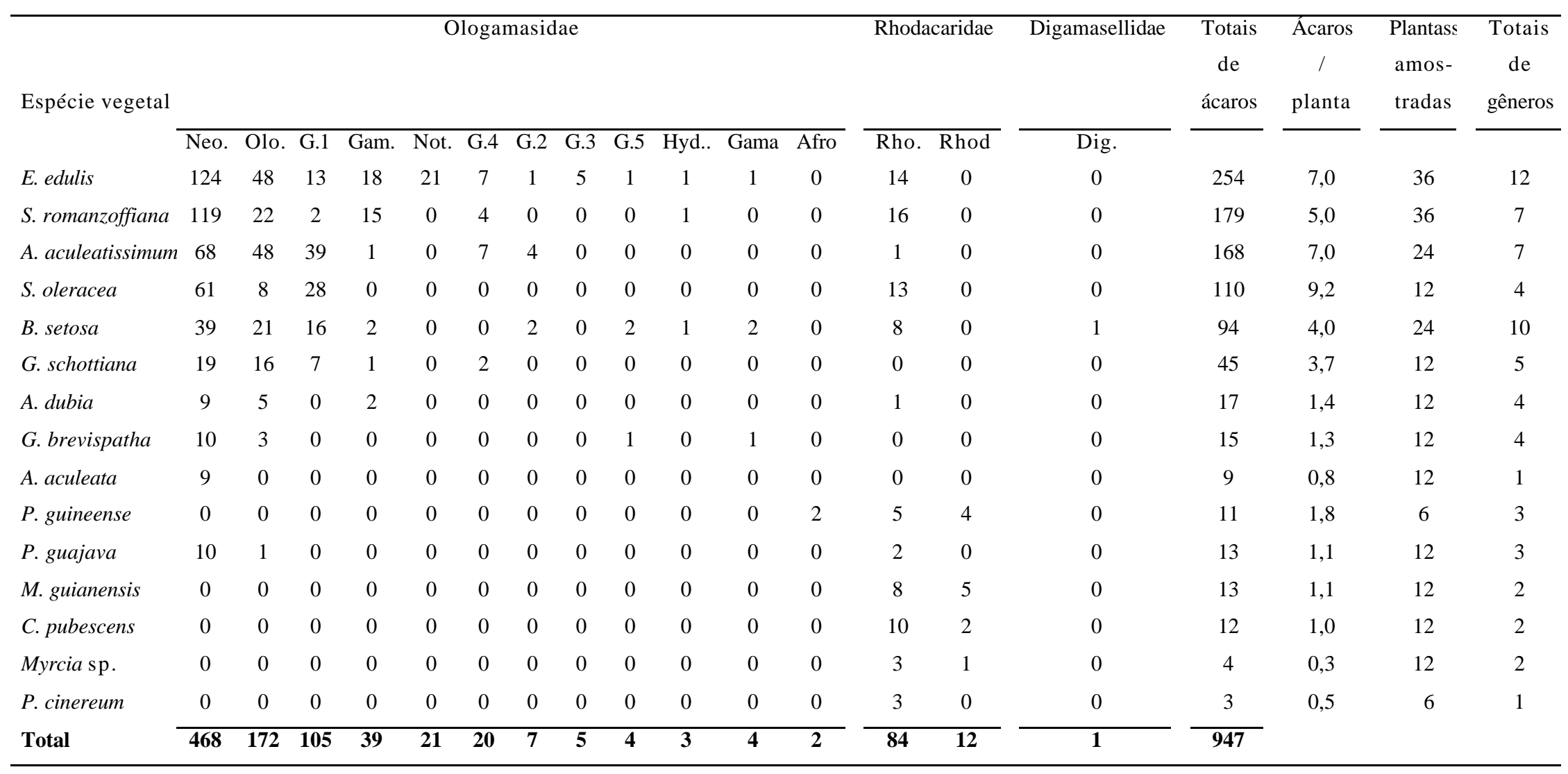

Neo. $=$ Neogamasellevans, Olo. $=$ Ologamasus, G.1 = Gênero novo 1, Gam. = Gamasiphoides, Not. = Notogamasellus, G. $4=$ Gênero novo 4, G. $2=$ Gênero novo 2, G. $3=$ Gênero novo 3, G. 5 $=$ Gênero novo 5, Hyd. = Hydrogamasellus, Gama = Gamasiphis, Afr. $=$ Afrogamasellus, Rho. $=$ Rhodacarus, Rhod $=$ Rhodacarellus, Dig. $=$ Digamasellus 
por A. aculeatissimum e B. setosa, plantas amostradas tanto em Pariquera-Açu quanto em Cananéia. A outra planta deste mesmo grupo (A. dubia) foi amostrada exclusivamente em Pariquera-Açu.

O segundo grupo é composto por E. edulis e $S$. romanzoffiana. Estas espécies vegetais foram amostradas em todos os locais de coleta.

G. schottiana, G. brevispatha e S. oleracea não formaram grupo com as demais plantas, nem entre si. A primeira foi amostrada apenas em Cananéia. As duas últimas foram amostradas apenas na região de Piracicaba.

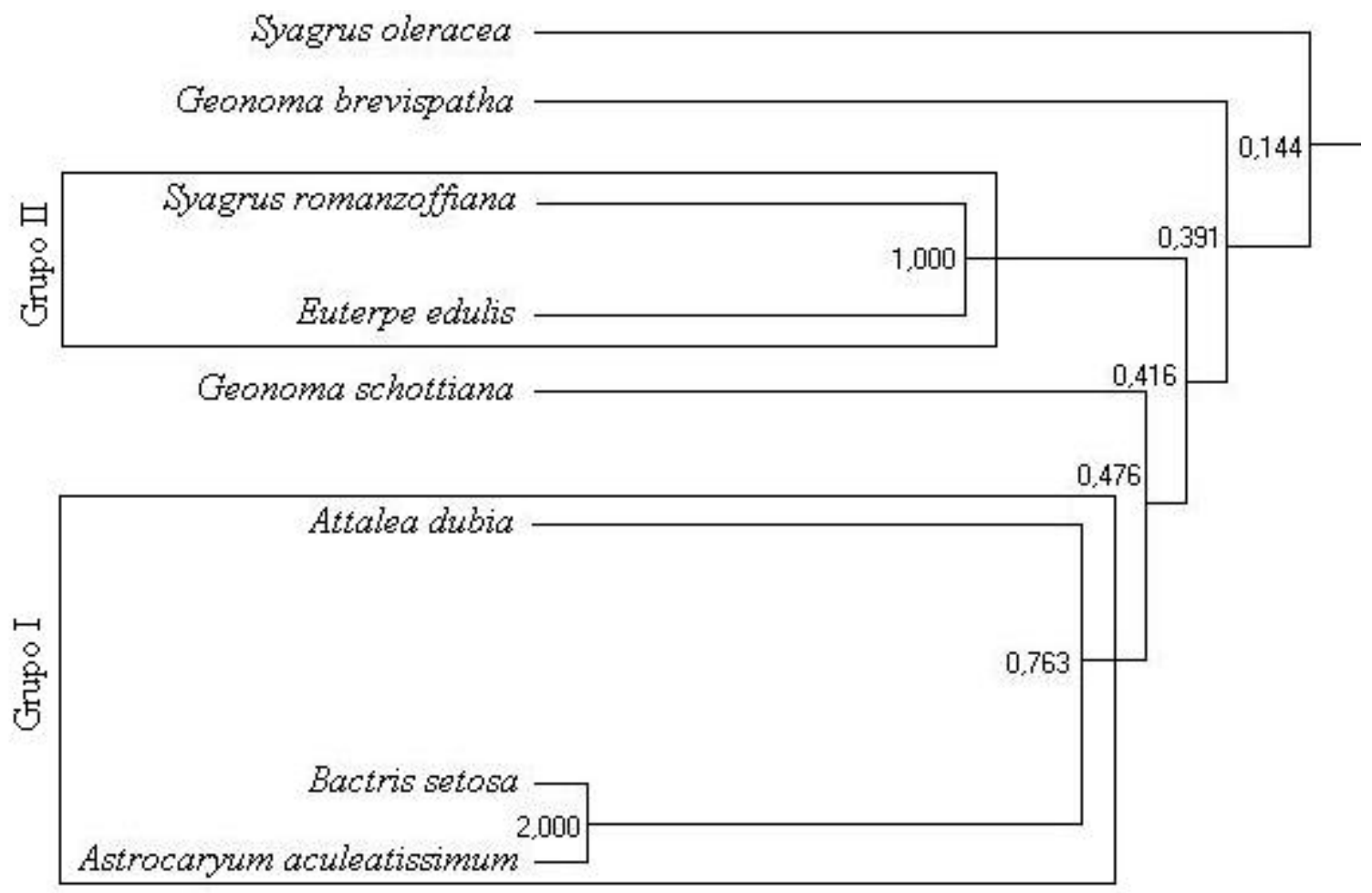

Figura 5 - Grupamento de espécies de Arecaceae da Mata Atlântica do Estado de São Paulo, pela ocorrência em comum de morfoespécies de Rhodacaroidea obtido com o índice de Mountford (Silveira Neto et al., 1976). 


\subsection{Discussão}

Discute-se a predominância da fauna de Rhodacaroidea em diferentes localidades da Mata Atlântica e do Cerrado, coletados no folhedo e solo, bem como, a diversidade de gêneros e morfoespécies destes ácaros, a uniformidade e a similaridade entre as espécies de Arecaceae em relação os gêneros de Rhodacaroidea encontrados.

\subsubsection{Predominância de Rhodacaroidea em diferentes localidades e substratos}

Uma grande quantidade de Rhodacaroidea foi encontrada neste estudo, na Mata Atlântica. Segundo Krantz (1978), estes ácaros são comuns em muitos ambientes naturais, agindo como predadores de colêmbolas, nematóides e outros artrópodes. Entretanto, não se dispõe de informações sobre a bioecologia destes ácaros e o porque são tão abundantes. Supõe-se que a abundância destes ácaros na Mata Atlântica esteja relacionada à espessa camada de folhedo reste ecossistema e, conseqüentemente, a uma maior disponibilidade de presas potenciais nestes locais.

Diferentemente, o pequeno número de Rhodacaroidea no Cerrado está possivelmente relacionado, com a menor espessura da camada de folhedo neste ambiente, o que poderia manter um menor número de presas potenciais. $\mathrm{O}$ tipo de solo e a quantidade de nutrientes também parecem ser fatores determinantes para a predominância de diferentes gêneros de Rhodacaroidea. Lee (1973) sugeriu que espécies de Athiasella preferem solos argilosos, com alto teor de nutrientes, enquanto Gamasellus pode estar confinado a solos arenosos, com baixos teores de nutrientes. Também Lee (1973) comparou a composição da fauna de Rhodacaroidea em um solo coberto por folhedo e outro por musgos e verificou que são similares.

É possível que a maior abundância de Rhodacaroidea no folhedo esteja relacionada à forma e estrutura do corpo dos ácaros encontrados. A maioria dos Rhodacaroidea encontrados pertencem à família Ologamasidae, a maioria parte dos quais apresentam 
pronunciada esclerotização e placa dorsal holonotal. Estas características limitam a capacidade da maioria dos ácaros desta família em explorar o perfil mineral do solo, especialmente nos casos de solos compactados ou arenosos, pela dficuldade de locomoção nesse meio. É possível que a quantidade relativamente pequena de Ologamasidae encontrada no solo, neste estudo, na verdade estivesse bem na superfície, logo abaixo do folhedo. A maior abundância dos Rhodacaridea no solo, em ambos os ecossistemas, está provavelmente ligada ao fato destes ácaros terem o formato do corpo mais adequado a explorar aquele substrato. Os Rhodacaridae geralmente tem tamanho reduzido, e apresentam a parte dorsal do idiossoma coberto por duas placas separadas, podonotal e opistonotal, de esclerotização muito variável. Estas características permitem aos Rhodacaridae explorarem grandemente a camada mineral do solo, facilitando o movimento destes ácaros por entre as partículas.

\subsubsection{Predominância de famílias, gêneros e morfoespécies de Rhodacaroidea}

Das três famílias de Rhodacaroidea encontradas neste estudo, Ologamasidae e Rhodacaridae foram predominantes, Digamasellidae foi rara.

A grande predominância foi de Ologamasidae, especialmente em ambiente de Mata Atlântica no folhedo, este resultado já era esperado. Em ecossistemas naturais de regiões tropicais, Mineiro \& Moraes (2001) e Van Den Berg \& Ryke (1967), estudando ácaros

edáficos, também constataram que a família de Mesostigmata mais abundante foi Ologamasidae.

Diferentemente, estudos realizados em regiões de florestas temperadas (Evans et al., 1968; Wallwork, 1970; Price, 1973; Evans \& Till, 1979; Coleman \& Crossley Jr., 1996) apontam a família Rhodacaridae como sendo mais abundante que Ologamasidae. Estes resultados indicam uma maior adaptação de ácaros Ologamasidae a regiões de clima tropical e de Rhodacaridae a regiões de clima temperado. Do mesmo modo, os Ologamasidae encontrados no presente estudo, foram raros no material coletado no Cerrado, enquanto os Rhodacaridae foram mais numerosos. O baixo número de ácaros da família Rhocacaridae 
observado no presente estudo concorda com os dados obtidos por Mineiro \& Moraes (2001) em Piracicaba, Estado de São Paulo. Naquele estudo, os autores obtiveram raros exemplares de ácaros daquela família, tanto no solo quanto no folhedo de uma área de mata nativa alterada e de um plantio de seringueira.

Krantz (1978) afirmou que espécies de Digamasellidae apresentam ampla distribuição na superfície do solo e em material orgânico, alimentando-se de colêmbolas, nematóides ovos de outros artrópodes e, possivelmente, fungos. Entretanto, apenas um exemplar desta família foi encontrado no presente estudo. Nenhum exemplar desta família foi encontrado por Mineiro \& Moraes (2001).

A diferença no número de gêneros de Rhodacaroidea coletados neste estudo, sob plantas de Arecaceae e Myrtaceae, possivelmente está relacionada à quantidade e diversidade de presas existentes nos locais de coleta. Possivelmente, esta quantidade e diversidade de presa estão relacionadas à quantidade e diversidade de matéria orgânica presente no solo, sob a copa de cada uma das plantas consideradas. Esta matéria orgânica, por sua vez, está em função da quantidade e diversidade de espécies vegetais encontradas tanto na Mata Atlântica quanto no Cerrado. Na Mata Atlântica, as espécies vegetais estão em maior quantidade e diversidade, forma uma cobertura mais densa, em relação à flora do Cerrado. Nesse estudo, os pontos de coleta de cada amostra pode corresponder ao substrato orgânico depositado no solo por plantas vizinhas àquelas selecionadas para serem amostradas. Isto certamente ocorreu, especialmente na Mata Atlântica, onde as espécies de arecáceas crescem à sombra de outras plantas. No Cerrado, talvez a influência de plantas vizinhas seja menor, pois normalmente há uma maior dispersão entre as espécies de plantas, diminuindo a diversidade de matéria orgânica sob cada planta, conseqüentemente reduzindo a diversidade de gêneros e morfoespécies de Rhodacaroidea.

Em locais onde os fatores de estresse atuam intensamente, a diversidade tende a diminuir, isto é, o número de espécimes de espécies mais abundantes tende a aumentar e o número de espécies e de espécimes mais raros tende a diminuir (Silveira Neto et al. 1976). O 
estresse, natural (condições meteorológicas extremas, por exemplo) ou antrópico, tende a tornar mais inclinadas as curvas do componente de dominância da diversidade proposto por Whittaker $\left(1965^{1}, 1972^{2}\right)$ in Odum (1988), de modo que estas possam ser usadas para avaliar o efeito das perturbações sobre a estrutura de espécies de uma comunidade (Odum 1988). Os componentes de dominância da diversidade neste estudo mostraram que no ecossistema de Mata Atlântica há menor estresse que no Cerrado, pois a maior diversidade em morfoespécies naquele ambiente permitiu que se obtivesse uma curva de componente da dominância da diversidade com menor inclinação. No Cerrado, a inclinação da curva de componente da dominância da diversidade foi grande, indicando uma maior perturbação neste ambiente. Um dos principais fatores de estresse a que os ácaros edáficos deste estudo possam estar expostos pode se referir à variação da precipitação, que na Mata Atlântica é elevada e melhor distribuída ao longo do ano, que no Cerrado onde é menor e mais concentrada no verão.

A maior uniformidade das frequiências de espécies no folhedo da Mata Atlântica também indica um menor grau de estresse neste substrato do que no solo. Neste caso, o fator de estresse mais provável parece ser o teor de água. Em coletas realizadas durante o período chuvoso, o solo se encontrava quase que totalmente encharcado. A altíssima umidade se mantém sempre por períodos muito mais prolongados no perfil mineral do solo que no folhedo. $\mathrm{O}$ folhedo, na verdade desempenha um papel importante na retenção da umidade no perfil mineral.

\subsubsection{Diversidade e predominância de gêneros de Rhodacaroidea sob as espécies vegetais consideradas}

Fatores como condições climáticas, tipo de solo e espécie vegetal parecem estar

\footnotetext{
${ }^{1}$ WHITTAKER, R. H. Dominance and diversity in land plant communities. Science 147: 250-260. 1965.

${ }^{2}$ WHITTAKER, R. H. Evolution and measurement of species diversity. Tarpon 21:213-251. 1972.
} 
envolvidos na quantidade de ácaros por planta e na diversidade de gêneros por espécie vegetal. Deve-se levar em consideração também o número de amostra coletada por espécie vegetal, pois, neste estudo as plantas que foram amostradas em maior número (E. edulis e $S$. romanzoffiana foram amostradas em todas as áreas de coleta da Mata Atlântica, e, A. aculeatissimum e B. setosa foram amostradas em duas daquelas áreas) foram as que apresentaram consideravelmente, um maior número de Rhodacaroidea, conseqüentemente aumentou-se a chance de se coletar um número maior de espécies, inclusive as mais raras. Proporcionalmente o número de ácaros e a diversidade de gêneros são equivalentes quando relacionados à quantidade de coletas de cada planta. No entanto, a espécie $S$. oleracea representa uma exceção quanto ao número de espécimes coletado sob a mesa. Esta planta foi amostrada em quantidades inferiores às citadas anteriormente e o número médio de Rhodacaroidea encontrado por planta foi o mais elevado. Entretanto, a diversidade em gêneros foi uma das menores. Outra exceção é a espécie B. setosa que apresentou um baixo número de Rhodacaroidea por planta e uma das maiores diversidades em gêneros. Deve-se considerar que $B$. setosa foi tomada o dobro de amostras em relação a $S$. oleracea. Com os resultados obtidos de cada planta, acredita-se que, a espécie de planta possa ter algum tipo de influência na composição da fauna de Rhodacaroidea sob sua copa.

Os mesmos fatores mencionados anteriormente podem ter sido a razão do pequeno número de espécimes e gêneros de Rhodacaroidea coletados nas espécies de mirtáceas.

\subsubsection{Similaridade entre espécies de arecáceas de acordo com as morfoespécies de Rhodacaroidea encontrados}

O grupamento das espécies de arecáceas obtida neste estudo parece em certo grau estar relacionado a condições climáticas reinantes nos locais de amostragem. A. aculeatissimum, B. setosa e A. dubia foram encontradas apenas em Pariquera-Açu e/ou Cananéia, e constituíram um grupo de espécies. S. romanzoffiana e E. edulis, por outro lado, foram amostradas em todas as regiões, e constituíram um outro grupo. As três espécies que se 
mostram distintas, não se grupam com outras espécies vegetais, foram amostradas cada uma em apenas uma região: G. schottiana apenas em Cananéia, $G$. brevispatha e S. oleracea apenas na região de Piracicaba.

Entretanto, as condições climáticas não parecem ter sido os únicos fatores envolvidos na formação de cada grupo. G. brevispatha e S. oleracea apesar de serem amostradas apenas na região de Piracicaba, mostraram-se bastante distintas entre si e em relação às demais espécies que também foram amostradas na mesma região (S. romanzoffiana e E. edulis). S. oleracea é uma planta muito diferente de G. brevispatha, e isto pode ter determinado a diferença na composição da fauna de Rhodacaroidea sob cada uma daquelas palmeiras. Pela mesma razão, parece ser este o motivo pelo qual G. schottiana, amostrada apenas em Cananéia, tenha se mostrado distinta de outras espécies vegetais encontradas também em Cananéia.

A distinção entre cada uma das espécies de Geonoma e as demais espécies de palmeiras sugere um considerável efeito da planta sob a qual as amostras foram coletadas sobre a forma de Rhodacaroidea predominante. Isto se torna particularmente interessante pelo fato de se tratar de um grupo de ácaros conhecido principalmente pelos seus hábitos predatórios. Seria o princípio de se esperar que o efeito da grande diversidade de outras plantas vizinhas pudesse diluir significativamente o efeito de plantas de porte tão pequeno, como são as espécies de Geonoma, que convivem à sombra das outras plantas da Mata Atlântica. Entretanto, os resultados obtidos neste estudo mostraram que este não parece ser o caso.

\subsection{Conclusões}

1) Os ácaros Rhodacaroidea são abundantes no folhedo da Mata Atlântica.

2) Ologamasidae é a família mais numerosa de Rhodacaroidea no folhedo da Mata Atlântica. 


\section{DIVERSIDADE DE ÁCAROS (ARACHNIDA: ACARI) E FITONEMATÓIDES (NEMATA) EDÁFICOS DA MATA ATLÂNTICA DO ESTADO DE SÃO PAULO}

\section{Resumo}

Existem poucas informações sobre a fauna de ácaros e nematóides edáficos em ambientes naturais brasileiros. O objetivo deste estudo foi avaliar a diversidade destes organismos no folhedo e em diferentes camadas do solo. Coletaram-se amostras de folhedo e solo em diferentes profundidades, na base de Euterpe edulis Mart. (Arecaceae) em Pariquera-Açu e Cananéia. As extrações foram feitas pelo método de BerleseTullgren modificado. Coletaram-se 2717 ácaros, 80\% dos quais, no folhedo. No solo, a maior quantidade de ácaros foi encontrada na camada de $0.5 \mathrm{~cm}$, exceto no outono. A maior abundância nos 2 substratos ocorreu no inverno. As proporções de cada ordem encontrada, em ambos os substratos foram: Oribatida (80\%), Mesostigmata (18\%), Prostigmata e Astigmata, juntos (2\%). No folhedo foram encontradas 14 famílias de ácaros e no solo, 17. As famílias mais abundantes foram Ologamasidae e Uropodidae, para Mesostigmata, e Labidostommatidae e Trombidiidae para Prostigmata. A família Acaridae foi a única representante dos Astigmata registrada. Foram encontrados 19 gêneros e 32 morfoespécies de ácaros no folhedo, e 19 gêneros e 27 morfoespécies no solo. Neogamasellevans Loots \& Ryke e Ologamasus Berlese foram os gêneros com maior número de morfoespécies. Os nematóides foram avaliados através de amostras de solo tomadas ao lado das amostras para extração de ácaros. As extrações de nematóides foram feitas pelo método de Jenkins. Representantes de Hoplolaimidae (Helicotylenchus Steiner e Aorolaimus Sher) e Criconematidae (Criconemella Taylor, Discocriconemella 
Grisse \& Loof, Hemicycliophora e Hemicriconemoides Chitwood \& Birchfield) foram predominantes. Os fitonematóides foram encontrados em grandes números no perfil do solo, em todas as profundidades avaliadas, enquanto os ácaros foram mais numerosos na camada superior $(0-5 \mathrm{~cm})$. Assim é de se esperar que os ácaros que por ventura estejam predando aqueles nematóides possam apresentar alguma eficiência apenas na camada mais superficial do solo. 


\section{DIVERSITY OF MITES (ARACHNIDA: ACARI) AND EDAPHIC PLANT NEMATODES (NEMATA) IN THE ATLANTIC FOREST OF THE STATE OF SÃO PAULO}

\section{Summary}

There are few information on the fauna of edaphic mites and nematodes in Brazilian natural ecosystems. The objective of this study was to evaluate the diversity of those organisms in the litter and at different depths in the soil. Samples of litter and soil at different depths were taken, at the base of Euterpe edulis Mart. (Arecaceae) in Pariquera-Açu and Cananéia. Extraction was done using a modified Berlese-Tullgren method. A total of 2717 mites was collected, $80 \%$ of which, in the litter. In the soil, the largest number of mites was collected at $05 \mathrm{~cm}$ from the surface, except in the fall. The largest number in both substrates was collected in the winter. The proportions of each mite order in both substrates were: Oribatida (80\%), Mesostigmata (18\%), Prostigamata and Astigamata (total of 2\%). Fourteen mite families were found in the litter and 17, in the soil. The most abundant families were Ologamasidae and Uropodidae (Mesostigmata), and Labidostommatidae and Trombidiidae (Prostigamata). Acaridae was the only representative of Astigmata collected in this study. Nineteen genera and 32 morpho-species were collected in the litter, and 19 genera and 27 morpho-species in the soil. Neogamasellevans Loots \& Ryke and Ologamasus Berlese were the most specious genera. Nematodes were evaluated in soil samples taken next to the points where samples were taken for the evaluation of mites. Nematode extraction was done using Jenkins' method. Representatives of Hoplolaimidae (Helicotylenchus Steiner and Aorolaimus Sher) and Criconematidae (Criconemella Taylor, Discocriconemella Grisse \& Loof, Hemicycliophora and Hemicriconemoides Chitwood \& Birchfield) were predominant. Plant nematodes were found in large numbers at all evaluated depths, while mites were most numerous near the surface $(0-5 \mathrm{~cm}$ depth). Thus, it is expected 
that mites that could be preying on those nematodes may have some efficiency only in the most superficial soil layers.

\subsection{Introdução}

Pouco se conhece sobre a fauna edáfica de ambientes naturais no Brasil. Esta escassez de conhecimento está relacionada ao pequeno número de trabalhos realizados nessas áreas. Muitos crimes ambientais acontecem constantemente, como o desmatamento, incêndios criminosos, poluição dos rios com pesticidas, tráfico de espécies em extinção, que provavelmente afetam consideravelmente estes organismos. $\mathrm{O}$ conhecimento das espécies de ácaros e nematóides edáficos representa um passo importante para o entendimento do papel de que estas espécies desempenham no ambiente.

No passado, a Mata Atlântica ocupava 12\% do território nacional, estendendo-se do Rio Grande do Norte ao Rio Grande do Sul. Extensa, compacta e exuberante, abrangia diversos ecossistemas interligados, como florestas de baixada e encostas da Serra do Mar, matas de araucária, mangues, brejos e restingas. Hoje, não passa de 7\% da área original, embora ainda mantendo parte de sua imponência primordial e grande importância ambiental; além de abrigar e fornecer alimento para homens e animais preserva seu riquíssimo patrimônio genético, histórico e cultural para as gerações vindouras (Bezerra, 2002).

Um dos maiores desafios enfrentados pela humanidade hoje é evitar o colapso dos recursos e serviços que comprometam as futuras gerações. Dentro deste contexto, a conservação da diversidade biológica e o manejo racional e sustentável dos recursos naturais são hoje os problemas mais sérios em nosso planeta, com interfaces abrangentes nos campos social e econômico. Para enfrentá-los há necessidade de se gerar conhecimentos sobre os recursos vivos do planeta e suas interações com as atividades humanas. 
Devido à redução significativa de áreas da Mata Atlântica, é de fundamental importância para a ciência que se conheça a fauna presente no solo desses ambientes, estudando suas interações com a flora local, buscando explicações para o equilíbrio ecológico que há nesses sistemas.

O palmito juçara (Euterpe edulis Mart.), da família Arecaceae, é uma das plantas mais importantes da Mata Atlântica do ponto de vista econômico. Esta planta, hoje ameaçada de extinção, tem sido ao longo dos anos fonte de alimento de povos e animais da floresta desde tempos remotos (Reis \& Reis, 2000). Na atualidade, plantios comerciais de juçara estão sendo implantados e estudos vinculados a plantas dessa família em ambientes naturais são de grande valia para que se possa conhecer organismos que convivem naturalmente com essas plantas. Como tem sido observado para muitas plantas, alguns organismos, que com elas convivem em harmonia em condições naturais, podem em condições de cultivo comercial thes afligir sérios danos. Estes mesmos organismos podem ainda causar danos severos a outras plantas, também em cultivos comerciais.

Os nematóides são organismos do filo Nemata, de comportamento muito variável. Muitos são parasitos de animais, inclusive do próprio homem (Weischer \& Brown, 2001). Outros são de vida livre, no solo, alimentando-se de fungos, bactérias, algas e até mesmo predando outros nematóides ou parasitando artrópodes. Outros ainda atacam plantas, podendo lhes causar danos significativos. Sasser et al. (1978) relataram que alguns fitonematóides podem causar perdas estimadas em $12 \%$ na produção agrícola, representando prejuízo anual de cerca de100 bilhões de dólares em todo o mundo.

Rossi (1995) encontrou o fitonematóide Pratylenchus coffeae (Zimmermann) parasitando raízes de juçara em plantios comerciais no município de Miracatu em São Paulo, embora sem causar danos aparentes à cultura. Esse fitonematóide ataca outras culturas como batata (Curi et al., 1974), banana (Almeida et al., 1978), mas são mais danosos a plantas de café (Monteiro \& Lordello, 1974) e citros (Prates \& Lordello, 1980). 
Os ácaros são organismos do filo Artropoda, agrupados em 2 superordens, 7 ordens (Evans, 1992) e cerca de 400 famílias. As ordens mais comuns são Oribatida, Mesostigmata, Prostigmata, Astigmata e Ixodida, outras duas ordens (Notostigmata e Holothyrida) são raras. Estes organismos apresentam uma considerável diversidade em relação ao comportamento alimentar e habitats que ocupam. O hábito alimentar dos ácaros varia consideravelmente mesmo dentro de cada família. Podemos encontrar dentre estes, espécies predadoras, fitófagas, algívoras, fungívoros, detritívoros, parasitos de vertebrados e invertebrados e ainda alguns que se alimentam de matéria orgânica em decomposição. Os ácaros podem ser encontrados desde as regiões polares até as desérticas, em quase todo tipo de substrato, como poeira, grãos armazenados, água, solo, folhedo, parasitando plantas e animais vertebrados e invertebrados (Krantz, 1978). Em alguns desses substratos, os ácaros são bem conhecidos, a exemplo dos ácaros fitófagos, alguns dos quais são pragas importantes. Em outros substratos, os ácaros são geralmente pouco conhecidos, como é o caso dos ácaros edáficos, principalmente no Brasil, devido ao restrito número de especialista e de publicações nessa área, e pela grande diversidade e inexistência de chaves taxonômicas apropriadas a acarofauna nacional (Flechtmann \& Moraes, 2000).

Os ácaros Mesostigmata constituem um grupo grande, adaptando-se a uma gama extensiva de hábitats (Krantz \& Ainscough, 1990). Muitos destes ácaros são predadores de artrópodes no folhedo ou solo (Krantz, 1978).

São conhecidos Mesostigmata edáficos pertencentes às famílias Ascidae, Laelapidae, Macrochelidae, Parasitidae, Eviphididae, Veigaiidae, Ologamasidae e Rhodacaridae, que predam fitonematóides. Existem vários trabalhos em outros países, que relatam ácaros de algumas daquelas famílias predando fitonematóides (Ito, 1971; Imbriani \& Mankau, 1983; Inserra \& Davis, 1983; Walter, 1986, 1988; Epsky et al.,1988).

No Brasil, a maioria dos trabalhos envolvendo Mesostigmata edáficos refere-se à taxonomia e registros de ocorrências. O maior número de trabalhos encontrados são referentes à superfamília Uropodina, especialmente no Estado de São Paulo, a maioria destes trabalhos, sobre descrição de espécies (Sellnick, 1954; Hirschmann, 1969c; 
1972a, b, c, d; 1973a, b, e, j; 1975a, b, c; 1976a, d, c; 1977a; 1978; 1981a, c b; 1991; 1992b; Hirschmann \& Zirngiebl-Nicol, 1972a, c; Zirngiebl-Nicol \& Hirschmann, 1972c; 1973a; 1975. No Estado do Acre, apenas Trichocylliba aguaboae está registrada como ácaro edáfico (Hirschmann,1992). No Estado do Pará, foram descritas; Tetrasejaspis eustructa (Hirschmann, 1973b); Baloghibrasiluropoda foveolatasimilis (Hirschmann, 1973c) e Baloghjakaszabia baloghi (Hirschmann, 1973d). O Estado do Amazonas possui a maior quantidade de espécies de ácaros edáficos descritas (Hirschmann, 1972b, c, d; 1973a, b, c, d, g, h, i, j; 1975d; 1977b; Hirschmann \& Zirngiebl-Nicol, 1972a, b, c)

No município de Goiana, em Pernambuco, Moraes et al. (1997) registraram a ocorrência do fitoseídeo Neoseiulus gracilis (Muma, 1962) em solo.

Em Brasília - Distrito Federal, Hirschmann (1973c) descreveu um gênero novo, Baloghibrasiluropoda e uma espécie nova, B. foveatoides. No Estado do Mato Grosso, no município de Rosário d'Oeste, Trajano \& Gnaspini-Neto (1990) relataram a ocorrência de ácaros Diarthrophollus sp. (Diarthrophollidae) e Macrocheles coprophila (Macrochelidae) na gruta do Currupira.

Nos Estados de Minas Gerais, Rio de Janeiro e São Paulo, há vários trabalhos de descrição e ocorrência de espécies de ácaros da subordem Mesostigmata (Trajano \& Gnaspini-Neto, 1990; Hirschmann, 1972).

Existe também relatos sobre a acarofauna no Estado de São Paulo, nos municípios de Pariquera-Açú, Cananéia e Piracicaba feitos por Denmark \& Muma, 1973; Mineiro \& Moraes 2001; Zacarias \& Moraes 2001. Um estudo recente sobre a abundância e diversidade de ácaros edáficos da ordem Mesostigmata no município de Piracicaba-SP foi conduzido por Mineiro \& Moraes (2001).

No Brasil, sobre a diversidade de ácaros edáficos da ordem Mesostigmata foi feito por Mineiro \& Moraes (2001), no município de Piracicaba-SP. Naquele estudo, os autores relataram a ocorrência de 49 espécies de Mesostigmata, pertencentes a 30 gêneros. Estes números representaram cerca de $43 \%$ de todos os ácaros coletados e identificados naquele estudo.

Face ao número restrito de informações sobre os ácaros edáficos, principalmente predadores de fitonematóides no Brasil, este trabalho teve como objetivo contribuir com 
estes estudos, através da avaliação da distribuição daqueles organismos no perfil do solo, sob plantas de palmito juçara em uma área de Mata Atlântica do Estado de São Paulo.

\subsection{Material e Métodos}

Para este estudo, foram feitas quatro coletas de amostras nos períodos de 14 e 15 de abril (outono), 24 e 25 de julho (inverno), 09 e 10 de outubro (início da primavera) e 11 e 12 de dezembro (fim da primavera) de 2001. Foram escolhidos três sítios da Mata Atlântica paulista, sendo dois no município de Pariquera-Açu (sítios I e II), na "Estação Experimental J. Cione" (240 36 ' 50" de latitude sul, $47^{0}$ 53' 00” de longitude oeste), pertencente ao Instituto Agronômico de Campinas, e um no município de Cananéia (sítio III), à margem da rodovia SP-226, (24 55'00” de latitude sul, $47^{0} \quad 50$ ' 00 ” de longitude oeste). A vegetação dos sítios I e II é caracterizada como Mata Ombrófila Densa, enquanto aquela no sítio III, como Restinga. As amostras foram tomadas a um raio de $50 \mathrm{~cm}$ da base de três plantas de palmito juçara em cada sítio e em cada período de coleta. Foi escolhida essa espécie vegetal em função de sua importância comercial e por encontrar-se esta em perigo de extinção.

\subsection{1. Ácaros edáficos}

Os ácaros foram avaliados em amostras de folhedo e em amostras de solo retiradas a 0-5, 10-15, 20-25 e 30-35 cm de profundidade.

\subsubsection{Coleta de material em campo}

Cada amostra de folhedo ou solo correspondeu a um volume de $63,8 \mathrm{~cm}^{3}$. Em cada ponto de coleta, inicialmente coletou-se a amostra de folhedo com o auxilio de um cilindro do mesmo tipo descrito no capítulo anterior. Este foi pressionada sobre o folhedo, até se atingir a camada mineral do solo subjacente, retirando o material que 
excedia o volume do cilindro, em sua parte inferior. As amostras coletadas foram acondicionadas em potes plásticos de $250 \mathrm{ml}$ e transportadas ao laboratório, como detalhado no capítulo anterior. As amostras de solo também foram retiradas utilizandose o mesmo tipo de cilindro. Para isso, cavou-se inicialmente uma vala de $50 \mathrm{~cm}$ de comprimento, $30 \mathrm{~cm}$ de profundidade e $20 \mathrm{~cm}$ de largura à base de cada planta; as amostras foram tomadas em regiões diferentes, ao longo das bordas da vala, de forma independente. Para tanto, removeu-se inicialmente a camada de solo acima da profundidade desejada, inserindo-se então o cilindro metálico de coleta na superfície exposta. Nesse processo, todo o cuidado foi tomado para se evitar a contaminação de amostra tomada, com solo de outras partes do perfil. As amostras de solo coletadas foram acondicionadas e transportadas como citada para o folhedo.

\subsubsection{Extração e triagem}

Estes processos foram realizados através dos procedimentos citados no capítulo anterior, com algumas alterações.

As amostras permaneceram no coletor por no mínimo sete dias, para que fosse atingida a temperatura máxima desejada. No primeiro dia, as lâmpadas ficaram apagadas. A partir do segundo dia, a temperatura foi aumentada gradativamente, pela elevação da intensidade das luzes a cada dia, de forma a permitir um acréscimo diário de temperatura (cerca de $3^{\circ} \mathrm{C}$ ), até atingir $50^{\circ} \mathrm{C}$.

\subsubsection{Identificação dos ácaros}

Foram adotados os mesmos procedimentos do capítulo anterior. Consideraram-se neste estudo todas as ordens de ácaros encontradas, embora o nível da identificação tenha variado de acordo com o grupo a que cada ácaro pertencia. Os ácaros Oribatida foram identificados apenas até o nível de ordem. Os Prostigmata e Astigmata foram identificados até o nível de gênero. Os Mesostigmata foram identificados até o nível de morfoespécie, dentro de cada gênero. 


\subsubsection{Nematóides}

Os nematóides foram avaliados apenas nas amostras de solo.

\subsubsection{Coleta de material em campo}

O procedimento utilizado na coleta das amostras para extração de nematóides foi semelhante ao adotado para os ácaros, no que se refere às profundidades e localização de cada amostra. As amostras para a extração de nematóides foram tomadas ao lado das regiões de onde foram tomadas as amostras para a extração dos ácaros. Entretanto, neste caso, cada amostra foi retirada com o auxílio de uma enxada, e correspondera a um volume de um litro de solo a cada profundidade. Cada amostra foi acondicionada em um saco plástico devidamente etiquetado. Posteriormente, foram colocadas em caixa de isopor resfriada por bolsas térmicas (à base de celulose vegetal) (Gelo- $\mathrm{x}{ }^{\circledR}$ ) previamente congeladas, para transporte ao laboratório (Oliveira, 1999), mantendo-se a temperatura no interior da caixa entre 12 e $21^{\circ} \mathrm{C}$.

\subsubsection{Extração dos nematóides}

A extração foi realizada pelo método do peneiramento e flutuação em centrífuga (Jenkins, 1964) também chamado "Método de Jenkins".

Em laboratório, subamostras de $200 \mathrm{ml}$ de solo foram tomadas de cada amostra coletada. Cada subamostra foi transferida para um balde (A) com capacidade para 10 litros, acrescentando-se água de torneira até a marca de 4 litros, agitando-se bem a mistura. A suspensão foi filtrada através de uma peneira de 20 Mesh, recolhendo-se o filtrado em outro balde (B). O material contido no balde (B) foi agitado, deixando-se em seguida em repouso por 30 segundos para ser o sobrenadante novamente filtrado através de uma peneira de 400 Mesh. O material retido nesta peneira foi transferido para um tubo de ensaio e centrifugado a $1800 \mathrm{rpm}$ durante cinco minutos. O sobrenadante no

tubo foi descartado. Juntou-se então ao material decantado no tubo uma solução de 
sacarose (400 ml de açúcar/750 ml de água) até atingir um volume aproximado de 100 ml. Em seguida, todo o conteúdo daquele tubo foi misturado vigorosamente e centrifugado a $1800 \mathrm{rpm}$ durante um minuto. Após este procedimento, o sobrenadante no tubo foi filtrado através de uma peneira de 500 Mesh, lavando-se em seguida com água destilada o material retido na peneira e transferindo-o para um frasco de vidro.

Para a morte e fixação dos nematóides, o material do processo foi aquecido em banho-maria até atingir $55 \mathrm{C}^{\circ}$. Em seguida, adicionou-se $1 \mathrm{ml}$ de formol (solução formalina a $40 \%$ ) a este material.

\subsubsection{Identificação e quantificação dos nematóides}

Foram considerados neste estudo todos os gêneros de fitonematóides encontrados. Entretanto, os demais nematóides (bacteriófagos e de vida livre) não foram avaliados.

O processo de identificação e contagem dos nematóides foi realizado com o auxílio do pessoal técnico do Laboratório de Nematologia do Departamento de Entomologia, Fitopatologia e Zoologia Agrícola da ESALQ-USP. O volume de cada amostra contendo nematóides foi reduzido para $10 \mathrm{ml}$ através de um sifão de cobre. Desse volume, tomou-se uma alíquota de $1 \mathrm{ml}$ para a quantificação. $\mathrm{O}$ volume tomado foi transferido para uma lâmina de contagem de 'Peters' e com o auxílio de e um microscópio óptico foi realizada a contagem dos nematóides. Após a contagem dos nematóides, o número de indivíduos encontrados em $1 \mathrm{ml}$ foi multiplicado pelo volume inicial de cada amostra $(10 \mathrm{ml})$ obtendo-se com isto o número total estimado de nematóides. Após a contagem, foram realizadas montagens de lâminas (uma lâmina para cada amostra de solo processada). Em cada lâmina foram colocados vários nematóides, sendo, um indivíduo de cada tipo, para que fossem identificados ao nível de gênero, separando os fitoparasitos dos de vida livre. Para a identificação dos gêneros de fitonematóides foram usadas chaves apropriadas (Mai \& Lyon, 1975; Monteiro e Ferraz, 1990). Posteriormente, foram montadas outras lâminas com vários exemplares de cada gênero de fitonematóide. Estas lâminas foram analisadas para confirmação dos táxons 
identificados anteriormente e daqueles que não foram identificados inicialmente, por possuírem apenas, um indivíduo de cada gênero por lâmina.

\subsection{Resultados}

Encontrou-se neste estudo um total de 2717 ácaros (adultos e imaturos) e uma estimativa de 37740 fitonematoides (adultos e imaturos).

\subsubsection{Proporções de ácaros coletados em diferentes camadas do substrato e diferentes estações}

As maiores proporções de ácaros foram obtidas no folhedo, em todos os sítios e épocas de coleta (Tabela 5). Nesse substrato, a variação das proporções entre as épocas de coleta e entre os sítios foi relativamente pequena (65 a 89\%).

$\mathrm{O}$ número de ácaros no solo reduziu progressivamente à medida que as amostras foram tomadas em camadas mais profundas. As proporções de ácaros obtidas na camada de $0-5 \mathrm{~cm}$ foram quase sempre superiores a $9 \%$, atingindo até mais de $33 \%$. As únicas exceções referiram-se às coletas realizadas nos sítios II e III, no outono, quando as proporções de ácaros nesta camada corresponderam à cerca de 5 e $6 \%$ respectivamente.

As proporções de ácaros nas camadas de 10-15, 20-25 e 30-35 cm foram quase sempre inferiores a 3,7; 2,3 e 2,0\%, respectivamente. As únicas exceções referiram-se as coletas realizadas em Cananéia (sítio III) no outono, quando as proporções dos ácaros corresponderam a cerca de 6,$4 ; 12,7$ e 4,5\% àquelas respectivas profundidade. 
Tabela 5. Proporções (\%) de ácaros edáficos coletados em diferentes épocas do ano, em folhedo e diferentes profundidades $(\mathrm{cm})$ do solo, em dois municípios da Mata Atlântica do Estado de São Paulo, 2001.

\begin{tabular}{|c|c|c|c|c|c|}
\hline Substratos & Outono & Inverno & $\begin{array}{l}\text { Primavera } \\
\text { (início) }\end{array}$ & $\begin{array}{l}\text { Primavera } \\
\text { (fim) }\end{array}$ & Total \\
\hline \multicolumn{6}{|c|}{ Pariquera-Açu - (Sítio I) } \\
\hline Folhedo & 80,7 & 77,3 & 85,2 & 64,5 & 76,5 \\
\hline \multicolumn{6}{|c|}{ Solo (profundidade) } \\
\hline$(0-5)$ & 15,1 & 18,6 & 14,4 & 33,4 & 20,9 \\
\hline$(10-15)$ & 0,0 & 3,7 & 3,4 & 2,1 & 1,5 \\
\hline$(20-25)$ & 2,3 & 0,0 & 0,0 & 0,0 & 0,5 \\
\hline$(30-35)$ & 1,9 & 0,4 & 0,4 & 0,0 & 0,6 \\
\hline \multicolumn{6}{|c|}{ Pariquera-Açu (Sítio II) } \\
\hline Folhedo & 88,3 & 88,7 & 85,4 & 86,7 & 87,7 \\
\hline \multicolumn{6}{|c|}{ Solo (profundidade) } \\
\hline$(0-5)$ & 4,9 & 9,2 & 11,2 & 11,9 & 9,2 \\
\hline$(10-15)$ & 3,7 & 1,8 & 1,7 & 1,4 & 2,1 \\
\hline$(20-25)$ & 1,8 & 0,0 & 0,0 & 0,0 & 0,4 \\
\hline$(30-35)$ & 1,2 & 0,0 & 1,7 & 0,0 & 0,6 \\
\hline \multicolumn{6}{|c|}{ Cananéia (Sítio III) } \\
\hline Folhedo & 70,0 & 88,7 & 80,8 & 77,6 & 82,8 \\
\hline \multicolumn{6}{|c|}{ Solo (profundidade) } \\
\hline$(0-5)$ & 6,4 & 11,1 & 15,8 & 21,5 & 13,0 \\
\hline$(10-15)$ & 6,4 & 0,0 & 3,4 & 0,9 & 1,8 \\
\hline$(20-25)$ & 12,7 & 0,0 & 0,0 & 0,0 & 1,7 \\
\hline$(30-35)$ & 4,5 & 0,2 & 0,0 & 0,0 & 0,7 \\
\hline
\end{tabular}

\subsubsection{Totais de ácaros em diferentes estações do ano}

Considerando-se o total geral de ácaros no folhedo, nos três sítios, a maior abundância foi verificada no inverno (Figura 4 A). Em Pariquera-Açu (sítio II) e em 
Cananéia (sítio III), o número de ácaros encontrado nessa estação foi sensivelmente maior do que nas demais estações.

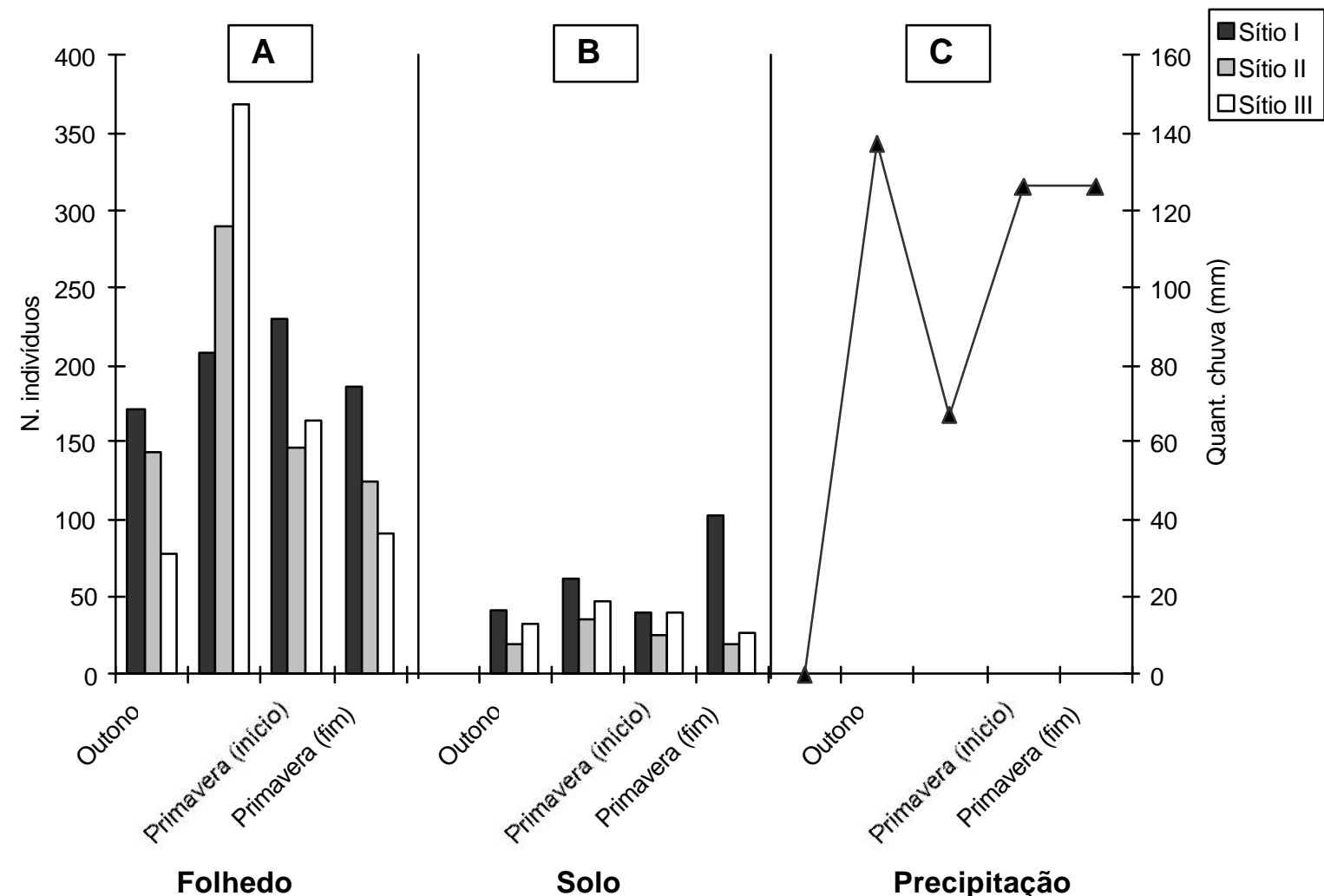

Figura 4 - Quantidade de ácaros obtidos no folhedo (A) e no solo (B), sob planta de Euterpe edulis Mart., em diferentes épocas do ano e em três sítios (PariqueraAçu, sítios I e II, e Cananéia, sítio III). Precipitação (C) ocorrida na região de Pariquera-Açu / Cananéia durante 30 dias que antecederam as coletas, 2001.

Semelhantemente ao que se observou no folhedo, também no solo o número de ácaros encontrados no inverno foi maior que no outono e início da primavera (Figura 4 B). Entretanto, neste caso, o número de ácaros encontrados no verão foi também relativamente alto, aproximando-se do número encontrado no inverno. No entanto devese ressaltar, que esta diferença se deve exclusivamente ao número relativamente alto de ácaros coletados no sítio I (Pariquera-Açu) nesta estação. 
$\mathrm{Na}$ figura $4 \mathrm{C}$, observa-se que o menor volume de precipitação ocorreu no inverno, que correspondeu aos maiores níveis de ácaros encontrados.

\subsubsection{Freqüência de ocorrência das ordens de ácaros}

Os Oribatida foram predominantes tanto no folhedo quanto no solo (Tabela 6). Cerca de $80 \%$ do total dos espécimes extraídos pertencem a esta ordem, nos dois substratos.

Tabela 6. Totais e proporções de ácaros edáficos por ordem, coletados em dois substratos, em ambiente de Mata Atlântica nos municípios de Pariquera-Açu (sítios I e II) e Cananéia (sítio III), Estado de São Paulo, 2001.

\begin{tabular}{|c|c|c|c|c|c|c|c|c|}
\hline \multirow[b]{2}{*}{ Ordens } & \multicolumn{2}{|c|}{ Sítio I } & \multicolumn{2}{|c|}{ Sítio II } & \multicolumn{2}{|c|}{ Sítio III } & \multicolumn{2}{|c|}{ Global } \\
\hline & Total & $\%$ & Total & $\%$ & Total & $\%$ & Total & $\%$ \\
\hline \multicolumn{9}{|c|}{ Folhedo } \\
\hline Oribatida & 661 & 83,2 & 561 & 78,5 & 559 & 79,3 & 1781 & 80,4 \\
\hline Mesostigmata & 128 & 16,1 & 150 & 21,0 & 141 & 20,0 & 419 & 18,9 \\
\hline Prostigmata & 5 & 0,6 & 4 & 0,6 & 4 & 0,6 & 13 & 0,6 \\
\hline Astigmata & 0 & 0 & 0 & 0 & 1 & 0,1 & 1 & 0,1 \\
\hline Total & 794 & 100 & 715 & 100 & 705 & 100 & 2214 & 100 \\
\hline \multicolumn{9}{|c|}{ Solo } \\
\hline Oribatida & 209 & 85,7 & 84 & 84,0 & 112 & 70,9 & 405 & 80,7 \\
\hline Mesostigmata & 34 & 13,9 & 13 & 13,0 & 39 & 24,7 & 86 & 17,1 \\
\hline Prostigmata & 1 & 0,4 & 2 & 2,0 & 4 & 2,5 & 7 & 1,4 \\
\hline Astigmata & 0 & 0 & 1 & 1,0 & 3 & 1,9 & 4 & 0,8 \\
\hline Total & 244 & 100 & 100 & 100 & 158 & 100 & 502 & 100 \\
\hline
\end{tabular}

Os Mesostigmata corresponderam à segunda ordem mais abundante em ambos os 
substratos, com uma proporção média de $18 \%$. No folhedo, os ácaros desta ordem foram encontrados em proporções similares nos três sítios, variando de 16 a 21\%. No solo, a maior proporção destes ácaros foi verificada em Cananéia (sítio III), correspondendo a quase $25 \%$. Os Prostigmata e Astigmata foram encontrados em pequenas proporções, tanto no folhedo quanto no solo. No folhedo, não houve variação das proporções de Prostigmata nos três sítios $(0,6 \%)$. Entretanto, no solo ocorreu uma variação entre 0,4 a 2,5\%, dos ácaros dessa ordem. No folhedo, apenas um espécime de Astigmata foi encontrado. No solo, quatro espécimes desta ordem foram encontrados, todos no sítio III (Cananéia).

\subsubsection{Diversidade de famílias de Mesostigmata, Prostigmata e Astigmata}

Ácaros pertencentes a 13 famílias foram encontradas no folhedo (Tabela 7).

A maior diversidade de famílias foi verificada na ordem Mesostigmata; sete das famílias encontradas pertencem a esta ordem. Em todos os sítios estudados, Ologamasidae, pertencente à ordem Mesostigmata, foi a família mais abundante, representando em média cerca de $63 \%$ dos ácaros encontrados. Uropodidae, pertencente à mesma ordem, foi a segunda família mais abundante, ultrapassando $25 \%$ dos ácaros encontrados. As demais famílias de Mesostigmata foram encontradas em pequenas proporções, variando de 1 a pouco mais de $2 \%$ do total de ácaros encontrados.

Prostigmata foi a segunda ordem com maior diversidade, cinco famílias foram encontradas. As famílias de Prostigmata mais abundantes, considerando as demais famílias da mesma ordem foram Labidostommatidae e Trombidiidae com 1,4\% do total de ácaros encontrados. 
Tabela 7. Totais e proporções de famílias de ácaros edáficos de três ordens, coletadas no folhedo em ambiente de Mata Atlântica nos municípios de Pariquera-Açu (sítios I e II) e Cananéia (sítio III) no Estado de São Paulo, 2001.

\begin{tabular}{|c|c|c|c|c|c|c|c|c|}
\hline Famílias & Sítio & $\%$ & Sítio & $\%$ & Sítio & $\%$ & Total & $\%$ \\
\hline \multicolumn{9}{|l|}{ Mesostigmata } \\
\hline Ologamasidae & 85 & 65,4 & 101 & 67,8 & 76 & 54,7 & 262 & 63,1 \\
\hline Uropodidae & 31 & 23,8 & 32 & 21,5 & 43 & 30,9 & 106 & 25,5 \\
\hline Laelapidae & 2 & 1,5 & 4 & 2,7 & 4 & 2,9 & 10 & 2,4 \\
\hline Ascidae & 1 & 0,8 & 2 & 1,3 & 5 & 3,6 & 8 & 1,9 \\
\hline Veigaiidae & 2 & 1,5 & 0 & 0,0 & 4 & 2,9 & 6 & 1,4 \\
\hline Polyaspididae & 2 & 1,5 & 1 & 0,7 & 1 & 0,7 & 4 & 1,0 \\
\hline Phytoseiidae & 0 & 0,0 & 3 & 2,0 & 0 & 0,0 & 3 & 0,7 \\
\hline
\end{tabular}

\section{Prostigmata}

$\begin{array}{lllllllll}\text { Labidostommatidae } & 4 & 3,1 & 0 & 0,0 & 2 & 1,4 & 6 & 1,4 \\ \text { Trombidiidae } & 2 & 1,5 & 2 & 1,3 & 2 & 1,4 & 6 & 1,4 \\ \text { Cunaxidae } & 1 & 0,8 & 0 & 0,0 & 0 & 0,0 & 1 & 0,2 \\ \text { Tarsonemidae } & 0 & 0,0 & 0 & 0,0 & 1 & 0,7 & 1 & 0,2 \\ \text { Pygmephoridae } & 0 & 0,0 & 0 & 0,0 & 1 & 0,7 & 1 & 0,2\end{array}$

Astigmata

$\begin{array}{llllllllll}\text { Acaridae } & \frac{0}{\mathbf{1 3 0}} & \frac{0,0}{\mathbf{1 0 0 , 0}} & \frac{1}{\mathbf{1 4 6}} & \frac{0,7}{\mathbf{1 0 0 , 0}} & \frac{0}{\mathbf{1 3 9}} & \frac{0,0}{\mathbf{1 0 0 , 0}} & \frac{1}{\mathbf{4 1 5}} & \frac{0,2}{\mathbf{1 0 0 , 0}}\end{array}$

A única família representante da ordem Astigmata foi Acaridae, com um único exemplar coletado no folhedo, em Pariquera-Açu.

No solo, também foram identificadas 13 famílias de ácaros (Tabela 8). 
Tabela 8. Totais e proporções de famílias de ácaros edáficos em três ordens, coletadas no solo em ambiente de Mata Atlântica nos municípios de Pariquera-Açu (sítios I e II) e Cananéia (sítio III) no Estado de São Paulo, 2001.

\begin{tabular}{|c|c|c|c|c|c|c|c|c|}
\hline Famílias & $\begin{array}{c}\text { Sítio } \\
\text { I }\end{array}$ & $\%$ & $\begin{array}{c}\text { Sítio } \\
\text { II }\end{array}$ & $\%$ & $\begin{array}{c}\text { Sítio } \\
\text { III }\end{array}$ & $\%$ & Total & $\%$ \\
\hline \multicolumn{9}{|l|}{ Mesostigmata } \\
\hline Ologamasidae & 28 & 77,5 & 10 & 52,6 & 14 & 41,2 & 52 & 58,4 \\
\hline Uropodidae & 4 & 11,1 & 1 & 5,3 & 6 & 17,6 & 11 & 12,4 \\
\hline Laelapidae & 0 & 0,0 & 2 & 10,5 & 3 & 8,8 & 5 & 5,6 \\
\hline Ascidae & 2 & 5,6 & 2 & 10,5 & 1 & 2,9 & 5 & 5,6 \\
\hline Veigaiidae & 0 & 0,0 & 1 & 5,3 & 0 & 0,0 & 1 & 1,1 \\
\hline Polyaspididae & 0 & 0,0 & 0 & 0,0 & 2 & 5,9 & 2 & 2,2 \\
\hline Phytoseiidae & 0 & 0,0 & 0 & 0,0 & 1 & 2,9 & 1 & 1,1 \\
\hline Rhodacaridae & 1 & 2,8 & 0 & 0,0 & 1 & 2,9 & 2 & 2,2 \\
\hline
\end{tabular}

\section{Prostigmata}

$\begin{array}{llllllll}0 & 0,0 & 1 & 5,3 & 0 & 0,0 & 1 & 1,1\end{array}$

Trombidiidae

$\begin{array}{llllllll}1 & 2,8 & 0 & 0,0 & 2 & 5,9 & 3 & 3,4\end{array}$

Cunaxidae

$0 \quad 0,0 \quad 0$

0,0

12,9

$1 \quad 1,1$

Stigmaeidae

$0 \quad 0,0$

$1 \quad 5,3$

$0 \quad 0,0$

$1 \quad 1,1$

Astigmata

\begin{tabular}{lllllllllll} 
Acaridae & $\frac{0}{\mathbf{3 6}}$ & $\frac{0,0}{\mathbf{1 0 0 , 0}}$ & $\frac{1}{\mathbf{1 9}}$ & $\frac{5,3}{\mathbf{1 0 0}}$ & $\frac{3}{\mathbf{3 4}}$ & $\frac{8,8}{\mathbf{1 0 0 , 0}}$ & $\frac{4}{\mathbf{8 9}}$ & $\frac{4,5}{\mathbf{1 0 0 , 0}}$ \\
\hline
\end{tabular}

A maior diversidade de famílias foi verificada também na ordem Mesostigmata; oito das famílias encontradas pertencem a esta ordem. Da mesma forma que no folhedo, em todos os sítios estudados, Ologamasidae foi à família mais abundante, representando em média cerca de $58 \%$ dos ácaros encontrados. Também Uropodidae foi a segunda família mais abundante, com uma proporção de $12 \%$ dos ácaros encontrados. As demais 
famílias foram encontradas em pequenas proporções, variando entre 1,1 e 5,6\% do total de espécimes encontrada.

Os Prostigmata no solo foram também os segundos mais abundantes. Trombidiidae foi a família de Prostigmata encontrada mais numerosa com 3,4\% do total de ácaros coletados, embora em termos absoluto apenas três indivíduos tenham sido encontrados. Apenas um exemplar foi encontrado das demais famílias dentro desta ordem.

Para Astigmata, foi identificada apenas a família Acaridae. Representaram 4,5\% do total de ácaros, embora em termos absoluto apenas quatro indivíduos tenham sido encontrados.

\subsubsection{Diversidade de gêneros e morfoespécies de Mesostigmata, Prostigmata e Astigmata}

A maior diversidade de gêneros foi verificada na família Ologamasidae (10 gêneros), seguida pelas famílias Acidae (4 gêneros), Rhodacaridae e Laelapidae (2 gêneros cada), e Uropodidae, Polyaspididae, Phytoseiidae e Veigaiidae (1 gênero cada) (Tabela 9).

A maior diversidade de morfoespécies (26) foi verificada na família Ologamasidae (26 morfoespécies). Nesta família, oito morfoespécies pertencentes ao gênero Neogamasellevans e igual número pertencente ao gênero Ologamasus foram encontrados. Ascidae foi a segunda família com maior diversidade de morfoespécies, tendo-se encontrado quatro gêneros. Todas as outras famílias foram representadas por apenas um a dois gêneros com uma morfoespécies cada.

No folhedo foi encontrada uma maior diversidade de gêneros (19) e morfoespécies (35), que no solo (14 e 19, respectivamente). 
Tabela 9. Totais de ácaros Mesostigmata de cada morfoespécie coletados em folhedo e solo, em ambiente de Mata Atlântica no Estado de São Paulo, 2001.

\begin{tabular}{|c|c|c|}
\hline Morfoespécies & Folhedo & Solo \\
\hline \multicolumn{3}{|l|}{ Ologamasidae } \\
\hline Neogamasellevans sp.1 & 11 & 7 \\
\hline Neogamasellevans sp.2 & 1 & 0 \\
\hline Neogamasellevans sp.3 & 17 & 1 \\
\hline Neogamasellevans sp.4 & 9 & 2 \\
\hline Neogamasellevans sp.5 & 3 & 0 \\
\hline Neogamasellevans sp.6 & 1 & 3 \\
\hline Neogamasellevans sp.7 & 0 & 1 \\
\hline Neogamasellevans sp.8 & 1 & 0 \\
\hline Ologamasus sp.1 & 6 & 0 \\
\hline Ologamasus sp.2 & 5 & 0 \\
\hline Ologamasus sp.3 & 10 & 0 \\
\hline Ologamasus sp.4 & 21 & 2 \\
\hline Ologamasus sp.5 & 14 & 2 \\
\hline Ologamasus sp.6 & 5 & 0 \\
\hline Ologamasus sp.7 & 2 & 0 \\
\hline Ologamasus sp.8 & 4 & 0 \\
\hline Gamasiphoides sp.1 & 2 & 0 \\
\hline Gamasiphoides sp.2 & 2 & 0 \\
\hline Gamasiphoides sp.3 & 5 & 1 \\
\hline Evansellus sp. & 5 & 3 \\
\hline Geogamasus sp. & 15 & 0 \\
\hline Hidrogamasellus sp. & 3 & 0 \\
\hline Gênero 1 & 14 & 6 \\
\hline Gênero 2 & 1 & 2 \\
\hline Gênero 3 & 5 & 0 \\
\hline Gênero 4 & 1 & 0 \\
\hline \multicolumn{3}{|l|}{ Rhodacaridae } \\
\hline Rhodacarus sp. & 0 & 1 \\
\hline Rhodacarellus sp. & 0 & 1 \\
\hline \multicolumn{3}{|l|}{ Uropodidae } \\
\hline Eutrachytes sp. & 30 & 0 \\
\hline \multicolumn{3}{|l|}{ Polyaspididae } \\
\hline Trachytes sp. & 5 & 0 \\
\hline \multicolumn{3}{|l|}{ Phytoseiidae } \\
\hline Typhlodromus sp. & 3 & 1 \\
\hline \multicolumn{3}{|l|}{ Veigaiidae } \\
\hline Veigaia sp. & 8 & 1 \\
\hline \multicolumn{3}{|l|}{ Ascidae } \\
\hline Blattisocius sp. & 0 & 3 \\
\hline Cheiroseius sp. & 4 & 3 \\
\hline Asca sp. & 1 & 0 \\
\hline Lasioseius sp. & 3 & 0 \\
\hline \multicolumn{3}{|l|}{ Laelapidae } \\
\hline Cosmolaelaps sp. & 7 & 2 \\
\hline Pneumolaelaps sp. & 1 & 1 \\
\hline
\end{tabular}


Tabela 10. Totais de ácaros Prostigmata e Astigmata de cada morfoespécie, coletados em dois substratos em ambiente de Mata Atlântica no Estado de São Paulo, 2001.

\begin{tabular}{|c|c|c|}
\hline Morfoespécies & Folhedo & Solo \\
\hline & \multicolumn{2}{|c|}{ PROSTIGMATA } \\
\hline \multicolumn{3}{|l|}{ Labidostommatidae } \\
\hline Labdostomma sp. & 6 & 1 \\
\hline \multicolumn{3}{|l|}{ Trombididae } \\
\hline Microtrombidium sp. 1 & 1 & 0 \\
\hline Microtrombidium sp. 2 & 4 & 1 \\
\hline Microtrombidium sp. 3 & 1 & 0 \\
\hline Microtrombidium sp. 4 & 0 & 2 \\
\hline \multicolumn{3}{|l|}{ Cunaxidae } \\
\hline Scutaceus sp. & 0 & 1 \\
\hline Neocunaxoides sp. & 1 & 0 \\
\hline \multicolumn{3}{|l|}{ Pygmephoridae } \\
\hline Pygmephoroidea sp. & 0 & 1 \\
\hline \multicolumn{3}{|l|}{ Stigmaidae } \\
\hline Eustigmeus sp. & 0 & 1 \\
\hline \multicolumn{3}{|l|}{ Tarsonemidae } \\
\hline \multirow[t]{2}{*}{ Tarsonemus sp. } & 0 & 1 \\
\hline & \multicolumn{2}{|c|}{ ASTIGMATA } \\
\hline \multicolumn{3}{|l|}{ Acaridae } \\
\hline Rhizoglyphus sp. & 1 & 4 \\
\hline
\end{tabular}

\subsubsection{Nematóides fitófagos coletados a diferentes profundidades no solo}

Foram encontrados 16 gêneros de fitonematóides nos três sítios de coletas (Tabela 12). Destes fitonematoides, 14 apresentaram estilete do tipo estomatostíleo. Estes são 
Tabela 12. Números estimados de nematóides fitófagos em $200 \mathrm{ml}$ de solo a diferentes profundidades, nos municípios de Pariquera-Açu e Cananéia, na Mata Atlântica no Estado de São Paulo, 2001.

Profundidades (cm)

\begin{tabular}{|c|c|c|c|c|}
\hline Gêneros & $0-5$ & $10-15$ & $20-25$ & $30-35$ \\
\hline & \multicolumn{4}{|c|}{ Pariquera-Açu (Sítio I) } \\
\hline Helicotylenchus & 7340 & 300 & 570 & 870 \\
\hline Discocriconemella & 0 & 40 & 750 & 240 \\
\hline Criconemella & 760 & 0 & 0 & 0 \\
\hline Hemicycliophora & 0 & 380 & 70 & 0 \\
\hline Trophurus & 0 & 0 & 0 & 470 \\
\hline Aorolaimus & 10 & 200 & 100 & 0 \\
\hline Paratylenchus & 40 & 30 & 30 & 60 \\
\hline Xiphinema & 40 & 30 & 60 & 20 \\
\hline Hemicriconemoides & 0 & 30 & 40 & 0 \\
\hline Paratrichodorus & 0 & 0 & 20 & 0 \\
\hline Gênero 2 & 360 & 10 & 40 & 0 \\
\hline Gênero 3 & 0 & 0 & 0 & 180 \\
\hline Ecphyadophora & 0 & 0 & 0 & 10 \\
\hline \multirow[t]{2}{*}{ Total } & 8550 & 1020 & 1680 & 1850 \\
\hline & \multicolumn{4}{|c|}{ Pariquera-Açu (Sítio II) } \\
\hline Helicotylenchus & 1120 & 2240 & 2310 & 1510 \\
\hline Discocriconemella & 80 & 1390 & 1390 & 50 \\
\hline Criconemella & 30 & 40 & 440 & 320 \\
\hline Hemicycliophora & 380 & 10 & 40 & 20 \\
\hline Trophurus & 240 & 260 & 50 & 390 \\
\hline Aorolaimus & 10 & 70 & 60 & 60 \\
\hline Paratylenchus & 30 & 220 & 160 & 60 \\
\hline Xiphinema & 70 & 80 & 0 & 10 \\
\hline Hemicriconemoides & 20 & 10 & 0 & 10 \\
\hline Paratrichodorus & 10 & 20 & 10 & 20 \\
\hline Pratylenchus & 30 & 60 & 0 & 20 \\
\hline Gênero 1 & 0 & 190 & 80 & 40 \\
\hline Gênero 2 & 200 & 350 & 20 & 90 \\
\hline Gênero 3 & 30 & 30 & 490 & 50 \\
\hline Total & 2250 & 4970 & 5050 & 2650 \\
\hline
\end{tabular}


Tabela 12. (Continuação) Números estimados de nematóides fitófagos em $200 \mathrm{ml}$ de solo a diferentes profundidades, nos municípios de Pariquera-Açu e Cananéia, na Mata Atlântica no Estado de São Paulo, 2001.

\section{Profundidades (cm)}

\begin{tabular}{lrrrr} 
Gêneros & $\mathbf{0 - 5}$ & $\mathbf{1 0 - 1 5}$ & $\mathbf{2 0} \mathbf{- 2 5}$ & $\mathbf{3 0} \mathbf{- 3 5}$ \\
\hline & \multicolumn{3}{c}{ Cananéia (Sítio III) } \\
Helicotylenchus & 390 & 20 & 40 & \\
Discocriconemella & 0 & 0 & 240 & 250 \\
Criconemella & 50 & 50 & 10 & 680 \\
Hemicycliophora & 200 & 310 & 330 & 0 \\
Trophurus & 10 & 0 & 0 & 120 \\
Aorolaimus & 920 & 1640 & 820 & 30 \\
Paratylenchus & 30 & 80 & 40 & 1600 \\
Xiphinema & 40 & 50 & 20 & 20 \\
Hemicriconemoides & 10 & 0 & 0 & 0 \\
Gênero 1 & 780 & 220 & 310 & 0 \\
Gênero 2 & 40 & 20 & 0 & 10 \\
Gênero 3 & 60 & 40 & 30 & 10 \\
Ecphyadophora & 40 & 50 & 30 & 30 \\
Dolichodorus & 0 & 10 & 0 & 10 \\
Total & $\mathbf{2 5 7 0}$ & $\mathbf{2 4 9 0}$ & $\mathbf{1 8 7 0}$ & $\mathbf{2 7 9 0}$ \\
\hline
\end{tabular}

Helicotylenchus Steiner, Discocriconemella Grisse \& Loof, Criconemella Taylor, Hemicycliophora de Man, Trophurus Loof, Aorolaimus Sher, Paratylenchus Micodetzky, Hemicriconemoides Chitwood \& Birchfild, Dolichodorus Andrassye, Pratylenchus Filipjev, Ecphyadophora de Man e também três gêneros de fitonematóides encontrados que devido a ausência de adultos para a identificação foram designados como Gênero 1, Gênero 2 e Gênero 3.três . Outros dois gêneros (Xiphinema Coob e Paratrichodorus Coob,) apresentam estilete do tipo odontostílio.

No sítio I (Pariquera-Açu), 13 gêneros de fitonematóides foram encontrados, em números variando de 10 a 7340 indivíduos. O gênero mais abundante foi Helicotylenchus (300 a 7340 indivíduos), seguido de Discocriconemella (variou entre 0 a 750 indivíduos). No sítio II (Pariquera-Açu), 14 gêneros de fitonematóides foram encontrados, houve uma variação no número de indivíduos entre 10 a 2310 indivíduos. O gênero mais abundante 
foi também Helicotylenchus (1120 a 2310 indivíduos), seguido de Discocriconemella (50 a 1390 indivíduos). No sítio III (Cananéia), 14 gêneros de fitonematóides foram encontrados, em números de 10 a 1640 indivíduos. $O$ gênero mais abundante foi Aorolaemus (820 a 1640 indivíduos), seguido do Gênero 1 (10 a 780 indivíduos).

A distribuição dos gêneros de nematóides no perfil do solo se deu de forma variada dentro de cada sítio. A quantidade extremamente alta de fitonematóides no sítio I (Pariquera-Açu) na camada de $0-5 \mathrm{~cm}$ de profundidade se refere ao gênero Helicotylenchus que apresentou 7340 indivíduos. No sítio III (Cananéia) este mesmo gênero apareceu em pequenas quantidades (390 indivíduos). No sítio II (Pariquera-Açu) a distribuição dos fitonematóides ao longo do perfil foi a mais uniforme em relação aos outros sítios de coleta, ressalta-se o gênero Discocriconemella que foi encontrado em maior quantidade nas camadas de $10-15$ e $20-25 \mathrm{~cm}$ de profundidade.

\subsection{Discussão}

Três das sete ordens conhecidas de ácaros não foram encontradas neste estudo: Notostigmata, Holothyrida e Ixodida. As duas primeiras são ácaros muito raros, existindo poucas espécies no mundo. A terceira corresponde a parasitos de animais, que embora ocorra no solo em parte de seu ciclo, são mais numerosos em regiões com grande concentração de animais ou em abrigos de animais (ninhos e tocas), o que não foi o caso em relação aos locais de coleta no presente estudo.

\subsection{1 Ácaros edáficos}

Alguns estudos têm demonstrado que em ambientes naturais as maiores proporções de ácaros são encontradas no folhedo e na camada superficial do solo (Wallwork, 1959; Berg \& Ryke, 1967; Price, 1972; Plowman, 1981; Franklin et al., 1997; Mineiro \& Moraes, 2001). O fato de se encontrar maiores proporções de espécimes no folhedo, está relacionado com o hábito alimentar dos grupos de ácaros encontrados, que em sua grande maioria alimentam-se de matéria orgânica ou de microorganismos que sobre esta se desenvolve. Estes ácaros correspondem 
principalmente aos Oribatida, certos Prostigmata, Mesostigmata e Astigmata (Wallwork et al., 1985).

Associados aos organismos que vivem da matéria orgânica ou dos microorganismos no solo estão os ácaros predadores que sobrevivem destes organismos. Em sua maioria, estes ácaros são Mesostigmata e alguns Prostigmata. Muitos destes predadores podem se alimentar também de outros organismos, como os nematóides que se distribui por todo o perfil do solo, como encontrado neste estudo.

Com a maior concentração de material em decomposição nas camadas superficiais do solo, aumenta-se à gama de alimento nessas camadas, propiciando melhores condições para a elevação das populações de ácaros que ali vivem. Quanto mais profunda for a camada de solo menor teor de matéria orgânica é encontrado. Isto resulta em uma menor quantidade de alimento para muitos grupos de ácaros, diminuindo assim seu número nas camadas mais profundas.

É importante ressaltar, entretanto, que certos grupos de nematóides se concentram em camadas mais profundas do solo (Weischer \& Brown, 2001). É por esta razão que se recomenda na agricultura, para fins de controle, que os nematóides sejam avaliados da superfície até 25 e $30 \mathrm{~cm}$ de profundidade (Tihohod, 1993). Associados a estes nematóides poderia se esperar a ocorrência de ácaros que deles pudessem se alimentar, como é o caso de alguns ácaros da superfamília Rhodacaroidea, família Laelapidae, Macrochelidae e Ascidae (Ito, 1970; Inserra \& Davis, 1983; Walter, 1988; Epsky et al., 1988; Walter \& Ikonen, 1989; Crossley Jr. et al. 1992).

O elevado número de espécimes de ácaros encontrado no inverno foi provavelmente pelo menos em parte determinado pela reduzida precipitação ocorrida no período de um mês, imediatamente antes das coletas. Resultados parecidos foram encontrados por Dantas (1979), estudando a ecologia e fauna do solo em pastagens da Amazônia. Naquele estudo, o maior número de indivíduos foi encontrado nos meses de menor precipitação. Mineiro \& Moraes (2001), estudando a diversidade de ácaros edáficos no município de Piracicaba, também observaram as maiores quantidades de espécimes nos períodos de menor precipitação. Aparentemente, o fator mais estressante sobre os ácaros edáficos na região em que o presente estudo foi conduzido é a 
quantidade de chuva na época úmida e não a falta de chuva na época seca. Entretanto, Lee (1973) observou em seu trabalho sobre os Rhodacaridae próximos a cidade de Adelaide na Austrália, que houve queda no número de Rhodacaridae nas amostras coletadas no verão, quando ocorreram os menores índices de precipitação.

O grande número de ácaros da ordem Oribatida no folhedo e no solo era esperado, pois estes representam a maior parte da acarofauna nas camadas superficiais do solo em ambientes naturais (Van Den Berg \& Ryke, 1976; Wallwork, 1970; Price, 1973; Petersen \& Luxton, 1982; Crossley Jr. et al., 1992; Tousignant \& Coderre, 1992; Oliveira \& Franklin, 1993; Coleman \& Crossley Jr., 1996; Tracba et al., 1997; Mineiro \& Moraes, 2001). Os Oribatida são ácaros bastantes esclerotizados, a maioria desses alimenta-se de matéria orgânica, agindo como agentes decompositores no ambiente (Krantz, 1990). Em função da grande quantidade de folhedo presente no ecossistema estudado, nota-se que houve uma maior concentração desses indivíduos neste substrato.

A grande predominância dos Oribatida neste estudo está também de acordo com os resultados de Franklin et al. (1997) estudando populações deste ácaro em áreas de várzea e igapó na Amazônia Central, em liteira e solo $(0-3,5 \mathrm{~cm}$ de profundidade). Aqueles autores verificaram que os Oribatidas corresponderam a 67\% e $85 \%$ dos ácaros coletados naquele respectivo substrato.

Também, Mineiro \& Moraes (2001) obtiveram em seu estudo sobre a ácarofauna edáfica, em solo e folhedo de um remanescente florestal de Piracicaba, Estado de São Paulo, alta proporção de Oribatida (aproximadamente 53 e 48\%, respectivamente).

No presente estudo, os Mesostigmata apareceram como a segunda ordem mais abundante. Resultados semelhantes a este foram obtidos por Mineiro \& Moraes (2001). Naquele trabalho, 31\% dos ácaros encontrados foram Mesostigmata. Tracba et al. (1997), estudando a fauna edáfica em floresta inundada da Reserva da Biosfera de Sian Ra'na em Cuba, também encontraram uma grande proporção de Mesostigmata. A maior parte das espécies dessa ordem apresenta hábito predador. Normalmente esses ácaros são encontrados em maior número no folhedo e na camada superficial do solo (Krantz, 1978; Walter, 1988; Dindal, 1990; Crossley Jr. et al., 1992). 
Os ácaros Prostigmata e Astigmata foram raros nesse estudo. Os indivíduos destas ordens normalmente possuem algumas características particulares como baixo nível de esclerotização (Krantz, 1978). Trabalhos realizados por vários autores (Van Den Berg \& Ryke, 1976; Wallwork, 1970; Price, 1973; Petersen \& Luxton, 1982; Crossley Jr. et al., 1992; Coleman \& Crossley Jr., 1996 e Mineiro \& Moraes, 2001) mostraram que estas duas ordens representam a menor parcela da acarofauna edáfica em ambientes naturais.

Os Astigmata são encontrados abundantemente como parasitos de animais, em depósito de alimentos e poeira domiciliar (Krantz, 1978). No solo, esses ácaros são importantes em certos ambientes agrícola, especialmente em culturas que produzem bulbos ou raízes tuberosas. A ausência de plantas com esta característica no local de onde as amostras para esse estudo foram tomadas devem justificar a pequena quantidade com que foram encontrados.

No presente estudo, Ologamasidae (Mesostigmata) foi à família de ácaros mais comum. Os resultados obtidos nesse estudo se assemelham aos obtido por Van Den Berg \& Ryke (1976) e Mineiro \& Moraes (2001), nos quais os Ologamasidae também foram os mais abundantes nos dois substratos estudados. Apesar destes ácaros serem tão abundantes, os trabalhos sobre sua biologia são muito raros. El-Banhawy et al. (1999) estudaram o desenvolvimento do ácaro predador Gamasiphis tylophagous El-Borolossy \& El-Banhawy (Ologamasidae) alimentado com uma espécie de nematóide praga de citrus (Tylenchulus semipenetrans Cobb.) com o ácaro Rhizoglyphus robini Claparède. Os autores verificaram que a duração do estágio adulto e a reprodução de $G$. tylophagous foram afetados pelo tipo de alimento.

A grande diversidade de gêneros de Ologamasidae identificados nesse estudo indica a importância desses ácaros, talvez como agentes controladores de populações de organismos edáficos. A maior diversidade dos gêneros Neogamasellevans, Ologamasus e Gamasiphoides em morfoespécies pode estar relacionada com a diversidade de outros organismos (colêmbolas, nematóides e outros artrópodes) presentes no ambiente onde estes ácaros foram encontrados e o hábito alimentar predador desse grupo. Esses mesmos gêneros foram encontrados em abundância por Mineiro \& Moraes (2001), na 
região de Piracicaba. Em regiões de clima temperado, os gêneros de ácaros encontrados em maior abundância pertencem à família Rhodacaridae (Price, 1973; Evans e Till, 1979; Coleman \& Crossley Jr., 1996). No entanto, apenas dois espécimes, pertencentes a gêneros diferentes de Rhodacaridae foram encontrados nesse estudo. Os espécimes de ácaros dessa família também foram raramente encontrados por Mineiro \& Moraes (2001), em Piracicaba - SP.

É possível que a metodologia empregada para extração dos ácaros nesse estudo (Berlese-Tullgren, modificado por Oliveira et al. 2000) não permitiu a extração de certos grupos de ácaros existentes nas regiões estudadas. Em uma avaliação feita por A. R. Oliveira \& R. A. Norton (não publicado), foram encontrados diversos exemplares de uma espécie de Nematalycidae, utilizando-se o método da flotação em áreas próximas ao sítio III (Cananéia) deste estudo. Estes ácaros são alongados e os representantes da família, são comumente encontrados em profundidades no solo maiores que $50 \mathrm{~cm}$ (Krantz, 1978). Nas amostras coletadas no presente estudo, nenhum exemplar de ácaros dessa família foi encontrado. Sabe-se que o método de Berlese-Tullgren modificado não tem uma eficiência de $100 \%$ na extração (Edwards \& Fletcher, 1971). Entretanto, este é o método mais utilizado no mundo para este tipo de estudo, por ser simples e porque através dele se consegue extrai a maioria da acarofauna sem causar nenhum dano às estruturas dos ácaros.

\subsubsection{Fitonematóide}

Dos 16 gêneros de fitonematóide encontrados neste estudo, quatro (Helicotylenchus, Aorolaimus, Criconemella e Pratylenchus), são pragas agrícola que causam grandes prejuízos econômicos para os agricultores, principalmente Pratylenchus (Weischer \& Brown, 2001). Todos os gêneros de nematóides encontrados e considerados como fitoparasitos estritos, com exceção de Pratylenchus (endoparasito migrador), compartilham o hábito de ectoparasito migrador. Segundo Weischer \& Brown (2001), os fitonematóides com este hábito alimentar causam menos danos do que fitonematóide endoparasitos, pois, o ataque daqueles fitonematóides às plantas é 
limitado às camadas celulares mais superficiais das raízes e também por produzirem secreções esofagianas cujos efeitos daninhos são, aparentemente, menos pronunciados. Entretanto, constituem exceções, os nematóides ectoparasitos portadores de estiletes muito longos, como os Xiphinema Coob, Paratrichodorus Coob e Dolichodorus Andrassye. Estes gêneros de fitonematóides são considerados os únicos com potencial para causar danos às plantas. Este, entretanto, ocorreram em baixos níveis populacionais. Ressalta-se, porém, que o método de extração utilizado no presente estudo não é indicado para Xiphinema. Um dos gêneros encontrados neste estudo, Dolichodorus, é de ocorrência muito rara no país, ocorrendo apenas em solos encharcados. Este é o caso do solo no sítio III, único local onde este nematóide foi encontrado.

Os nematóides considerados Gênero 2, assemelha-se com juvenis da família Heteroderidae, um grupo de nematóide sedentário, capaz de trazer sérias complicações a algumas plantas cultivadas.

Nos sítios de Pariquera-Açu foi observado um grande predomínio de Helicotylenchus e em Cananéia, de Aorolaimus. Este predomínio pode estar relacionado à existência de algum fator abiótico e/ou biótico, como a quantidade de matéria orgânica e o tipo de solo, favorecendo a um ou a outro gênero em cada localidade.

Dentre os gêneros de fitonematóides mais abundantes, foi identificada a espécie de fitonematóide H. erythrinae Steiner, pertencente aos Helicotylenchus. Esta espécie esteve presente nos três sítios estudados. Entretanto, não foi possível identificar a espécie de Aorolaimus, que provavelmente foi àmesma nos três sítios.

Nos ambientes naturais estudados, aparentemente, não foi observado sintoma de dano, causado nas plantas, por fitonematóides. No entanto, se estas áreas forem desmatadas para a implantação de plantios comerciais, alguns dos nematóides coletados podem aumentar sua população e passar à condição de praga das plantas então cultivadas. 


\subsubsection{Associação de ácaros e fitonematóide}

Os fitonematóides foram encontrados em grandes números no perfil do solo, até a profundidade máxima em que as avaliações neste estudo foram realizadas $(30-35 \mathrm{~cm})$. Os ácaros, por outro lado, apresentaram uma concentração muito grande de indivíduos na camada superior $(0-5 \mathrm{~cm})$. Assim, é de se esperar que os ácaros que por ventura estejam predando aqueles nematóides possam apresentar alguma eficiência apenas na camada mais superficial do solo.

Alguns ácaros que vivem no solo, a exemplo de Mesostigma, algumas famílias de Prostigmata e também de Oribatida, são predadores de vários outros organismos edáficos, e normalmente são predominantes naquele substrato (Walter \& Proctor, 1998). Estes ácaros, em ambientes naturais, provavelmente, contribuem para que haja um equilíbrio na população de pragas no solo como fitonematóides.

Estudos de preferência alimentar, capacidade de predação e biologia com aquelas ordens de ácaros quando alimentados de nematóides, vem sendo desenvolvidos. Ito (1970), estudando preferência alimentar e capacidade de predação, testou quatro espécies de ácaros Mesostigmata (Macrocheles muscadomesticas (Scopoli), Parasitus sp., Fuscuropoda sp. e Glyptholaspis confusa (Foa)) em cinco espécies de nematóides de vida livre (Rhabditis elongata (Schneider), R. teres (Schneider), Panagrellus redivivus (Linaeu), Aphelenchus avenae Bastian e Aphelenchoides composticora Franklin). O autor concluiu que as três primeiras espécies de ácaros se alimentaram de todas as espécies de nematóides. Entretanto, G. confusa predou apenas $R$. elongata e $P$. redivivus em pequenas proporções. Walter (1987) estudou o comportamento de Gamasellodes vermivorax Walter (Ascidae), alimentado com nematóides, observou que estes ácaros levaram 10 dias para chegar a adultos, a taxa de oviposição e a longevidade de cada fase não foram afetadas. Imbriani e Mankau (1983) estudaram o ciclo de vida e os hábitos alimentares de Lasioseius scapulatus (Ascidae), testando nematóides como fonte de alimento, estes autores concluíram que houve uma drástica redução na população de nematóides, oferecida como alimento àqueles ácaros, no entanto, a reprodução daqueles ácaros foi afetada, ocorrendo redução de progeni, apesar disto, concluíram que tal 
espécie de ácaro possui potencial para ser utilizado no controle biológico de fitonematóides. Epsky et al., (1988) estudaram a relação entre ácaros nematófagos e nematóides entomopatogênicos. A. R. Oliveira, 2002 (comunicação pessoal) testou ácaros Pergalumna sp. (Oribatida) utilizando com fonte de alimento fitonematóides (Pratylenchus coffeae (Zimmermann) e Meloidogyne javanica) e observou que aqueles ácaros quando alimentados com $P$. coffeae consumiram em média 42 fitonematóide por dia, e quando alimentados com $M$. javanica consumiram 18 fitonematóides por dia, foi observado também que o ciclo de vida destes ácaros não foi afetado. Walter \& Ikonen (1989), apresentaram estudos detalhados sobre fatores como alimentação, fases de desenvolvimento e potencial reprodutivo, que influenciam a habilidade que ácaros mesostigmata tem de regular as populações de nematóides. Embora estes autores tenham considerado estes ácaros como importantes predadores de nematóides de vida livre em campo, em condições de laboratório estas informações não foram confirmadas. Neste mesmo trabalho, foi verificado que o menor ácaro testado, Protogamasellus mica, consumiu cerca de $1.09 \mu \mathrm{g}$ de fitonematóide/ $\mu \mathrm{g}$ de peso corporal do ácaro/dia, que é uma quantidade muito maior que a consumida por ácaros maiores, como por exemplo, Lasioseius sp., que consumiu 0.218. $\mu \mathrm{g}$ de fitonematóide/ $\mu \mathrm{g}$ de peso corporal do ácaro/dia.

Todos estes trabalhos comprovam que existem muitas espécies de ácaros edáficos que se alimentam de nematóides. Com isso, há necessidade de se pesquisar mais a fundo as interações entre os ácaros predadores e os fitonematóides encontrados neste estudo.

Apesar da existência de muitos organismos que compõem a flora e a fauna natural e abundam na maioria dos solos, como: bactérias, fungos, protozoários, nematóides, anelídeos e artrópodes com ação antagonista sobre fitonematóides, tentativas de desenvolvimento de técnicas que permitissem o emprego de tais formas com alta eficiência e em escala comercial no controle desses nematóides têm quase sempre falhado (Weischer \& Brown, 2001).

Alguns gêneros de ácaros encontrados neste estudo possuem espécies que são relatadas como potenciais predadores de pragas no solo, como por exemplo, 
fitonematóides. Entre estes gêneros estão Neogamasellevans, Ologamasus, Gamasiphoides, Geogamasus, Rhodacarus, Rhodacarellus, Asca, Lasioseius, Cosmolaelaps e Typhlodromus (Ito, 1971; Imbriani \& Mankau, 1983; Walter, 1986, 1988; Epsky et al., 1988; Walter \& Ikonen, 1989; Crossley Jr. et al., 1992; Walter \& Proctor, 1998). Em estudos futuros, seria importante a realização de testes de preferência alimentar e estudos bioecológicos sobre alguns dos gêneros de ácaros encontrados com abundância no presente estudo como Neogamasellevans e Ologamasus, para que possa se pensar na possível utilização destes ácaros em programas de controle de pragas.

\subsection{Conclusões}

1) A maior abundância de ácaros edáficos é encontrada no folhedo e na camadas superiores do perfil do solo.

2) Os Mesostigmata edáficos apresentam grande diversidade de família, gêneros e espécies em Cananéia e Pariquera-Açu.

3) Helicotylenchus e Discocriconemella são os fitonematóides muito abundantes em Cananéia e Pariquera-Açu 


\section{CONCLUSÕES GERAIS}

* Os ácaros Rhodacaroidea são abundantes no folhedo da Mata Atlântica.

* Ologamasidae é a família mais numerosa de Rhodacaroidea no folhedo da Mata Atlântica.

* A maior abundância de ácaros edáficos é encontrada no folhedo e na camadas superiores do perfil do solo.

* Os Mesostigmata edáficos apresentam grande diversidade de família, gêneros e espécies em Cananéia e Pariquera-Açu.

* Helicotylenchus e Discocriconemella são os fitonematóides muito abundantes em Cananéia e Pariquera-Açu 


\section{REFERÊNCIAS BIBLIOGRÁFICAS}

ADIS, J. Extraction of arthropods from neotropical soils with a modified Kempson apparatus. Journal of Tropical Ecology, v.3, p.131-138, 1987a.

ADIS, J. Vertical distribution and abundance of arthropods in the soil of a neotropical secondary forest during the rainy season. Journal of Tropical Ecology, v.22, n.4, p.189-197, 1987b.

ADIS, J. On the abundance and density of terrestrial arthropods in Central Amazonian dryland forests. Journal of Tropical Ecology, v.4, p.19-24, 1988.

ADIS, J.; RIBEIRO, E. F.; MORAIS, J. W. de; CAVALCANTE, E. T. S. Vertical distribution and abundance of arthropods from white sand soil of a neotropical campinarana forest during the dry season. Studies on Neotropical Fauna and Environment, v.24, n.4 , p.201-211, 1989.

ALMEIDA, R. T.; LANDIM, C. M. U.; CARATELLI, A. Ocorrência de Pratylenchus coffeae (Zimmermann, 1898) Filipjev \& Schuurmans Stekhoven, 1941 em Musa cavendishii Lamb. No Ceará. Fitopatologia Brasileira, v.3, p. 295-299, 1978.

ALTIERI, M. A. Biodiversity and pest menagement in agroecosystems. New York: Food Products Press, 1994. 185p. 
BELFIELD, W. The Arthropoda of the soil in a west African pasture. Journal of Animal Ecology, v.25, p.275-287, 1956.

BEZERRA, J. A. Palmito: todos no mesmo barco. Revista Globo Rural, n.197, p.3944, 2002.

CAFÉ FILHO, A. C.; HUANG, C. S. Nematóides do gênero Pratylenchus no Brasil. Fitopatologia Brasileira, v.13, p. 232-235, 1988.

COLEMAN, D. C.; CROSSLEY JUNIOR., D. A. Fundamentals of soil Ecology. San Diego, CA: Academic Press, 1996. 205p.

CROSSlEY JUNIOR., D. A.; MULlER, B. R.; PERDUE, J. C. Biodiversity of microarthropods in agricultural soil: relations to processes. Agriculture, Ecosystems and Environment, v.40, p. 37-46, 1992.

CURI, S. M.; SILVEIRA, S. G. P.; MIRANDA, H.; VIVARELLI, J. B. Pratylenchus coffeae (Zimmermann, 1898) Filipjev \& Schuurmans Stekhoven, 1941 em batata no Estado de São Paulo. Nematologia Brasileira. v. 14, p.143-145. 1990.

DANTAS, M. Pastagens da Amazônia Central: Ecologia e fauna do solo. Acta Amazônica, v.9, n.2, 1979. 54p.

DENMARK, H. A.; MUMA, M. H. Phytoseiid mites of Brazil. Revista Brasileira de Biologia, v. 33, n.2, p.235-276, 1973.

DINDAL, D. L. Soil biology guide. New York: John Wiley, 1990. 1295p.

EDWARDS, C. A. The assessment of populations of soil-inhabiting invertebrates. Agriculture, Ecosystems and Environment, v.34, p.145-176, 1991. 
EDWARDS, C. A.; FLETCHER, K. E. A comparison of extraction methods for terrestrial arthropods. In: PHILLIPSON, J. Methods of study in quantitative soil ecology: population, production and energy flow.. Edinburgh Blackwell Scientific Publications, 1971. p.150-180. (IBP Handbook, 18).

EL-BANHAWY, E. M.; EL-SAWAF, B. M.; OSMAN, H. O. and AFIA, S. I. Effect of type of prey on the life parameters of the soil predacious mite, Gamasiphis tilophagous (Mesostigmata: Ologamasidae), a predator of the citrus parasitic nematode, Tylenchulus semipenetrans (Tylenchida: Tylenchulidae). Acarologia, v. 40, n.1, p.25-28, 1999.

EPSKY, N. D.; WALTER, D. E.; CAPINERA, J. L. Potential Role of Nematophagous Microarthropods as Biotic Mortality Factors of Entomogenous Nematodes (Rhabditida: Steinemematidae, Heterorhabditidae). Journal of Economic Entomology, v.81, n.3, p. 821-825, 1988.

EVANS, G. O. Principles of Acarology, Wallingford: CAB Internacional, 1992. 563p.

EVANS, G. O.; TILL, W. M. Mesostigmatic mites of Britain and Ireland (Chelicerata: Acari-Parasitiformes): an introduction to their extemal morphology and classification. Transactions of the Zoological Society of London, v.35, p.139-270, 1979.

EVANS, G. O.; SHEAlS, J. G.; MACFARLANE, D. The terrestrial Acari of the British isles. An introduction to their morphology, biology and classification,. Locali: Alden \& Mowbray. 1968. v.1, 219p.

FLECHTMANN, C. H. W. Ácaros de importância agrícola. 5. ed. São Paulo: Nobel, 1983. 189 p. 
FLECHTMANN, C. H. W.; MORAES G. J. de. Biodiversidade de Ácaros no Estado de São Paulo. In: BRANDÃO, R. F.; CANCELLO, E. M. (Ed.). Biodiversidade do Estado de São Paulo, Brasil: síntese do conhecimento do final do século XX, 5: invertebrados terrestres. São Paulo: FAPESP, 2000. cap.6, p.58 - 63.

FRANKLIN, E. N.; ADIS, J.; WOAS, S. The Oribatid mites. In: JUNK, W. J. (Ed.). The Central Amazon Floodplaint: Ecology of a pulsing system, Berlin: SpringerVerlag, 1997. p. 331-349.

FRANKLIN, E. N.; SCHUBART, H. O. R.; ADIS, J. Ácaros (Acari: Oribatida) edáficos de duas florestas inundáveis da Amazônia Central: distribuição vertical, abundância e recolonização do solo após a inundação. Revista Brasileira de Biologia, v.57, n.3, p.501-520. 1997.

FRANKLIN, E. N.; WOAS, S.; SCHUBART, H. O. R.; ADIS. Ácaros (Acari: Oribatida) arborícolas de duas florestas inundáveis da Amazônia Central. Revista Brasileira de Biologia, v.58, n.2, p.317-335. 1998.

GILL, R. W. Soil microarthropod abundance following old-field litter manipulation. Ecology, v.50, n.5, p.805-816, 1969.

HARADA, A. Y.; BANDEIRA, A. G. Estratificação e densidade de invertebrados em solo arenoso sob floresta primária e plantios arbóreos na Amazônia Central durante a estação seca. Acta Amazônica, v.24, n.1/2, p.103-118. 1994.

HIRSCHMANN, W. Gangsystematik der Parasititormes. Teil 39. Neunzehn neue Uropoda-Arten. Acarologie, v.12, p.20-30, 1969a.

HIRSCHMANN, W. Gangsystematik der Parasitiformes. Teil 45. Eine neue Uroobovella- Art (Dinychini, Uropodinae). Acarologie, v.12, p.42-43, 1969 b. 
HIRSCHMANN, W. Gangsystematik der Parasitiformes. Teil 46. Sieben neue Deraiophorus-Arten. Acarologie, v.12, p.43-45, 1969c.

HIRSCHMANN, W. Gangsystematik der Parasitiformes. Teil 106. Gang, Teilgange, Stadien von 7 neuen Nenteria-Arten (Trachyuropidini, Uropodinae). Acarologie, v.18, p.6-9, 1972a.

HIRSCHMANN, W. Gangsystematik der Parasitiformes. Teil 108. Teilgange, Stadien von 8 neuen Trichouropoda-Arten (Trichouropodini, Uropodinae). Acarologie, v.18, p.11-15, 1972b.

HIRSCHMANN, W. Gangsystematik der Parasitiformes. Teil 115. Teilgange und Stadien von 22 neuen Discourella-Arten (Uropodini, Uropodinae). Acarologie, v.18, p.29-41, 1972c.

HIRSCHMANN, W. Gangsystematik der Parasitiformes. Tei1121. Teilgange, Stadien von 6 neuen Uropoda (Metadinychus)-Arten (Uropodini, Uropodinae). Acarologie, v.18, p.74-77, 1972d.

HIRSCHMANN, W. Gangsystematik der Parasitiformes. Teil 123. Teilgange, Stadien von 21 neuen Uropoda (Phaulodinychus)-Arten (Uropodini, Uropodinae). Acarologie, v.18, p.79-92, 1972e.

HIRSCHMANN, W. Gangsystematik der Parasitiformes. Teil 151. Gange, Teilgange, Stadien von 22 neuen Deraiophorus-Arten (Dinychini, Uropodinae). Acarologie, v.19, p.60-81,1973a.

HIRSCHMANN, W. Gangsystematik der Parasitiformes. Teil 159. Gange, Teilgange, Stadien von 8 neuen Tetrasejaspis-Arten (Dinychini, Uropodinae). Acarologie, v.19, p.91-100, 1973b. 
HIRSCHMANN, W. Gangsystematik der Parasitiformes. Teil 160. Die Gattung Baloghibrasiluropoda nov. genus und Teilgang, Stadien von 3 neuen Baloghibrasiluropoda-Arten (Trachyuropodini, Uropodinae). Acarologie, v.19, p.100- 103, 1973c.

HIRSCHMANN, W. Gangsystematik der Parasitiformes. Teil 162; Teilgãnge, Stadien von 3 neuen Baloghjkaszabia -Arten (Uropodini, Uropodinae ). Acarologie, v.19, p.105-107, 1973d.

HIRSCHMANN, W. Gangsystematik der Parasitiformes. Teil 163. Stadien von 5 neuen Kaszabjbaloghia-Arten (Uropodini, Uropodinae). Acarologie, v.19, p.107-110, $1973 \mathrm{e}$.

HIRSCHMANN, W. Gangsystematik der Parasitiformes. Teil 164. Teilgange, Stadien von 5 neuen Discourella-Arten (Uropodini, Uropodinae). Acarologie, v.19, p.111$113,1973 f$.

HIRSCHMANN, W. Gangsystematik der Parasitiformes. Tei1166. Teilgange von Cyllibula nov. esp. (Dinychini, Uropodinae). Acarologie, v.19, p.114-116, 1973g.

HIRSCHMANN, W. Gangsystematik der Parasitiformes. Tei1168. Gang und Teilgang von 2 neuen Clausiadinychu-Arten (Dinychini, Uropodinae). Acarologie, v.19, p.117-120, $1973 \mathrm{~h}$.

HIRSCHMANN, W. Gangsystematik der Parasitiformes. Teil 170. Stadien von neuen Trichocylliba-Arten (Dinychini, Uropodinae). Acarologie, v.19, p.121-123, 1973 i.

HIRSCHMANN, W. Gangsystematik der Parasitiformes. Teil 183. Stadien von 4 neuen Uroobovella-Arten (Dinychini, Uropodinae). Acarologie, v.19, p.166-168, 1973j. 
HIRSCHMANN, W. Gangsystematik der Parasitiformes. Teil 196. Stadien einer neuen Discourella-Art (Uropodini, Uropodinae). Acarologie, v.21, p.14-15, 1975a.

HIRSCHMANN, W. Gangsystematik der Parasitiformes. Teil 197. Stadien einer neuen Uropoda (Phaulodinychus) - Art (Uropodini, Uropodinae). Acarologie, v.21, p.16-17, $1975 b$.

HIRSCHMANN, W. Gangsystematik der Parasitiformes. Teil 213. Stadien einer neuen interessanten Oplitis-Art (Trachyuropodini, Oplitinae). Acarologie, v.21, p.101, $1975 c$.

HIRSCHMANN, W. Gangsystematik der Parasitiformes. Teil 214. Stadien von 8 neuen Trachyzlropoda-Arten (Trachouropodini, Oplitinae). Acarologie, v.21, p.101-105, 1975 d.

HIRSCHMANN, W. Gangsystematik der Parasitiformes. Teil 216.3 neue Trachyzlropoda -Arten der magna-gruppe (Trachyuropodini, Oplitinae). Acarologie, v.22, p.16-18, 1976a.

HIRSCHMANN. W. Gangsystematik der Parasitiformes. Teil 222. 1 neue Trachyzlropoda Art der Berlesiana-gruppe (Trachyuropodini. Oplitinae). Acarologie, v.22, p.26-27, 1976b.

HIRSCHMANN, W. Gangsystematik der Parasitiformes. Teil 224. 6 neue Trachyzlropoda -Arten der graeca -gruppe (Trachyuropodini, Oplitinae). Acarologie, v.22, p.30-34, 1976c.

HIRSCHMANN. W. Gangsystematik der Parasitiformes. Teil 226. 9 neue Trachyzlropoda -Arten der origmorpha - gruppe (Trachyuropoda, Oplitinae). Acarologie. v.22, p.39-44, 1976d. 
HIRSCHMANN, W. Gangsystematik der Parasitiformes. Teil 251. Teilgange und Stadien von 2 neuen Brasiluropoda-Arten aus Brasilien und Panama (Trachyuropodini, Uropodinae). Acarologie, v.23, p.53-54, 1977a.

HIRSCHMANN, W. Gangsystematik der Parasitiformes. Teil 253. Teilgange von 2 neuen Trachyuropoda-Arten aus Brasilien (Trachyuropodini, Oplitinae). Acarologie, v.23, p.58-59, 1977b.

HIRSCHMANN, W. Gangsystematik der Parasitiformes. Teil 269. Stadien von 6 neuen Trachyuropoda-Arten aus der Verwandtschaft um Trichouropoda interstructura Hirschmann \& Zirngiebl-Nicol 1961 aus Kanada, Mexiko und Brasilien (Trachyuropodini, Uropodinae). Acarologie, v.24, p.31-34, 1978.

HIRSCHMANN, W. Gangsystematik der Parasitiformes. Teil 416. Stadien von 2 neuen Rotundabal.oghia-Arten aus Bolivien und Brasilien (Dinychini, Uropodinae). Acarologie, v.28, p.121-122, 1981a.

HIRSCHMANN, W. Gangsystematik der Parasitiformes. Teil 418. Stadien von 2 neuen Uroobovella-Arten der ipidis - gruppe aus Brasilien (Dinychini, Uropodinae). Acarologie, v.28, p.123-124, 1981b.

HIRSCHMANN, W. Gangsystematik der Parasitiforrnes. Teil 421. Stadien von 3 neuen Uroobovella-Arten der minima - gruppe aus Vietnam und Brasilien (Dinychini, Uropodinae). Acarologie, v.28, p.127-128, 1981c.

HIRSCHMANN, W. Gangsystematik der Parasitiforrnes. Die Bispirata-gruppe der Ganggattung Oplitis. Acarologie, v.38, p.10-12, 1991.

HIRSCHMANN, W. Gangsystematik der Parasitiforrnes. Teil 532. Gange von 2 Trichocylliba-Arten (Dinychini, Uropodinae). Acarologie, v.39, p.1-9, 1992a. 
HIRSCHMANN, W. Gangsystematik der Parasitiformes. Teil 536. 41 Rotundabal.oghiaArten aus Sudamerika (Venezuela, Ekuador, Peru, Bolivien, Brasilien) und Mittelamerika (Guatemala) (Dinychini, Uropodinae). Acarologie, v. 39, p.69-95, 1992b.

HIRSCHMANN, W.; ZIRNGIEBL-NICOL, I. Gangsystematik der Parasitiformes. Teil 111. Adulte Tiere von 5 neuen Trichouropodella-Arten (Trichouropodini, Uropodinae). Acarologie, v.18, p.18-20, 1972a.

HIRSCHMANN, W.; ZIRNGIEBL-NICOL, I. Gangsystematik der Parasitiformes. Teil 127. Teilgange, Stadien von 19 neuen Urobovella-Arten (Dinychini, Uropodinae). Acarologie, v.18, p.110-19, 1972b.

IMBRIANI, J. L.; MANKAU, R. Studies on Lasioseius scapulatus: Mesostigmatid mite predaceus on nematodes. Journal of Nematology, v.15, n.4, p.523-528, 1983.

INSERRA, R. N.; DAVIS, D. W. Hypoaspis aculeifer: a mite predacious on 1oot-knot and cyst nematodes. Journal of Nematology, v.15, n.2, p.324-325,1983.

ITO, Y. Predation by manure-inhabiting mesostigmatids (Acarina: Mesostigmata) on some free-living nematodes. Applied Entomology and Zoology, v.6, n.2, p.51-56, 1971.

JEKINS, W. R. A rapid centrifugal-flotation technique for separating nematodes from soil. Plant. Diasease Reporter. n.48, p.692, 1964.

JOLY, A. B. Botânica: introdução à taxonomia vegetal. São Paulo, Editora Nacional, 1991. 777p.

JOLY, A. B. Botânica: introdução à taxonomia vegetal. 11. ed. São Paulo: Editora Nacional, 1993. 778p. 
KARG, W. Systematische Untersuchung der Gattungen und Untergattungen der Raubmilbem familie Phytoseiidae Berlese, 1916, mite der Beschreibung von 8 neuen Arten. Mitteilungen des Zoologischen Museums, v.59, n.2, p.293-328, 1983.

KARG, W. Zur Kenntnis der Eugamasides Karg mit neuen Arten aus den Regenwaldern von Ecuador (Acarina, Parasitiformes). Tropischer und subtropischer Gabiete. Mitteilungen aus dem Museum fur Naturkunde in Berlin. Zoologischen Reihe, v.74, n.2, p. 185-214, 1998.

KARG, W. Neue Raubmilbenarten der Gattung Gamasiphis Berlese, 1904, (Acarina, Parasitiformes) von 8 neuen Arten. Mitteilungen des Zoologischen Museums Berlim, v.59, n.2, p.293-328, 1983.

KRANTZ, G. W. A manual of acarology. 2. ed. Corvallis: Oregon State University, 1978. 509p.

KRANTZ, G. W.; AINSCOUGH, B. D. Acarina: Mesostigmata (Gamasida). In: DINDAL, D. L.. Soil biology guide. New York: John Wiley, 1990. p.583-665.

LEE, D. C. Rhodacaridae (Acari: Mesostigmata): from near Adelaide, Australia. II. Sistematics. Records of the South Australian Museum, v.97, n.2, p.139-152, 1973.

LEE, D. C. The Rhodacaridae (Acari: Mesostigmata): classification, external morphology and distribution of genera. Records of the South Australian Museum, v.16, n.3, p.1-219, 1970.

LINDQUIST, E. E. Digamasellus Berlese, 1905, and Dendrolaelaps Halbert, 1915, With descriptions of new taxa of Digamasellidae (Acarina: Mesostigmata). The Canadian Entomologist, v.107, n.1, p. 1-45, 1975.

LORDELLO, L. G. E. Nematóides das plantas cultivadas, 6 ed.. São Paulo, Ed. Nobel, 1981. 314p. 
LORENZI, H. Palmeiras do Brasil: nativas e exóticas. Nova Odessa: Editora Plantarum, 1996. 303p.

MAY, W. F.; LYON, H. H. Pictorial key to genera of plant-parasitic nematodes. 4. ed. Local: Cornell University, 1975. 224p.

MINEIRO, J. L. C.; MORAES, G. J. Sistematics morphology and physiology, Gamasida (Arachnida: Acari) edáficos de Piracicaba, Estado de São Paulo. Neotropical Entomology, v.30, n.3, p. 379-385, 2001.

MONTEIRO, A. R.; LORDELLO, L. G. E. Encontro do nematóide Pratylenchus coffeae atacando cafeeiro em São Paulo. Revista de Agricultura, v.49, p.164, 1974.

MONTEIRO, A. R.; FERRAZ, L. C. C. B. Curso de identificação de nematóides parasitos de plantas. Piracicaba: ESALQ, Departamento de Zoologia, FEALQ, SP. 1990. 313p.

MORAES, G. J. de; McMURTRY, J. A.; DENMARK, H. A. A. Catalog of the mite family Phytoseiidae: references to taxonomy, synonymy, distribution and habitat. Brasilia: EMBRAPA-DDT, 1986. 353p.

MORAES, G. J. de; MELO, E. L.; GONDIM JUNIOR, M. G. C. Description of a new species of phytoseiid mite from northeastern Brazil and redescription of Neoseiulus gracilis (Acari: Phytoseiidae). The Florida Entomologist, v.80, n.3, p.319-324, 1997.

MORAES, G. J.; OLIVEIRA, A. R. Mite diversity in Brazil. In: BICUDO, C. E. M.; MENEZES, N. A. Biodiversity in Brazil: a first approach. São Paulo: CNPq, 326p., 1996.

MUMA, M. H. New Phytoseiidae (Acarina: Mesostigmata) from Florida. Florida Entomologist, v. 45, p. 1-10, 1962. 
ODUM, E. P. Ecologia. Rio de Janeiro: Guanabara Koogan, 1988. 434p.

OLIVEIRA, A. R. Efeito do Baculovirus anticarsia sobre Oribatida edáficos (Arachnida: Acari) na cultura da soja. São Paulo, 1999. 69p. Dissertação (Mestrado) - Instituto de Biociências, Universidade de São Paulo.

OlIVEIRA, A. R.; MORAES, G. J. de; DEMÉTRIO, C. G. E.; NARDO, E. A. E. de. Eifeito do vírus de poliedrose nuclear de Anticarsia gemmatal.is sobre Oribatida edáficos (Arachnida: Acari) em um campo de soja. Jaguariúna: Embrapa Meio Ambiente, 2000. 32p. (Boletim de Pesquisa).

OLIVEIRA, E. P. de; FRANKLIN, E. Efeito do fogo sobre a mesofauna do solo: recomendações em áreas queimadas. Pesquisa Agropecuária Brasileira, v.28, n.3, p.357-369. 1993.

PETERSEN, H.; LUXTON, M. A comparative analysis of soil fauna populations and their role in decomposition processes. Oikos, v.39, n.3, p.287-388, 1982.

PLOWMAN, K. P. Litter and soil fauna of two Australian subtropical forests. Journal of Animal Ecology. Local: Blackwell Scientific, v.4, p.47-104, 1979.

PRATES, H. S.; LORDELLO, L. G. E. Mais um nematóide nocivo à citricultura. Sociedade Brasileira de Nematologia. v.4, p.177-178. 1980.

PRICE, D.W. Abundance and vertical distribution of microarthropods in the surface layers of a California pine forest soil. Hilgardia. v.42, n. 4, p. 121-147, 1973.

PRICE, D. W.; BENHAM, G. S. Vertical distribution of soil-inhabiting microarthropods in an agricultural habitat in California. Environmental Entomology, v.6, n.4, p.575$580,1977$. 
REIS, A.; REIS, M. S. dos. Euterpe edulis Martius (Palmiteiro): biologia, conservação e manejo. Itajaí: Herbário Barbosa Rodrigues, 2001. 86p.

RIBEIRO, E. F.; SCHUBART, H. O. R. Oribatídeos (Acari: Oribatida) colonizadores de folhas em decomposição de três sítios florestais da Amazônia Central. Boletim do Museu Paraense Emílio Geoldi, v.5, n.2, p.243-276. 1989.

RODRIGUES, J. M. G. Abundância e distribuição vertical de Arthropoda do solo em capoeira de terra firme. Manaus, 1986. 80p. (Mestrado) Instituto Nacional de pesquisas da Amazônia, Fundação Universidade do Amazonas.

ROSSI, C. E.; ZORZENON, F. J.; INOMOTO, M. M. Ocorrência do nematóide das lesões radiculares, Pratylenchus coffeae, em palmiteiros no Vale do Ribeira, SP. Ecossistema, v.20, p.209-211, 1995.

SASSER, J. N.; FRECKMAN, D. W. A world perspective on nematology: the role of the society. In: VEECH, J.; DICKSON, D. W.; (Ed.). Revista on nematology: a comemoration of the twenty-fifth aniversary of the Society of Nematologists. Hyatsville: The Society of Nematologists, 1978. p.7 - 14.

SELLNICK, M. Neue Milben aus Brasilien I. Chelomuropoda bispirata nov. gen., nov. esp. (Acar. Urop.). Dusenia, v.5, n.34, p.195-208, 1954.

SILVEIRA NETO, S.; NAKANO, O.; BARBIN, D. et al. Manual de ecologia dos insetos. Piracicaba: Ceres, 1976. 419p.

SOUTHWOOD, T. R. E. Ecological methods. London: Methuen \& Coltd, 1971. 391p.

TRAJANO, E.; GNASPINI-NETO, P. Composição da fauna cavernicula brasileira, com 
uma análise preliminar da distribuição dos táxons. Revista Brasileira de Zoologia, v.7, n.3, p.383-407,1991.

TIHOHOD, D. Nematologia Agrícola Aplicada. Jaboticabal: FUNEP, 1993. 372 p.

VAN DEN BERG, R. A. and RYKE, P. A. J. A Systematic-ecological investigation of the acarofauna of the forest floor in magoebaskloof (South Africa) with special reference to the Mesostigmata. Revista de Biologia, v.6, n.12, p.157-234, 1967.

WALTER, D. E. Life history, trophic behavior, and description of Gamasellodes vermivorax n. sp. (Mesostigmata: Ascidae), a predator of nematodes and arthropods in semiarid grassland soils. Canadian Journal of Zoology, v.65, p.1689-1695, 1986.

WALTER, D. E. Nematophagy by soil arthropods from the shortgrass steppe, Chihuahuan Desert and Rocky Mountains of the Central United States. Agriculture, Ecossystems and Environment, v. 24, p.307-316, 1988.

WALTER, D. E.; IKONEN, E. K,. Species, guilds, and functional groups: taxonomy and behavior in nematophagous arthropods. Journal of Nematology, v.21, n.3, p.315$327,1989$.

WALTER, D. E. Trophic Behavior of "Mycophagous" Microarthropods. Ecology, v.68, n.1, p.226-229, 1987.

WALTER, D.E.; PROCTOR, H. C. Predatory Mites in Tropical Australia: Local Species Richness and Complementarity. Biotropica, v.30, n.1: p.72-81, 1998.

WALLWORK, J. A. The distribution and dynamics of some forest soil mites. Ecology, v. 40, n.4, p. 557-563, 1959. 
WALLWORK, J. A. Ecology of soil animals. McGraw - Hill England, 1970. 283p.

WALLWORK, J. A. Oribatids in forest ecosystems. Annual Review of Entomology. v.28, p.109-130. 1983.

WALLWORK, J. A. Distribution and diversity patterns of soil mites and other microarthropods in a Chihuahuan desert site. Journal of Arid Environments, v.9, p.215-231. 1985.

WEISCHER, B.; BROWN, D. J. F. Conhecendo os nematóides: nematologia geral, livro-texto para estudantes e não especialistas. Local: Bulgária. Sofia: Editora, 2001. 209 p.

WISNIEWSKI, J.; HIRSCHMANN, W. Gangsystematik der Parasitiformes. Teil 548. Katolog der Ganggattungen, Untergattungen, Gruppen und Arten der Uropodiden der Erde (Taxonomie, Literatur, Grôsse, Verbreitung, Vorkommen) Acarologie, v.40, p.221-291, 1993.

ZACARIAS, M. S.; MORAES, G. J. de. Two new species of phytoseiid mites (Acari: Phytoseiidae) from the State of São Paulo, Brazil. Applied Entomology and Acarology, v.6, p.95-100. 2001.

ZIRNGIEBL-NICOL. I.; HIRSCHMANN, W. Gangsystematik der Parasitiformes. Teil 176. Stadien von neuen Oplitis-Arten, von Ungarischen Zoologen in Stidamerika und Afrika gesammelt (Trachyuropodini, Oplitinae). Acarologie, v.19, p.135-140, 1973a.

ZIRNGIEBL-NICOL, I.; HIRSCHMANN, W. Fïnf neue Brasiluropoda -arten (Uropodinae -Trichouropodini). Acta Zoologica Academiae Scientiarum Hungaricae, v.21, n. 3/4, p. 455- 464, 1975. 